\title{
Tamil Identity in Sri Lanka: A Secular State of Becoming.
}

\author{
A Thesis \\ Submitted to Victoria University of Wellington \\ In Fulfilment of the Requirements for the \\ Degree of Master of Arts in Religious Studies
}

\author{
School of Art History, Classics \\ and Religious Studies
}

\section{Anushka Perinpanayagam 2008}




\section{Acknowledgements}

I would like to acknowledge all my aunts, uncles, cousins and friends who have taken an ongoing interest in my project. I would also like to acknowledge the help I've received from both my supervisors - Rick Weiss and Michael Radich. In particular, my primary supervisor Rick has spent many hours helping me develop my ideas. I also could not have completed this project without the support of my family - my parents, sister and Tim. Finally, I would like to acknowledge both my grandmothers, two women of great courage and wisdom, whose stories have prompted me to learn more about the world from which they came. 
Introduction: Religion and Nationalism in Sri Lanka: Introducing Context, Questions and Framework ..................................................................... 2

1.1 Context: History and Demographics............................................................. 7

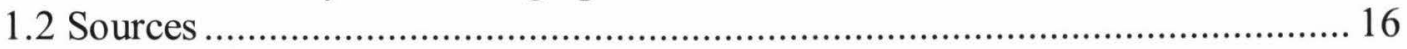

1.3 Religion and the Secular: An Asad-based Response to the Scholarly Debate.....

Chapter Two: Exploring the Religious Difference ……............................... 28

2.1 Establishing the Religious Difference......................................................... 29

2.2 Explaining the Religious Difference: A Historical Argument ....................... 35

2.2.1 Caste Identities in the Revivalist Movements............................................ 37

2.2.2 The Impact of Language Missions on the Revivalist Movements............. 42

2.3 Tamil Nationalists: Representing a Vellalar, Tamil Identity......................... 47

Chapter Three: The Construction of History ................................................ 57

3.1 Enlightenment History in the Sri Lankan Context .........................................5 58

3.2 A Militant Presentation of the Past: The Maravars, Cholas and the Sangam

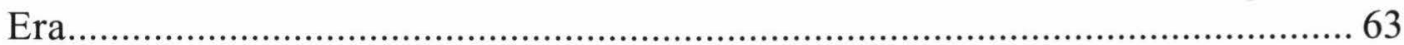

3.3 The Jaffna Kingdom: Legitimating the Claim to Eelam.................................... 68

3.4 The Post Colonial Narrative: Mobilising a Group Identity ................................ 71

3.5 History or Myth? Reading Religion into the LTTE's Historical Discourse ..... 78

Chapter Four: Violence and Death- Liberating the Self and the Nation 82

4.1 Violence and Death: The Claim to be Secular ............................................... 83

4.2 Violence and Death: Liberating the Self...................................................... 89

4.3 Violence and Death: Liberating the Nation.................................................... 91

4.4 The Deification of the Dead: Evidence of Religion? ........................................ 95

4.5 Deification of the Dead: An Alternative Reading .......................................... 101

Conclusion: Exploring Becoming and Suggestions for Future Research..... 105

5.1 Tamil Identity: A Secular State of Becoming .............................................. 106

5.2 Suggestions for Future Research: Returning to Asad ................................... 109

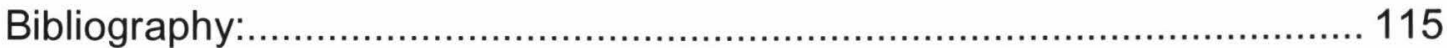




\section{Introduction}

\section{Religion and Nationalism in Sri Lanka: Introducing Context, Questions and Framework}

Since the island nation of Sri Lanka attained independence in 1948, it has experienced periods of civil unrest marked by riots and government implemented curfews. In the mid-1980s this agitation erupted into civil war between two parties: the Liberation Tigers of Tamil Eelam (LTTE) and the Sri Lankan government. Each is associated with a different ethnic group and a very particular nationalist rhetoric. ${ }^{1}$ The LTTE, a group of militant separatists, claims to represent the Tamil population of the north and east, while the Sri Lankan government is mostly comprised of politicians belonging to the island's ethnic majority - the Sinhalese. ${ }^{2}$

The island's politics have been examined by historians, political scientists and anthropologists. These scholars cover a range of issues and advance a variety of arguments. When I first began to engage with this scholarly literature, I became aware of some common themes and conclusions. In particular, I noted that scholars commonly label the government's nationalism as SinhaleseBuddhist. ${ }^{3}$ Tamil nationalism, on the other hand, appears to be secular. Tamil nationalists have always proclaimed themselves secularists, ${ }^{4}$ disavowing religion and denying the kinds of connections that Sinhalese nationalists make between religion and politics. This religious difference between the two nationalisms seems remarkable, when we consider that the religious divide complements the

\footnotetext{
${ }^{1}$ Kristian Stokke and Anne Kirsti Ryntveit, "The Struggle For Tamil Eelam in Sri Lanka," Growth and Change 31 (2000): 285.

${ }^{2}$ Serena Tennekoon, "Newspaper Nationalism: Sinhala Identity as Historical Discourse," in Sri Lanka: History and the Roots of Conflict, ed. Jonathon Spencer (London: Routledge, 1990), 205.

${ }^{3}$ Ibid. When I call the Sri Lankan government's nationalism 'Sinhalese,' I do not mean to suggest that minority groups are not included in the Sri Lankan government. In fact, the government comprises members of several minority communities (e.g. Tamils, the Muslims and the Burghers). Instead, I am suggesting that we can associate the Sri Lankan government with Sinhalese Buddhist nationalism, because, since independence, successive governments have adopted rhetoric and policies which are Sinhalese-Buddhist in tone. The Sri Lankan government thus implies that being Sri Lankan means being Sinhalese-Buddhist. Many nation-states connect national identity to the identity of one group; the Sri Lankan government is not unusual in this regard. The Sri Lankan government, however, is perhaps more explicit than other governments in how it delineates this relationship.

${ }^{4}$ Partha S. Ghosh, Ethnicity versus Nationalism: The Devolution Discourse in Sri Lanka (New Delhi: Sage Publications, 2003), 76.
} 
ethnic divide; the majority of Sinhalese are Buddhists and the majority of Tamils, Hindus. Given this parallel, one would expect Tamil nationalists to counter Sinhalese-Buddhist claims with an overtly Tamil-Hindu discourse, rather than a secular one.

As I researched further, however, I encountered the work of a small band of scholars who complicated the religious difference that I had identified. These scholars engage in a lively debate over LTTE practices and terminology. Some identify evidence of religion in the LTTE's practices, symbols and terminology, while others defend the LTTE's secularity. This scholarly literature clearly has important consequences: if the LTTE's nationalism is religious, then is the LTTE insincere when it claims to be secular? Or is it unaware that its nationalism is religious? Or perhaps all nationalisms are religious, ${ }^{5}$ in which case: is the LTTE's nationalism any more religious than nationalisms elsewhere? And finally - if the LTTE's nationalism is religious, then is it religious in the same way as Sinhalese nationalism?

My project has been shaped by these issues arising out of the scholarly literature. In particular, the scholarly literature has prompted me to ask the following questions, all of which structure my study: Is there a religious difference between Sinhalese and Tamil nationalism? And if so, what is it, and how did it develop? Also, if there is a difference, how have Tamil nationalists (and more particularly, the LTTE) mobilised a group identity without using religion in the same way as Sinhalese nationalists?

In this thesis, I argue that scholars miss the point when they argue over whether the LTTE is a truly secular organisation. This is because 'religion' and 'secular' have no fixed meanings. In this sense, there is no religious difference. Sinhalese nationalism is not somehow innately religious, and Tamil nationalism, secular. But in another important sense, there is a difference that pertains not to the absence or presence of religion, but to how the categories of religion and the secular are represented and mediated. While Tamil nationalists distance national identity from religious identity, Sinhalese nationalists depict the two as almost synonymous. I argue that these representations of national identity (and their

\footnotetext{
5 "There is certainly a long and interesting tradition that suggests nationalism is a religion." Talal Asad, Formations of the Secular: Christianity, Islam, Modernity (California: Stanford University Press, 2003), 187.
} 
relationship to the categories of religion and the secular) developed through a particular set of historical circumstances in the late $19^{\text {th }}$, early $20^{\text {th }}$ century.

In this study, I also argue that the LTTE mobilises a group identity through two discourses: history, and violence and death. I draw four conclusions about these discourses which, in turn, inform us about how the LTTE mobilises a group identity. First, these discourses are structured by the claim to be secular. The LTTE thus mobilises a group identity through claims, traditions and practices that are represented as being secular. Second, these discourses propagate shared experiences of suffering (in the recent post-colonial past) and liberation (in the present and future). I thus argue that the LTTE mobilises a group identity through these shared experiences. Third, these discourses refer to Tamil traditions which the LTTE explicitly claims to mould or even supersede. Consequently, I argue that the LTTE mobilises a group identity through reshaped, Tamil traditions. The fourth conclusion arises out of the last two. LTTE discourses emphasise an individual, societal and cultural transformation. I thus conclude that the LTTE mobilises a group identity through notions of becoming and transformation. Those who study the LTTE often miss these features when they apply the category of 'religion' in self-evident ways. In particular, I argue that scholars miss the theme of becoming which pervades LTTE rhetoric and imagery.

My thesis thus focuses on two issues: the religious difference between Sinhalese and Tamil nationalisms, and the LTTE's efforts to mobilise a group identity. I tackle the first issue, here in the Introduction and in Chapter Two. Chapters Three and Four are devoted to the second issue.

Here, in the Introduction, I establish Talal Asad's ideas about religion and the secular. Informed by his insights, I assert that we are correct when we intuitively perceive some kind of religious difference between the two nationalisms. I suggest that this difference pertains not to a religious or secular essence but to how Sinhalese and Tamil nationalists represent the categories of religion and the secular. In Chapter Two I substantiate this assertion, arguing that one identity, Sinhalese identity, is implicitly associated with religious concerns and symbols (i.e. concerns and symbols that are represented as religious), while the other, Tamil identity, is explicitly distanced from religious concerns and symbols. I also show how these representations of group identity developed 
during the Buddhist and Hindu (Saivite) revivals of the late $19^{\text {th }}$ Century. ${ }^{6}$ Sinhalese identity came to be connected to Buddhist ideals and symbols while Tamil identity was aligned to the caste ideals of the Vellalars. While these Vellalar ideals were originally represented as religious traits, they eventually came to be represented as cultural characteristics. Influenced by different factors and conditions, the two group identities thus came to develop quite different relationships to the category of religion. I then discuss how this Vellalar-based identity presented problems for early Tamil nationalists who wanted to mobilise a group identity.

Chapter Two thus leads neatly to the second issue: the LTTE's efforts to mobilise a group identity. From the material covered in Chapter Two we can appreciate that the LTTE has had to overcome significant challenges in order to successfully mobilise a group identity. It has had to counter the Buddhist rhetoric of its Sinhalese counterparts (without employing an overtly religious rhetoric) and also transcend the elitist representation of Tamil identity advanced by earlier nationalists. While the material related in Chapter Two lays the groundwork for the rest of this thesis, it also provides part of the answer to the question that I ask in the following chapters: How has the LTTE mobilised a group identity? In the final section of Chapter Two, I argue that the LTTE mobilises a group identity through reshaped Vellalar values. This is the first instance where we see the LTTE mobilise a group identity through a reformulated Tamil tradition.

In the following chapters, I discuss how the LTTE mobilises a group identity through two discourses: the LTTE's historical discourse in Chapter Three, and its discourse pertaining to violence and death in Chapter Four. In Chapter Three I explore three 'pasts' that the LTTE promulgates: the militant past, the Jaffna Kingdom and the post-colonial narrative. I argue that while all three pasts are involved in the LTTE's project, it is the post-colonial narrative that is most important to how the LTTE mobilises a group identity. The postcolonial narrative is structured by the claim to be secular. Furthermore, it emphasises recent experiences of suffering. We thus see how the LTTE mobilises a group identity through a secular narrative (i.e. a narrative that is represented as being secular) which emphasises a shared experience.

\footnotetext{
${ }^{6}$ Saivism is a branch of Hinduism, focussing on the deity Siva.
} 
While the post-colonial narrative is crucial to how the LTTE mobilises a group identity, the militant past is also involved in the LTTE's efforts to evoke national sentiment. Through this past, the LTTE depicts an ancient martial tradition. Here, as with the Vellalar values, we can see how the LTTE explicitly admits to and even celebrates its reformulation of tradition. When scholars analyse how the LTTE employs tradition, they become embroiled in the categories of religion and the secular. Consequently, they overlook how the LTTE celebrates a self-consciously fashioned tradition.

In Chapter Four, I turn to the LTTE's discourse around violence and death. Once again, we see how the LTTE mobilises a group identity through claims, arguments and practices that are represented as secular. I also explore how the discourse mobilises a group identity through experiences of liberation. When cadres fight and die on the battlefield, they liberate themselves from suffering; they also bring the liberation of the nation closer. The discourse thus presents the answer to the post-colonial narrative of suffering.

When cadres liberate themselves and the nation, they also conquer death. Consequently, LTTE rhetoric suggests that the cadres live on in a metaphorical sense. Some anthropological research and LTTE poems even suggest that the dead live on in a more literal sense, as deities who can influence the struggle from beyond the grave. When scholars analyse this notion (of the deification of the dead), they implicate the category of religion. In the final section of Chapter Four, I offer an alternative reading of the practice, which focuses on how the LTTE represents the relationship between the secular and national identity. I argue that the deification of the dead (if it is happening) powerfully underlines the transformative power of dying for the nation.

In the conclusion I draw together all the LTTE traditions, experiences and claims discussed throughout the study. In particular, I focus on the transformation or becoming which the LTTE promises. I show how this process of becoming is represented as a secular transformation - hence the title of this work. The Tamil nation is in a secular state or process of becoming, part of which involves attaining the mechanisms of a secular state - Eelam. I also return to Asad's ideas, showing how his approach might inform future studies of nationalism in Sri Lanka. 
In order to grapple with the argument advanced in this study, the reader must be familiar with Sri Lanka's demographics and history, issues pertaining to LTTE sources, and finally Talal Asad's ideas about religion and the secular. These pieces of groundwork are also important because they have shaped my project in significant ways. I will explore each piece of groundwork, discussing how it is important to my study.

\subsection{Context: History and Demographics}

The island of Sri Lanka is home to a number of groups who identify themselves by religious affiliation, cultural practices, region and language. Here I will elaborate only on those groups which are important for my project.

Perhaps the best place to begin is with the Sinhalese-Tamil distinction. As with all cultural and religious distinctions in Sri Lanka, this distinction is more complex than it first appears. Even though ethnic identity came to the forefront of the political scene in the early post-colonial years, Sri Lankans continued and still continue to articulate other competing regional and caste identities. For my project, it is important that we understand both how the Sinhalese-Tamil divide is commonly represented and explained, and the layers of complexity that underlie such representations. First, I will outline how the Sinhalese and Tamil identities are generally represented. I will then look at key events and groups during the colonial and postcolonial years that shaped these identities (with a particular emphasis on Tamil identity). Finally, I will explore other competing identities that complicate the Sinhalese-Tamil distinction.

When scholars and nationalists depict who the Sinhalese and Tamils are, they typically begin with a selection of facts and figures: In 1981, prior to the outbreak of the war, the Sinhalese constituted seventy four percent of the island's population, and the Tamils, thirteen percent. ${ }^{7}$ The Sinhalese speak Sinhala, an Indo-European language only spoken in Sri Lanka, and the majority of Sinhalese identify as Buddhists. The Tamils, on the other hand, speak Tamil, a Dravidian language that is also spoken in India (although in a slightly different dialect).

\footnotetext{
${ }^{7}$ Stokke and Ryntveit, "The Struggle For Tamil Eelam in Sri Lanka," 289. This figure excludes the Estate Tamils, a group whom I discuss later.
} 
Most Tamils are Hindus although there is a significant Christian minority. ${ }^{8}$ Many Sri Lankans would accept this description. Clearly, then, this description is important; it is involved in how Sri Lankans identify themselves. But as an explanation of Sri Lanka and the people who live there, such accounts only relate half the story.

The Sinhalese-Tamil distinction has not always been represented in the way that it is today. Nationalists project the Sinhalese-Tamil identities of today upon peoples who inhabited the island in pre-colonial times. While we do not know a lot about the Sinhalese and Tamil identities prior to colonial contact, we can surmise that they were flexible, malleable entities. Unlike today, they tolerated difference and comfortably coexisted alongside other overlapping and contrasting identities. "Speakers of Tamil, speakers of Sinhala, speakers of Tamil and Sinhala, Buddhist Tamils, non Buddhist Tamils, Buddhist Sinhalas and non Buddhist Sinhalas, Shaivites - Tamil speakers and possibly Sinhala speakers drifted with relative ease, at different times for different purposes and conveniences, from one sociological formation into another."9

This changed only when the colonisers arrived. Sri Lanka was colonised by the Portuguese, the Dutch and then finally the British. It is the British who most significantly influenced how the two identities came to be articulated. With their penchant for categorisation, statistics and the disciplines of history and biology, the British cemented and rigidified the Sinhalese and Tamil identities. These once pliable identities were then sharpened and politicised further during the post colonial era, when nationalists used ethnic confrontation to mobilise support. ${ }^{10}$ As the Sinhalese and Tamil identities gained salience, other competing identities - caste, regional, and religious - were increasingly rendered irrelevant. Distinctions that were once fiercely marked, like those between the Kandyan and Low Country Sinhalese, or the Jaffna and East Coast Tamils faded into the background. ${ }^{11}$ Consequently, pre-colonial allegiances that occurred across the Tamil-Sinhala divide were forgotten, and almost erased from the historical

\footnotetext{
${ }^{8}$ Robert Kearney, "Ethnic Conflict and the Tamil Separatist Movement in Sri Lanka," Asian Survey 25:9 (1985): 899

${ }^{9}$ E. Valentine Daniel, Charred Lullabies: Chapters in an Anthropography of Violence (Princeton: Princeton University Press, 1996), 44.

${ }^{10}$ Elizabeth Nissan and R.L Stirrat, "The Generation of Communal Identities," in Sri Lanka. History and the Roots of Conflict, ed. Jonathon Spencer (London: Routledge, 1990), 26-30.

${ }^{11}$ Ibid., 27, 30.
} 
narratives of nationalist groups. ${ }^{12}$ What follows is a description of some of the key events and groups that shaped the two identities into the modern, postcolonial entities that we see today.

During the early part of British rule, the British adopted a form of communal representation in the legislative and executive councils. Under this system, the Tamils had enjoyed equal or near equal representation with their Sinhalese compatriots in the councils. ${ }^{13}$ In addition, the majority of positions within the public service were held by Tamils. ${ }^{14} \mathrm{With}$ independence looming, Tamil politicians became concerned that the representational system that the British were implementing would reduce the participation of Tamils in government. One Tamil politician, G.G. Ponnambalam suggested a system that was famously dubbed fifty-fifty. Fifty percent of all seats in parliament would be reserved for minorities, while the other fifty percent would represent Sinhalese constituents. ${ }^{15}$ The British repudiated Ponnambalam's suggestions, saying that communal representation encouraged communalism. Instead they implemented a system of proportional representation. ${ }^{16}$

Going into independence, the first set of elections was won by the UNP (the United National Party). ${ }^{17}$ The country's first government consisted of mainly elite members of both the Tamil and Sinhalese communities. As one scholar puts it, the masses had yet to be invited into history and into the parliamentary process. ${ }^{18}$ This was redressed at a subsequent election in 1956 when a Sinhalese politician, S.W.R.D. Bandaranaike, led a newly formed party - the SLFP (Sri

\footnotetext{
${ }^{12}$ Dagmar Hellmann Rajanayagam, "The Concept of a Tamil Homeland in Sri Lanka - its Meaning and Development," South Asia 13:2 (1990): 109. For example, in pre-colonial times, parts of the East Coast were allied to the Kandyan Kingdom in the South.

${ }^{13}$ Murugar Gunasingam, Sri Lankan Tamil Nationalism: A Study of its Origins (Sydney: M.V. Publications, 1999), 73-76.

${ }^{14}$ While some have tried to construe this as evidence of a divide and rule policy, others offer alternative arguments: The communal representation in councils and the British differentiating between the different groups "should not be interpreted as the manifestation of a wish to 'divide and rule'; it was done out of misguided 'liberal' sentiments which sought to protect the different customs of different 'races." Nissan and Stirrat, "The Generation of Communal Identities," 29.

${ }^{15}$ Ghosh, Ethnicity versus Nationalism, 69.

${ }^{16}$ David Little, Sri Lanka: The Invention of Enmity, (Washington: United States Institute of Peace Press, 1994), 53-4.

17 T.D.S.A Dissanayake, War or Peace in Sri Lanka (Mumbai: Popular Prakashan, 2005), 66.

${ }^{18}$ Jonathon Spencer, "Introduction: The Power of the Past," in Sri Lanka: History and the Roots of Conflict, ed. Jonathon Spencer (London: Routledge, 1990), 9.
} 
Lanka Freedom Party) - to victory. ${ }^{19}$ Bandaranaike won this election on the promise that he would institute Sinhalese as the only official language in the country (until this point, Sinhala, Tamil and English had all been official languages). With this 'Sinhala Only' policy, Bandaranaike mobilised mass support. ${ }^{20}$ After the election, Tamil politicians led satyagraha ${ }^{21}$ protests against the bill. ${ }^{22}$

The Sinhala Only act was the first of many post-colonial government policies that fuelled Sinhalese-Tamil animosity. Others, including the resettlement policies (where Sinhalese people were settled into areas where Tamils predominated), ${ }^{23}$ standardisation policy (in which the access of students from Tamil areas to university education was hampered), ${ }^{24}$ and the 1972 constitution (which revoked clauses protecting minorities) ${ }^{25}$ further entrenched the Sinhalese-Tamil distinction. ${ }^{26}$ In Chapter Three, I will discuss the LTTE's description of these policies.

During this increasingly turbulent period, the FP (Federal Party) emerged as the most influential Tamil political party. The party was formed shortly after Sri Lanka became independent. Its party manifesto declared its intent to establish a Tamil state within a united Sri Lanka. ${ }^{27}$ In the first few elections they contested, the FP received very little support from Tamil constituents, showing that most Tamils were not interested in a federal state. ${ }^{28}$ This soon changed. Government policies impelled Tamils to support the FP's demands for a separate

\footnotetext{
${ }^{19}$ Kenneth D. Bush, The Intra-Group Dimensions of Ethnic Conflict in Sri Lanka: Reading to Read between the Lines (Hampshire: Palgrave Macmillan, 2003), 84. The SLFP was the main party in a coalition of parties called the MEP (Mahajana Eksath Peramuna).

${ }^{20}$ William McGowan, Only Man Is Vile: The Tragedy of Sri Lanka (New York: Farrar, Straus and Giroux, 1991), 154-5.

${ }^{21}$ Neil De Votta, Blowback: Linguistic Nationalism, Institutional Decay and Ethnic Conflict in Sri Lanka (Stanford, Stanford University Press, 2004), 139-40. Satyagraha refers to non-violent protests that usually involve acts of civil disobedience. Gandhi famously led satyagraha campaigns against the British. In Sri Lanka, Tamil leaders used the term satyagraha to refer to their non-violent campaigns. They believed that if they followed Gandhi's tactics, they too would bring about political change.

22 Ghosh, Ethnicity versus Nationalism, 78.

${ }^{23}$ Robert Kearney, "Ethnic Conflict and the Tamil Separatist Movement in Sri Lanka," 904.

${ }^{24}$ McGowan, Only Man Is Vile, 168.

${ }^{25}$ De Votta, Blowback, 134.

${ }^{26}$ Dagmar Hellmann Rajanayagam, "The Jaffna Social System: Continuity and Change under Conditions of War," Internationales Asienforum 24 (1993): 271.

${ }^{27}$ Stokke and Ryntveit, "The Struggle For Tamil Eelam in Sri Lanka," 291-2.

${ }^{28}$ Devanesan Nesiah, Tamil Nationalism, Marga Monograph Series on Ethnic Reconciliation 6 (Colombo: Marga Institute, 2001), 13.
} 
state. The FP, like the SLFP, was thus able to use ethnic tension to mobilise mass support and win votes. ${ }^{29}$

During the 1970s, the FP and other Tamil political parties were influenced by the Tamil youth, who felt particularly marginalised by the government and increasingly frustrated with the parliamentarian strategies of their elected representatives. Feeling this frustration, a group of Tamil parties (including the FP) amassed and formed a conglomerate known as TUF (Tamil United Front), later renamed TULF (Tamil United Liberation Front). The TULF issued a declaration in 1976 where it stated its decision to pursue Eelam - a sovereign, autonomous state for the Tamil people. ${ }^{30}$ Around this time, Tamil militant groups began to emerge. When the TULF failed to win Eelam or even make concrete progress towards Eelam, it was sidelined by these emergent groups. Several of these groups still exist today in some form or other, but the most influential is the Liberation Tigers of Tamil Eelam (LTTE). ${ }^{31}$ Renowned for its ruthlessness, the LTTE has attained this status by eliminating dissidents within the organisation and opponents outside it. But this is only one condition of its success. The LTTE has won its hegemony at least equally through its capacity to formulate a sense of national identity that resonates deeply with the Tamil public.

Having established how Sinhalese and Tamil identities are often represented and the events and groups which shaped these representations, I will now complicate the Sinhalese-Tamil distinction and show that it is not as selfevident as it appears. As I have already intimated, the Tamil speaking community is not a homogeneous group. A careful observer can apprehend old allegiances to caste, region and religion simmering beneath nationalist projects, goals and rhetoric. While most Tamil speakers classify themselves as Tamils (the Muslim community are an exception here), they would also identify as Estate Tamils, East Coast Tamils, and Peninsular Tamils, and as particular castes within these groups. Here, I will outline these divisions amongst the Tamil speaking community, and then I will elaborate on them as necessary in the chapters that follow.

\footnotetext{
${ }^{29}$ Hellmann Rajanayagam, "The Concept of a Tamil Homeland in Sri Lanka," 99-103.

${ }^{30}$ Ghosh, Ethnicity versus Nationalism, 76.

${ }^{31}$ Dagmar Hellmann Rajanayagam, The Tamil Tigers: Armed Struggle For Identity (Stuttgart:

Franz Steiner Verlag, 1994), 1, 9-11.
} 
Tamil speaking peoples live throughout the island but predominate in the Jaffna Peninsula (in the north), the Vanni proper (the area south of the Peninsula and north of Anuradhapura) and the East Coast (which is often regarded as an extension of the Vanni). ${ }^{32}$ In addition, there are significant Tamil speaking communities in Colombo (the country's capital) and in the central highlands where the plantations are. ${ }^{33}$ The region most closely associated with Sri Lankan Tamil consciousness and nationalism is the Jaffna Peninsula, from where the first Tamil nationalists came. ${ }^{34}$ The Jaffna Peninsula is considered the most conservative corner of the island. Caste and religious practices are upheld rigorously there. ${ }^{35}$

Tamil national identity is not only connected to the Jaffna Peninsula but also to a particular caste group on the peninsula, the Vellalars. While the Vellalars officially belong to the Sudra varna (the lowest of the varna, according to Sastric ranking) ${ }^{36}$, they enjoy a high status in Jaffna. They are a landowning caste, associated with the fertility of the earth and the prosperity of the community. ${ }^{37}$ The Jaffna Vellalars traditionally owned most of the temples on the Peninsula. ${ }^{38}$ In these Vellalar-owned temples, the Brahmans (who belong to the highest varna) perform daily and annual rituals, the benefits of which accrue to the patrons of the temple, rather than to the officiants or the attendees. ${ }^{39}$ In Jaffna, the Brahmans are thus regarded as the salaried staff of the Vellalars. This is quite different from the situation in South India where a small minority of Brahmans presided over the population. ${ }^{40}$

But the Jaffna situation is not anomalous. In fact, in the Brahman-Vellalar alliance, Jaffna preserves a hallmark of ancient Dravidian civilisation. ${ }^{41}$ In South India this relationship changed in medieval times when Brahmans became

\footnotetext{
${ }^{32}$ Dennis McGilvray, Tamil and Muslim Identities in the East, Marga Monograph Series on Ethnic Reconciliation 24 (Colombo: Marga Institute, 2001), 1-2.

${ }^{33}$ Daniel Bass, Landscapes of Malaiyaha Tamil Identity, Marga Monograph Series on Ethnic Reconciliation 8 (Colombo: Marga Institute, 2001), 6.

${ }^{34}$ Bryan Pfaffenberger, "The Cultural Dimension of Tamil Separatism in Sri Lanka," Asian Survey 21:11 (1981): 1146.

${ }^{35}$ Ibid., 1148.

${ }^{36}$ According to classical texts, the people are divided into four main varna: the Brahmans, the Kshatriya, Vaishyas and the Sudra. The Untouchables are placed outside this system.

${ }^{37}$ Bryan Pfaffenberger, Caste in Tamil Culture: The Religious Foundations of Sudra Domination in Tamil Sri Lanka (Syracuse: Syracuse University, 1982), 5.

${ }^{38}$ Hellmann Rajanayagam, "The Jaffna Social System," 252.

${ }^{39}$ Pfaffenberger, Caste in Tamil Culture, 61, 63-4.

${ }^{40}$ Hellmann Rajanayagam, "The Jaffna Social System," 252.

${ }^{41}$ Pfaffenberger, "The Cultural Dimension of Tamil Separatism in Sri Lanka," 1151.
} 
increasingly powerful. ${ }^{42}$ Because Jaffna Brahmans never attained the same kind of power, the area has remained untouched by the anti-Brahman movement that swept through South India. ${ }^{43}$ The Jaffna Vellalars thus retained their power well into the $20^{\text {th }}$ Century. The values and symbols of this group shaped the contours of Tamil national identity in the colonial and early post-colonial years. ${ }^{44}$ In Chapter Two I will outline how this Vellalar based conception of Tamil identity caused problems for the Federal Party when it tried to mobilise a national identity.

The Karaiyar, another caste on the peninsula, stand apart from the ancient agrarian dominance of the Vellalars. While other castes sought to acquire Vellalar status, the Karaiyar articulated an independent identity. Originally a fishing caste, the Karaiyar comprises ten percent of the peninsular population. ${ }^{45}$ They are mentioned extensively in sources about the Jaffna kingdom, a precolonial kingdom centred in the northern peninsula. Their traditions cast them as brave warriors who were recruited in pre-colonial times to fight as mercenaries. ${ }^{46}$ This tradition of doughtiness lived on in the colonial era, when many Karaiyar resisted colonial rule and became notorious as smugglers. ${ }^{47}$

The Karaiyar retained a degree of autonomy from the Vellalar not only through their martial traditions, but also by being a politically active group. When universal franchise was granted in 1931, they were the only caste, other than the Vellalar, to vote in significant numbers. This, along with the way they pursued English education, annoyed conservative Vellalars who wanted to preserve education and politics as domains of Vellalar power and influence. ${ }^{48}$ Their independence from the Vellalar establishment may also be attributed to their large scale conversion to Catholicism. Here, they differed from even Vellalar Christians, who were mainly Protestants. ${ }^{49}$ The majority of LTTE cadres

\footnotetext{
${ }^{42}$ Pfaffenberger, Caste in Tamil Culture, 26-7.

${ }^{43}$ Ibid., 31-2.

${ }^{44}$ Pfaffenberger, "The Cultural Dimension of Tamil Separatism in Sri Lanka," 1146.

${ }^{45}$ Oivind Fuglerud, Life on the Outside: The Tamil Diaspora and Long Distance Nationalism (London: Pluto Press, 1999), 27.

${ }^{46}$ Hellmann Rajanayagam, "The Jaffna Social System," 265-267.

${ }^{47}$ Stokke and Ryntveit, "The Struggle For Tamil Eelam in Sri Lanka," 297.

${ }^{48}$ Dagmar Hellmann Rajanayagam, "From Differences To Ethnic Solidarity," in Sri Lankan Society in an Era of Globalisation: Struggling to Create a New Social Order, ed. S.H. Hasbullah and Barrie M. Morrison (New Delhi: Sage Publications, 2004), 105.

${ }^{49}$ Ibid., 103. Fifteen percent of the Jaffna Tamil population are Christians. Of this, eighty percent are Catholics.
} 
are drawn from the Karaiyar caste ${ }^{50}$ Consequently there is a significant Catholic contingent in the LTTE.

Like the Karaiyar and Vellalars of the Jaffna Peninsula, the Tamil population of the East Coast identify as Tamils, while retaining caste and regional identities. East Coast Tamils diverge from the peninsular Tamils in their social and religious practices. For example, while there are Vellalars on the east coast, the dominant caste is the Mukkuvars (a caste of lagoon fishers). ${ }^{51}$ Also, familial lineages are traced differently in the two regions; the Jaffna Tamils are patrilineal while the east coast Tamils are matrilineal. ${ }^{52}$ Furthermore, East Coast Tamils do not assiduously observe the Brahmanic rituals so important to Jaffna Tamils, but persist with a number of popular religious practices that have long been repudiated in the north. ${ }^{53}$

We can explain this chasm between the two groups at least partly through the physical and political separation of the two regions. The East Coast Tamils were never allied to the Jaffna Kingdom that existed in the north. In fact, when the Portuguese arrived, significant sections of the East Coast were allied to the Kandyan Kingdom in the South. ${ }^{54}$ In addition, the East Coast Tamils espouse different immigration traditions from the northerners, tracing their origins to different parts of India. ${ }^{55}$ The East Coast Tamils have resisted being assimilated or equated with Jaffna Tamils, although this has slowly changed with postindependence politics. Since independence, successive governments have alienated the East Coast Tamils through their resettlement schemes. In this way, the government has encouraged the East Coast Tamils to ally with their Jaffna brethren. As a result, the two regional identities have conflated to some extent. ${ }^{56}$

Another Tamil speaking group that lives on the East Coast are the Muslims. They comprise about seven percent of the island's population. ${ }^{57}$ Although they speak Tamil, the Muslims have not posited a common identity

\footnotetext{
${ }^{50}$ Fuglerud, Life on the Outside, 35.

${ }^{51}$ Hellmann Rajanayagam, "From Differences To Ethnic Solidarity," 103.

${ }_{53}$ McGilvray, Tamil and Muslim Identities in the East, 5.

${ }^{53}$ Ibid.

${ }^{54}$ Hellmann Rajanayagam, "The Concept of a Tamil Homeland in Sri Lanka," 89.

${ }^{55}$ Ibid., 89-93.

${ }^{56}$ Bryan Pfaffenberger, "The Political Construction of Defensive Nationalism: The 1968 Temple Entry Crisis in Sri Lanka," in The Sri Lankan Tamils: Ethnicity and Identity, ed. Chelvadurai Manogram and Bryan Pfaffenberger (Colorado: Westview Press, 1994), 162-3.

${ }^{57}$ Fuglerud, Life on the Outside, 20.
} 
with either the East Coast Tamils or the Northerners, but maintained a distinct, Muslim identity. ${ }^{58}$ While Muslim groups sometimes align themselves with the LTTE and other Tamil nationalist groups, this has not always the case. ${ }^{59}$ On the Tamil side, the TULF and the LTTE have made various provisions for the Muslims within a Tamil state. ${ }^{60}$ In 1990, however, the LTTE estranged the Muslim community when it ordered all Muslims living on the peninsula to leave. $^{61}$

The last group which we must discuss are the Estate or Hill Country Tamils, a population who live primarily within the highlands of the Uva province (near Kandy). Today's Estate Tamils are the descendents of Indian labourers, brought to Sri Lanka by the British at the turn of the $20^{\text {th }}$ Century. ${ }^{62}$ Most of today's Hill Country Tamils continue to work on the tea plantations where their forefathers toiled. While the Estate Tamils share common language and religious features with the East Coast and Northern communities, they have traditionally not been accorded the same status on account of their caste, their links to India, their place of abode and their short history in the island. ${ }^{63}$ At independence, with the support of Ceylon Tamil politicians, they were disenfranchised through two successive acts of parliament. ${ }^{64}$ The LTTE welcomes the Estate Tamils, inviting them to join the struggle and live in the future state of Eelam. The LTTE's map of Eelam, however, does not include the hill country region where the Estate Tamils live. ${ }^{65}$

\footnotetext{
${ }^{58}$ S.H. Hasbullah, "Justice for the Dispossessed: The Case of a Forgotten Minority" in Sri Lanka's Ethnic Conflict," in Sri Lankan Society in an Era of Globalisation: Struggling to Create a New Social Order, ed. S.H Hasbullah and Barrie M. Morrison (New Delhi: Sage Publications, 2004), 222.

${ }^{59}$ Daniel, Charred Lullabies, 18-9.

${ }^{60}$ Dagmar Hellmann Rajanayagam, "Religious Ideology Among the Tamils," in Sri Lanka's Ethnic Conflict," in Sri Lankan Society in an Era of Globalisation: Struggling to Create a New Social Order, ed. S.H Hasbullah and Barrie M. Morrison (New Delhi: Sage Publications, 2004), 79-80. The FP made provisions for the Muslims in a federal state. They promised to make Amparai (a district with a Muslim majority on the East Coast) an autonomous unit within a federal scheme. In its blueprint for Eelam, the LTTE has promised the Muslim community 30\% of all the seats in parliament and $35 \%$ of all newly developed land in the East - $5 \%$ in the North and $30 \%$ in Mannar.

${ }^{61}$ Hellmann Rajanayagam, "From Differences To Ethnic Solidarity," 109.

${ }^{62}$ Daniel, Charred Lullabies, 18.

${ }^{63}$ Stokke and Ryntveit, "The Struggle For Tamil Eelam in Sri Lanka," 291.

${ }^{64}$ Bass, Malaiyaha Tamil Identity, 10.

${ }^{65}$ Hellmann Rajanayagam, The Tamil Tigers, 57. While the borders of Eelam do not encompass the areas where the Estate Tamils lived, they do include areas where Tamil speakers had originally lived, before becoming Sinhalised.
} 
In the chapters to follow, I explore how Sri Lankan Tamils formulate and articulate a national identity. When I refer to the Sri Lankan Tamils, I am referring to the Tamil speaking people, who identify as Tamils and that either live in, or trace their origins back to, the North or the East. As Nesiah points out, when one uses the term 'Sri Lankan Tamil' in this way, one must also acknowledge the identity politics that underlie the category:

The term Sri Lankan Tamils is...inaccurate since it implies that the other Tamil group resident in Sri Lanka, the Hill Country Tamils, are not Sri Lankan. If, in the course of time, the ethnic identities of the Sri Lankan Tamils and the Hill Country Tamils merge, then the term Sri Lankan Tamil could be used to correctly distinguish between the Tamils of Sri Lanka and those of India and elsewhere, and not to draw distinctions among the Tamils of Sri Lanka. I have not made any attempt to coin new 'politically correct' terms or to anticipate future developments but have used the terms Tamil Nationalism and Sri Lankan Tamils as widely understood in Sri Lanka. ${ }^{66}$

The information presented in the foregoing discussion is important to my project for several reasons. First, throughout the study I refer to groups (such as the Jaffna Vellalars) and events (such as the 1956 elections) recounted above. Second, the preceding discussion gives us some insight into the Tamil community which the LTTE addresses and claims to represent. Third, the discussion highlights how Sinhalese and Tamil identities are flexible entities that have been shaped by ideological, political and economic circumstances. Consequently, in my project, I assume that there is nothing essentially Tamil about the LTTE's representation of national identity. I thus approach the LTTE's formulation of national identity as a malleable entity that offers only one possible depiction of what it means to be Tamil.

\subsection{Sources}

My study has been shaped not only by Sri Lanka's demographics and history, but also by considerations pertaining to LTTE sources. The LTTE's English sources differ in content from its Tamil sources. I cannot read or speak Tamil and am consequently limited to English language sources. Therefore, I have had to carefully consider how and why the English and Tamil sources

\footnotetext{
${ }^{66}$ Nesiah, Tamil Nationalism, 1.
} 
differ. These differences have shaped my project in important ways. I now turn to this next piece of groundwork: LTTE sources.

The LTTE has created a broad range of literature. It values literary accomplishments, encouraging Tamil poets, writers and composers. In addition to this canon of creative literature, the LTTE has produced a website as well as a number of official books and pamphlets that detail the movement, its cause and the ongoing difficulties the organisation encounters in trying to attain Eelam. While the material written in Tamil is directed primarily at the Sri Lankan Tamil community (both in Sri Lanka and in the diaspora), the English materials are aimed primarily at the International audience. The English materials include both LTTE texts written solely in English as well as those texts which the LTTE translates into English.

Compared with the English language sources which are in plentiful supply, scholarly translations of the Tamil sources are difficult to find. In their articles, scholars sometimes translate excerpts from Tamil sources (e.g. Peter Schalk's translation of a paragraph from a Heroes' Day Address and Oivind Fuglerud's translation of a speech from an LTTE cassette. ${ }^{67}$ Dagmar Hellmann Rajanayagam and Peter Schalk have also translated two LTTE texts written in Tamil - a compilation of LTTE poetry and a collection of Prabhakaran's sayings. ${ }^{68}$ From these scholarly translations and from the scholars' analyses of these and other Tamil texts, I have become aware of how the LTTE's Tamil texts diverge from (but also converge with) the English ones. ${ }^{69}$

In particular, the English language texts omit references to the LTTE's martial traditions, which are mentioned across a wide variety of Tamil sources. Even more importantly, scholars identify religious terminology in Tamil sources that is either omitted or toned down in the English language sources. We see these sorts of omissions when we compare the LTTE's official translation of Velupillai Prabhakaran's 1992 Heroes' Day Address with Schalk's translation of

\footnotetext{
${ }^{67}$ Peter Schalk, "Beyond Hindu Festivals: The Celebration of Great Heroes' Day by the Liberation Tigers of Tamil Ealam (LTTE) in Europe," in Tempel und Tamilien in Zweiter Heimat, ed. Martin Baumann (Wuerzburg: Ergon Verlag, 2003), 402; Fuglerud, Life on the Outside, 155-6.

${ }^{68}$ Dagmar Hellmann Rajanayagam, "And Heroes Die: Poetry of the Tamil Liberation Movement in Northern Sri Lanka," in South Asia: Journal of South Asian Studies 28:1 (2005); LTTE, Reflections of the Leader, trans. by Peter Schalk and Alvappillai Veluppillai (n.p: LTTE, 2007). http://publications.uu.se/abstract.xsql?dbid=8404 (accessed May 12, 2008).

${ }^{69}$ Hellmann Rajanayagam, The Tamil Tigers, 4.
} 
an excerpt of this speech. ${ }^{70}$ When I compare the two, I cannot even find an equivalent paragraph for the passage which Schalk translates.

We can speculate as to why the LTTE's English texts differ in this way. Perhaps the LTTE supposes that an international readership might interpret these 'Tamil references' (to martial history and Hindu ritual) as evidence that the LTTE is an organisation of religious fanatics, with visions of imperial grandeur. The LTTE wants to win the support of the international community, and so it either deliberately or unthinkingly omits these references from the English language sources, references which it believes might be misinterpreted by the international community.

Alternatively, in the case of translations, the LTTE may view rigorous translations as too difficult or inappropriate for the context in which they are provided. Scholarly translations gloss Tamil words, explaining the context in which they are used; footnotes and parentheses are required. For the LTTE, translating like this may be too difficult or even inappropriate for the context in which such translations will be circulated (for example, posting on the internet).

Because I cannot read Tamil, I have been mainly limited to the LTTE's English language sources. This 'limitation' has had important consequences for my project. For example, in the following chapters the reader will see that I rely primarily upon the secondary analysis when I discuss how the LTTE employs martial and Hindu traditions. I recognise that this inability to access a range of LTTE sources has limited my research, and I openly discuss this in this thesis. This 'limitation,' however, has also influenced the direction that my study has taken.

Because I could not directly access the Tamil sources, I was forced to rely on the scholarly literature for most of my information about the LTTE's Tamil sources. Consequently, I became aware of how the scholarly literature is rife with contradictions. In particular, I identified how the category of religion hinders,

\footnotetext{
${ }^{70}$ Schalk, "Beyond Hindu Festivals", 402; Velupillai Prabhakaran, "English Translation of Martyrs' Day Speech 1992," http://www.ltteps.org/?view=422\&folder=9 (accessed, May 12, 2008). Velupillai Prabhakaran is the enigmatic, much revered leader of the LTTE. According to the LTTE, he inaugurated the organisation under the name Tamil New Tigers. The organisation was renamed as The Liberation Tigers of Tamil Eelam in 1976. Every year at the Mavirar Nal celebrations, Prabhakaran delivers a speech, summarising the events of the year and encouraging the people to recommit to the struggle. Mavirar Nal literally means Great Heroes' Day, but the LTTE often translates it as Martyrs' Day. A.S. Balasingham, Liberation Tigers and Tamil Eelam Freedom Struggle (n.p: LTTE, 1983), 25.
} 
rather than helps, scholarly analysis. Even more importantly, this 'limitation' has forced me to really tackle the English language sources and recognise the similarities (as well as the differences) between the English and Tamil sources. I take both sets of sources seriously. I do not consider the English language sources to be a façade or a fabrication purely for the benefit of the international community. The English and Tamil sources share many common features (for example, both emphasise the recent post-colonial past). The references in the Tamil sources, invisible to us in the English equivalents, complement and coalesce with what is common to both the English and Tamil sources. Although the English and Tamil sources are directed at different audiences, they are nonetheless equally involved in how the LTTE shapes its cause, its nationalism and most importantly, Tamil identity.

\subsection{Religion and the Secular: An Asad-based Response to the Scholarly Debate}

The final piece of groundwork involves the scholarly discussion that I alluded to both in the opening paragraphs of this chapter and in the preceding discussion on sources. Scholars disagree over whether religion is involved in the LTTE's nationalism. Some support the LTTE's declaration that they are a secular organisation, while others (either explicitly or implicitly) contest it. I will elaborate on this debate in the following chapters, but here I will outline some of the assertions that scholars make. I will then delineate Talal Asad's ideas, showing how they have enabled me to intervene in the scholarly debate and formulate an approach for this study.

Peter Schalk, Dagmar Hellmann Rajanayagam, Cristiana Natali and Michael Roberts argue that the LTTE's nationalism is religious in some way. Schalk employs a functionalist definition of religion, suggesting that the LTTE's nationalism is a new kind of religion. ${ }^{71}$ Hellmann Rajanayagam advances another claim: the LTTE employs syncretistic religious symbols and terms which diverge from its secular proclamations. ${ }^{72}$ Natali pushes this conclusion further, arguing that the LTTE is aware of these religious facets, and yet, does nothing to

\footnotetext{
${ }^{71}$ Peter Schalk, "The Revival of Martyr Cults Among Ilavar," Temenos 33 (1997): 154. Peter Schalk is being polemical when he advances his argument. In most of his articles, he emphasises the secular character of the LTTE's nationalism.

${ }^{72}$ Hellmann Rajanayagam, “And Heroes Die," 118.
} 
eradicate them. ${ }^{73}$ She implies that the LTTE is insincere when it asserts a secular status. Finally, Michael Roberts argues that the LTTE's nationalism contains both rational and enchanted facets. Consequently, he argues that the LTTE should not be understood (from a critical, analytical perspective) as a secular organisation. In fact, to Roberts, the LTTE is akin to overtly religious organisations like Al Qaeda. Both organisations possess enchanted facets and thus "share a shoring in cosmological realities." 74

As I have already pointed out, this debate impacts upon how we assess the LTTE's secularity and the religious difference also. We must thus intervene in this debate if we are to answer my first set of questions: Is there a religious difference between the two nationalisms? And if so, what is it and how did it develop?

From the scholarly discussion, we can see that the categories of religion and the secular are implicated not only in how the LTTE mobilises a group identity, but also in how scholars discuss and analyse the LTTE's nationalism. Therefore, we can only engage with the scholarly discussion, when we establish a theoretical framework that enables us to discuss religion and the secular as rhetorical strategies. Talal Asad's work provides us with such a framework.

In his book Formations of the Secular, Talal Asad problematises the categories of religion and the secular. For Asad, religion and the secular are not self-evident categories that can be used to describe phenomena. Although religion and the secular are presented in modern societies as autonomous, distinct arenas, when we investigate them further we find that so called religious objects and institutions overlap with secular objects and institutions. Furthermore the meanings of 'religion' and 'secular' are made and remade in different contexts. At different historical moments people provide very different definitions of religion, consisting of quite different attributes and criteria. ${ }^{75}$ Because 'religion' and 'the secular' overlap, and because their meanings are context dependent,

\footnotetext{
${ }^{73}$ Cristiana Natali, "Building Cemeteries, Constructing Identities. Funerary Practices and Nationalist Discourse Among the Tamil Tigers of Sri Lanka," http://www.basas.ac.uk/conference05/natali,\%20cristiana.pdf (accessed April 26, 2008). Michael Roberts cites this conference paper in the following article: Michael Roberts, "Pragmatic Action and Enchanted Worlds: A Black Tiger Rite of Commemoration," Social Analysis 50:1 (2006). ${ }^{74}$ Roberts, "Pragmatic Action and Enchanted Worlds," 95-6.

75 Talal Asad, "The Trouble With Thinking: an Interview with Talal Asad," in Powers of the secular modern: Talal Asad and his interlocutors, ed. David Scott and Charles Hirschkind (California: Standford University Press, 2006), 287.
} 
Asad argues that the categories have little value as analytical or descriptive categories. ${ }^{76}$ When we classify an institution, experience or text as religious or secular, we provide little insight into the object being investigated. While Asad repudiates the categories as conventional, analytical categories, he does not entirely dismiss the categories.

Based on these observations, Asad encourages a new mode of analysis which is nonetheless still concerned with religion and the secular. Rather than ask whether an object is religious, Asad asks: how are religion and the secular represented? He argues that the categories of 'religion' and 'the secular' can be represented in diverse ways. He provides a striking example of this, when he compares Britain, France and America, three societies that are generally considered secular. He shows how the secular is represented differently in each society; what is perceived as a transgression of the secular in one society is entirely consonant with secularism in another. The secular, like religion, can thus be represented in diverse ways. Furthermore, its meanings are not static, but are constantly revised and refashioned in different contexts to fit new challenges and demands. ${ }^{77}$ These different representations of the secular show us not only that religion and the secular are invalid as analytical tools, but also that the categories can and do mediate national identity in diverse ways. ${ }^{78}$ In this way, Asad deconstructs the categories of religion and the secular as they are conventionally understood, and instead, focuses upon how the categories are represented and the implications of these representations. In the process, he acknowledges that representations of the categories have very real implications for how modern people express their identity and experience their world: "In modern and modernising states representations of the 'secular' and the 'religious' mediate people's identities, help shape their sensibilities, and guarantee their experiences." 79

While Asad deconstructs the secular (as it is conventionally used), he also reconstructs it as an ontological category. This reconstructed secular is an important component of Asad's theory. Alongside representations of religion and the secular, the reconstructed secular is presented as integral to modern living: "I

\footnotetext{
${ }^{76}$ Asad, Formations of the Secular, 25-6.

${ }^{77}$ Ibid., 5.

78 Ibid.

${ }^{79}$ Ibid., 14.
} 
take the secular to be a concept that brings together certain behaviours, knowledges and sensibilities in modern life." ${ }^{\prime 80}$ In particular, Asad's reconstructed secular refers to the genealogies of concepts and sensibilities which arose out of a shift in early modernity; as the secular emerged as a category that structured people's experiences, concepts derived from Christian tradition were radically reformulated. Consequently, meanings and practices changed: "Words and practices were rearranged and new discursive grammars replaced previous ones. I suggest that the fuller implications of those shifts need to be explored." This shift in the grammar of concepts does not merely connote a shift in linguistic usage. It has real ontological implications for "how the body lives pain and punishment, compassion and pleasure, hope and fear." 82

Asad refers to these ontological and epistemological implications as secular, presumably because they emerged at the time that secularism developed as a political doctrine. He thus characterises the secular (in this reconstructed sense), not by the absence of religion, but by the concepts and binaries on which it is predicated, and the sensibilities, practices and knowledges that it enables. ${ }^{83}$ While Asad acknowledges that this ontology (like representations of the secular) is constantly made and remade, he also argues that secular life is underpinned by a key cluster of concepts. Although their meanings shift, the web of concepts nonetheless remains. ${ }^{84}$

Asad's 'reconstructed secular' thus does not concern how an individual or group understand their relationship to religion (although this is important for how that group represents the categories of religion and the secular). Instead it concerns the discourse and rhetoric of such individuals and groups. More particularly, it concerns the genealogies of reworked Christian concepts and sensibilities which pervade this discourse and rhetoric. In this way, Asad is able to refer as secular to individuals, groups and phenomena that claim to be religious. For example, he discusses how the 'secular Christian' is bound to

\footnotetext{
${ }^{80}$ Ibid., 25.

${ }^{81}$ Ibid., 25-6.

${ }^{82}$ Ibid., 99.

${ }^{83}$ I will later explore particular sensibilities and concepts that Asad identifies as 'secular' (in his reconstructed sense). Here I only want to emphasise his overall argument about the reconstructed secular - secular ontology consists of sensibilities, knowledges and behaviours that grew out reformulated Christian concepts.

${ }^{84}$ Asad, Formations of the Secular, 23.
} 
modern, secular sensibilities of pain. In the secular, modern formulation, pain and suffering are considered reprehensible and even scandalous. The secular Christian thus struggles to make sense of suffering, even though suffering historically held an honoured position in Christian tradition. ${ }^{85}$ Asad thus characterises modern Christians as secular (in this reconstructed sense). While they profess religious faith, they are nonetheless influenced by sensibilities which arise out of reworked Christian concepts.

Similarly, Asad presents nationalism as essentially secular, even though some nationalists claim to be religious. He stakes this claim on the grounds that nationalism depends on the notion of the secular, a space distinct from and prior to religion: ${ }^{86}$ "Nationalism...requires the concept of the secular to make sense. The loyalty that the individual nationalist owes is directly and exclusively to the nation. Even when the nation is said to be "under God" it has its being only in 'this world'- a special kind of world." 87

It seems that the secular sensibilities that Asad identifies have a "thisworldly focus' (and this is why Asad can apply the term to explicitly religious objects). ${ }^{88}$ In other words, modern, secular sensibilities claim to apprehend this world (the real world) as it really is. As Asad points out, however, there is no apprehension of the real; the "secular world is not merely discovered (through clear-sighted knowledge of the real) but precariously assembled and lived in contradictory fashion." 89 The secular thus presents yet another conception of the world, not the true apprehension of it. ${ }^{90}$ But the claim that the real is being

\footnotetext{
${ }^{85}$ Ibid., 106-107. "Christianity which was traditionally rooted in the doctrine of Christ's passion, consequently finds it difficult to make good sense of suffering today. Modern theologians have begun to concede that pain is essentially and entirely negative... it follows that such pain should be eliminated from the world of human interaction - even from religious disciplines, and from the enactment of martyrdom, where it once had an effective and honoured place. The secular Christian must now abjure passion and choose action. Pain is not merely negativeness. It is, literally, a scandal."

${ }^{86}$ Ibid., 191-2.

${ }^{87}$ Ibid., 193.

${ }^{88}$ Ibid., 64.

${ }^{89}$ Ibid., 63.

${ }^{90}$ For Asad the reconstructed secular is also characterised by uncertainty: "In brief, this world is 'secular' not because scientific knowledge has replaced religious belief (that is, because the 'real' has at last become apparent) but because, on the contrary, it must be lived in uncertainly, without fixed moorings even for the believer, a world in which the real and the imaginary mirror each other. In this world the politics of certainty is clearly impossible." Asad suggests that the "emphasis on this-wordliness is a consequence of that tension." Ibid., 64-65.
} 
apprehended is an important part of these sensibilities that Asad describes as secular. ${ }^{91}$

For Asad, modernity, like the secular, is characterised by the sense that the real is being apprehended: "The notion that these experiences constitute 'disenchantment'- implying a direct access to reality, a stripping away of myth, magic, and the sacred - is a salient feature of the modern epoch." 92 Asad thus construes modernity as almost synonymous with the secular: "I suggest that the idea of cruelty in modern discourse has distinctive characteristics, and that in describing them one is also identifying aspects of the secular." 93

In my opinion, Asad is not entirely coherent when he applies the term 'secular' in this reconstructed sense. If modern sensibilities are synonymous with so-called secular ones, then what do we gain by calling them secular? More importantly, Asad confuses his reader, first repudiating the term 'secular' (as it is conventionally used) and then applying it himself in a reconstructed sense. I do, however, think that Asad's reconstructed secular points to an important insight that stands, regardless of whether we agree with his appellation 'secular.' When Asad discusses secular sensibilities, he demonstrates how modernity presents another conception of the world, not the true apprehension of it.

This study draws on both Asad's concept of the reconstructed secular as well as his insights about representation. For the bulk of my thesis, however, I focus on notions of representation, discussing first, how scholars apply (represent) the categories of religion and the secular when they analyse the LTTE, and second, how the LTTE represents the categories of religion and the secular in their discourses. When we consider Asad's observation about how religion and the secular overlap, it seems hardly surprising that the LTTE's supposedly secular nationalism has 'religious facets.' In a sense, Roberts is correct. The LTTE's nationalism has enchanted, religious facets like Al Qaeda's (or the Sri Lankan government's) rhetoric. What Asad helps us to appreciate, however, is that any secular organisation or nationalism has enchanted, religious facets. The LTTE resembles not only Al Qaeda, but also Western, secular

\footnotetext{
${ }^{91}$ Of course, pre-modern people also thought their narratives, practices and beliefs were 'true.' The difference, however, is that they did not perceive a need to verify and assert the truth of their narratives and practices. The claim to apprehend a verifiable reality thus characterises modern, secular narratives, practices and beliefs.

${ }^{92}$ Asad, Formations of the Secular, 13.

${ }^{93}$ Ibid., 100.
} 
governments. Furthermore, these secular governments in the West share commonalities with Al Qaeda too; both propagate rhetoric and symbols that have enchanted facets.

Throughout this study, I will argue that scholars of the LTTE provide little analytical insight when they identify 'religious' facets in LTTE practices. Furthermore, they detract from the LTTE's claim to be secular, a claim which shapes how the LTTE and the Tamil public understand their identity as Tamils.

Asad's ideas thus allow me to intervene in the scholarly debate. They also enable me to formulate an approach to the first of my questions: Is there a religious difference between Sinhalese and Tamil nationalisms? When we study the rhetoric of Sinhalese and Tamil nationalists, we identify some kind of religious difference between the two: Sinhalese nationalists seem to align Sinhalese identity with Buddhist identity while Tamil nationalists distance Tamil identity from Hindu identity. We clearly cannot explain this difference through conventional understandings of religion and the secular. In other words, we provide no real explanation of this difference if we call one nationalism religious, and the other, secular. But does this mean there is no difference at all? Are we confused or deluded when we perceive that the two nationalisms differ in some way, relating to religion? Using Asad, we can suggest that there is indeed a difference between the two nationalisms. This difference pertains not to a religious or secular essence, but to how Sinhalese and Tamil nationalists represent the categories of religion and the secular. We are thus not deluded when we intuitively perceive some kind of 'religious difference.' It's just that our conventional understanding of the categories (as two mutually exclusive domains) hinders us from being able to really engage with this difference. In Chapter Two, I elaborate on this insight, showing exactly how Sinhalese and Tamil nationalists represent the categories of religion and the secular.

In Chapter Two, and throughout this study, I use the phrase 'religious difference.' To reiterate once more, when I use this term I do not mean to suggest that there is some kind of essential religious difference between the two nationalisms. Instead, I use it to refer to our intuitive assessment that there is some kind of difference between the two nationalisms that pertains to religion. I also use it to refer to my critical assessment of this intuitively perceived difference: Sinhalese and Tamil nationalists differ in how they represent the 
categories of religion and the secular. It is on this basis that I assert: the religious difference pertains to how Sinhalese and Tamil nationalists represent the categories of religion and the secular. Similarly, when I refer to religious symbols, concerns and identity, I do not mean to imply that these features are innately religious; instead they are represented as being religious. Like 'religion' and 'secular,' the terms 'Sinhalese' and 'Tamil' do not refer to any kind of essence. When I talk about 'Sinhalese concerns' or 'Tamil identity,' I am referring to concerns that are represented as being Sinhalese and an identity that is represented as being Tamil. My study thus does not assume an ethnic or religious essence.

Asad's ideas also shape how I approach the material covered in Chapters Three and Four. In these chapters, I shift my attention from representations of religion and the secular to LTTE discourses. I do not, however, altogether abandon my interest in the categories. I show how these discourses are structured by the claim to be secular. Furthermore, I show how scholars obscure important insights when they impute religion to practices and terms within these the discourses. In contrast, I show how these so-called religious practices and terms might inform us about how the LTTE's represents a secular, national identity.

This study thus relies mainly upon Asad's insights around representation and not the reconstructed secular. For the most part, I do not try to assess whether the sensibilities which underpin LTTE discourses are secular in Asad's reconstructed sense. In my conclusion, however, I suggest how future studies of the LTTE may involve Asad's reconstructed secular. I also acknowledge the reconstructed secular in Chapter Three when I discuss Enlightenment History. Enlightenment History overlaps with several features that characterise Asad's reconstructed secular. Consequently, those who theorise about Enlightenment History, like Qadri Ismail and Valentine Daniel, bear many similarities to Asad. Like Asad, Ismail and Daniel identify how aspects of modernity (in this case Enlightenment History) present a particular conception of the world. For all three scholars, this conception is disguised by modernity's claim to apprehend reality. Where appropriate I make the connections between these theorists and Asad. ${ }^{94}$

\footnotetext{
${ }^{94}$ Please see footnotes 15 and 91 in Chapter Three.
} 


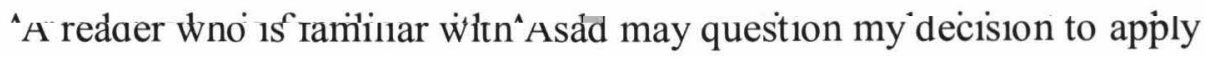
Asad's theory to the Sri Lankan context. After all, as the subtitle of Formations of the Secular suggests, the book mainly draws from Islamic and Christian history when discussing the development of secularism. From this, one might infer that Asad's theory only has relevance to Western Europe. However, Asad does not focus on Western history because he wants to tie his theory exclusively to the region of Europe. Rather, he primarily discusses Europe's history because it is this history which has shaped how secularism is discussed and understood around the world: "I draw my material almost entirely from West European history because that history has had profound consequences for the ways that the doctrine of secularism has been conceived and implemented in the rest of the modernizing world." 95 As we can see from this extract and from the previous discussion, Asad clearly connects secularism to modern and modernising states (and not solely to European history). Given this, it is certainly relevant to apply Asad's theory to Sri Lanka and the LTTE. As a modernising state and as an organisation which wishes to establish a modern state, the Sri Lankan state and the LTTE are certainly involved in representing and mediating a particular depiction of religion and the secular. In Sri Lanka, just as in Europe, such depictions shape how people understand, express and experience themselves and the world with which they interact.

From the foregoing discussion, one can appreciate that my thesis has been shaped by important considerations pertaining to Tamil and Sinhala identities, English and Tamil sources and religion and the secular. I hope to provide a nuanced discussion that honours the complexities involved in all these domains.

\footnotetext{
${ }^{95}$ Ibid., 25.
} 


\section{Chapter Two}

\section{Exploring the Religious Difference}

In this chapter, I substantiate the claim made in the Introduction - the religious difference pertains not to a religious or secular essence but to how Sinhalese and Tamil nationalists represent the categories of religion and the secular. I will argue that on the Sinhalese side, religious interests and identity are represented as being almost synonymous with national interests and identity. ${ }^{1}$ Furthermore, Sinhalese nationalists represent Buddhist practices and objects as symbols of Sinhalese identity. Tamil nationalists, however, distance religious interests from national interests, and therefore also, religious identity from national identity. While the LTTE does employ symbols and terms derived from Hindu tradition, these are not represented as being religious. Nor are they represented as symbols of Tamil identity.

The argument I advance involves several tasks: first, identifying identities, objects, symbols, interests and concerns that are commonly perceived as being religious. Second, it involves examining whether these identities, objects, symbols, interests and concerns are distanced from or made synonymous with national identities, objects, symbols, concerns and interests. In order to understand this relationship we must delve into what Sinhalese and Tamil nationalists do and say, and, in some cases, even what they do not say. I thus discuss the demands, rhetoric, statements, legislation and political campaigns of Sinhalese and Tamil nationalists, all of which are involved in mediating a particular depiction of religion, the nation and the relationship between the two.

Having established the religious difference, I then inquire into how these representations of national identity developed. I employ a historical argument, in which I inquire into the conditions which shaped Sinhalese and Tamil identities. I argue that a number of historical factors converged. On the one hand, Sinhalese identity was fused to values and symbols that were perceived as religious; while on the other, Tamil identity came to depend on elite caste values that were represented as being separate from religion. This second exercise yields insights

\footnotetext{
${ }^{1}$ As stated in the Introduction, when I refer to 'religious' identity or 'national' interests, I am referring to an identity that is represented as being religious, and interests that are represented as being of national concern.
} 
into the development and thus also the character of Tamil nationalism as we know it today.

\subsection{Establishing the Religious Difference}

Sinhalese and Tamil nationalists posit very different relationships between religious concerns and national concerns, and consequently, between religious identity and national identity. On the Sinhalese side, Buddhist identity is closely aligned with national identity. This representation arises at least partly out of how Sinhalese nationalists represent religious interests in relationship to national interests. Sinhalese nationalists do not explicitly state that one must be Buddhist in order to be Sinhalese (or even Sri Lankan). But by representing Buddhist concerns as Sinhalese concerns, they imply that Buddhism has a special relationship to national life and identity. Tamil nationalists, like their Sinhalese counterparts, are not explicit about the relationship between religious identity and national identity. They do not openly reject or embrace Hinduism as a constitutive trait of Tamil identity. They do, however, explicitly distance Tamil concerns from Hindu concerns. In this way, they suggest that being Tamil does not necessarily mean being Hindu.

In the following discussion, I will explore these differences more fully, examining the political campaigns, rhetoric, statements and demands of the government as well as the sangha, the TULF as well as the LTTE. While the sangha differs from the government, and the TULF from the LTTE, these differences are a matter of inflection only.

In Sinhalese politics, Buddhist interests are represented as (Sinhalese) national interests. The government protects and promotes Buddhist interests through various policies, legislation and initiatives, implying that Buddhist interests are synonymous with national interests. For example, the government has two institutions to promote Buddhist interests: the Ministry of Buddhist Sasana and the Department of Buddhist Affairs. Amongst other things, these institutions are responsible for compiling and printing Buddhist encyclopaedias, supervising how Buddhist institutions and temples are administered (including

\footnotetext{
${ }^{2}$ The sangha is the Buddhist council of monks. In Sri Lanka, the sangha has influenced the country's politics.
} 
the Temple of the Tooth), ${ }^{3}$ sponsoring Buddhist pilgrimages to India, and the sale of Buddhist publications. More generally, these government departments are entrusted with protecting and fostering Buddhist values, and safeguarding Buddhist culture from alien influence. ${ }^{4}$

It is important to emphasise here that the government patronises Buddhist interests at the expense of Muslim, Christian and Hindu interests. More importantly still, the government does not even try to portray (represent) its patronage of Buddhism as equal to that received by other religious groups. Instead, it explicitly claims that Buddhism and Buddhist interests deserve a privileged place on the island; the Sri Lankan constitution entrenches Buddhism as the country's foremost religion. ${ }^{5}$ When Sinhalese nationalists explicitly promote Buddhist interests in this way, they represent religious concerns as national concerns. Implicit is the suggestion that being Sinhalese (or even Sri Lankan) involves being Buddhist.

The Sri Lankan government is perhaps less direct than governments elsewhere in how it depicts the relationship between religious interests and national interests, and the parallel relationship between religious identity and national identity. In fact, Sinhalese politicians have artfully avoided presenting Sri Lanka as either a secular or a Buddhist state. In the Sri Lankan constitution, the term 'secular' is quite deliberately omitted. At the same time, the constitution does not require its citizens to be Buddhists. ${ }^{6}$ This deliberate ambiguity is an important part of how Sinhalese nationalists represent the relationship between religious interests and national interests. We might speculate that the government is necessarily ambiguous. After all, the government does claim to represent the entire population, including a significant non-Buddhist minority.

The sangha, however, is not constrained by such considerations. It is therefore less ambiguous and more emphatic in how it delineates the relationship

\footnotetext{
${ }^{3}$ The Temple of the Tooth is a temple in Kandy. It houses a relic, believed to be the tooth of the Buddha. The relic is believed to confer powers of kingship. Consequently, it was a blow to the Kandyan people when the British seized control of the relic in The Great Rebellion of 1817. McGowan, Only Man Is Vile, 130-2.

${ }^{4}$ Peter Schalk, "Present Concepts of Secularism Among Ilavar and Lankans," Asian Ethnicity 3: 1 (2002): 55-8. It is worth noting that in 1978 a Division of Hindu Religious affairs was formed in the Ministry of Regional development. Similarly a division of Muslim Religious affairs was established in 1981. While the state does not solely patronise Buddhism, it does give Buddhism the foremost place.

${ }^{5}$ De Votta, Blowback, 134.

${ }^{6}$ Peter Schalk, "Present Concepts of Secularism Among Ilavar and Lankans," 37.
} 
between national interests and religious interests. For example, it asserts that Buddhism should be the official religion of the island. The sangha, like the government, thus presents Buddhist interests as national interests. It too posits a special relationship between Buddhism and the nation. ${ }^{7}$ The government's representation of this relationship is thus predicated on the same kinds of connections as the sangha's representation. The sangha, however, delineates these connections more explicitly and assertively than the government.

Tamil nationalists do not have the mechanisms of a state, and so we cannot investigate how the LTTE or the TULF patronise religion. What is clear, however, is that while Sinhalese nationalists use official policies to protect Buddhist interests, Tamil nationalists assert that religious concerns will not influence their policy-making process. The LTTE articulates the following position in their proposal for an Interim Self Governing Authority (ISGA): "No religion shall be given the foremost place in the North East." ${ }^{\prime 8}$ The TULF espoused a similar position: "Tamil Eelam shall be a secular state giving equal protection and assistance to all religions to which the people of the state may belong." ${ }^{9}$ The former statement is less clear than the latter, because it does not tell us whether the ISGA will be strictly secular, and sponsor no religion, or whether it will be pluralistic, and patronise all religions. ${ }^{10}$ Regardless of this ambiguity, we can see how both the TULF and the LTTE disavow the sorts of connections that Sinhalese nationalists make between religious concerns and national concerns.

Because Tamil nationalists distance religious concerns from national concerns, they also distance religious identity from national identity. Neither the TULF, nor the LTTE, name Hinduism as a feature of Tamil identity. Being Hindu is not a criterion of being Tamil. In fact, in several LTTE documents which I have encountered, religion is omitted altogether as a feature of Tamil identity. Instead the Tamil nation is founded upon a shared economic life,

\footnotetext{
${ }^{7}$ Spencer, "Introduction," 3.

${ }^{8}$ LTTE, "The Proposal by the Liberation Tigers of Tamil Eelam on Behalf of the Tamil People for an Agreement to Establish an Interim Self Governing Authority for the North-East of the Island of Sri Lanka," http://www.eelam.com/isga/proposal.pdf (accessed May 13, 2008). The LTTE authored the ISGA proposal to the Government of Sri Lanka in November 2003, because it was dissatisfied with the government proposals for the devolution of power to Tamil regions. In this, the LTTE details the financial, judicial and legal authority of a proposed Interim Authority.

${ }^{9}$ Dissanayake, War or Peace in Sri Lanka, 26.

${ }^{10}$ Schalk, "Present Concepts of Secularism Among Ilavar and Lankans," 46.
} 
history, heritage, culture and language: "The Tamils of the island of Ceylon (now called Sri Lanka) constitute themselves as a nation of people, forming into a coherent social entity with their own history, tradition, culture, language and economic life. The nation is popularly called Tamil Eelam." 11

This position differs somewhat from that of the LTTE's predecessors. The TULF declared that the religions (note the plural) of the Tamil people are among the constitutive elements of Tamil identity. "The Tamils of Sri Lanka, by virtue of their great language, their religions, their separate culture and heritage, their separate state over a distinct territory for several centuries... and, above all their will to exist as a separate entity ruling themselves in their own territory, are a nation distinct and apart from the Sinhalese." ${ }^{\prime 2}$ Here, all the religions practised by Tamil people are accepted as equally Tamil; Tamil-speaking Hindus are not considered more essentially Tamil than their Christian counterparts. While the TULF did not exclusively tie Hindu identity to Tamil identity, it nonetheless connected Tamil identity to the religious practices of Tamils. The LTTE seems to have severed even this tenuous connection, situating religious concerns and identity outside Tamil concerns and identity. For both the LTTE and TULF, Hinduism was not (and still is not) a defining criterion of Tamil identity.

It may seem as though my comparison thus far has been an unfair one. I focussed on what Sinhalese nationalists $d o$, when I analysed how they represent religious identity in relation to national identity. When I undertook the same analysis of Tamil nationalism, however, I focussed on what Tamil nationalists say. One might argue that the LTTE does not have the mechanisms of a state. Perhaps if it did, it too might patronise religious groups, even though it explicitly disavows religion. My response to this is: we should not focus on whether the LTTE would patronise religious groups or promote religious concerns.

Undoubtedly it would. Every secular government in the world patronises religious organisations to some degree. What distinguishes the government from the LTTE is the claim that religion should not have any role in politics. ${ }^{13} \mathrm{We}$ should thus focus on how the LTTE might represent its patronage of religious organisations. Because it distances religious interests from national interests, we

\footnotetext{
${ }^{11}$ LTTE, Towards Liberation (location unspecified: LTTE, 1984), 22.

${ }^{12}$ Dissanayake, War or Peace in Sri Lanka, 25.

${ }^{13}$ Schalk, "Present Concepts of Secularism Among Ilavar and Lankans," 42-3.
} 
might expect the LTTE to claim that it equally patronises all religions. ${ }^{14}$ This sort of patronage, represented through notions of pluralism, is significantly different from the explicitly one-sided patronage that we see from the government.

The religious difference concerns not only national interests and identity, but also national symbols. On the Sinhalese side, Buddhist objects and practices are represented as evocative symbols of Sinhalese identity. For example, the Mahavamsa, a Buddhist chronicle, is frequently presented as an evocative symbol of Sinhalese national identity. Not only do nationalists draw from the text, but the text itself is represented as a symbol of national identity: The same is true of the Temple of the Tooth: "It is indeed true that the Kandy ritual complex has provided legitimization to every Sinhala party and politician since independence, including the Trotskyites who, on being elected to office, visited the temple to receive the blessings of the triple gem." ${ }^{15}$ Stanley Tambiah helps us to understand this kind of symbolism. He claims that Sinhalese nationalists have fetishized Buddhist texts, reifying them as symbols of national identity. "Progressively removed from its original interpretation, both the original doctrinal texts and the mytho-historical chronicles have value as sacred objects themselves that are markers of special ethnic entitlement, self respect and identity." 16

How does this type of Sinhalese-Buddhist symbolism compare with the symbolism that the LTTE uses? I am aware of no instances where the LTTE represents religious objects or practices as symbols of Tamil identity. Several scholars, however, have identified LTTE terms and symbols in LTTE, which are derived from Saivite tradition. For example, the LTTE uses the term arppanippu, sacrifice, to connote the contributions made by dead cadres. In the temple context, the term refers to the dedication of a sacrifice, libation or any offering presented to a god. Similarly, the LTTE refers to its cadres as tiyaki, renouncers, ${ }^{17}$ a term derived from the Bhagavadgita. ${ }^{18}$

\footnotetext{
${ }^{14}$ Whether the LTTE would live up to such claims is another matter. What is important, however, is how it would represent its patronage of religious groups.

${ }^{15}$ Daniel, Charred Lullabies, 60-1.

${ }^{16}$ Stanley Jeyaraja Tambiah, Buddhism Betrayed?: Religion, Politics and Violence in Sri Lanka (Chicago: Chicago Universtiy Press, 1992), 59.

${ }^{17}$ Schalk, "The Revival of Martyr Cults Among Ilavar," 163-4.

${ }^{18}$ Ibid., 166.
} 
Scholars contest the religious meanings of such terms and symbols. Some, like Margaret Trawick and Peter Schalk, argue that the LTTE has transposed these religious terms and symbols into a secular setting. ${ }^{19}$ "LTTE terminology is rich in religious terms - in a completely secular context. ${ }^{, 20}$ Others, however, like Dagmar Hellmann Rajanayagam imply that these terms are religiously alive: "Fallen heroes are therefore honoured not in a secular manner, but with syncretistic religious symbols and terms." ${ }^{21}$ Michael Roberts advances a similar assertion: "The argument here is that the images employed in LTTE commemorations have the capacity to draw on sakti and accaryam-divine power and marvellous potency." 22 Clearly, the LTTE does employ symbolism that is derived from Hindu (and sometimes Christian) traditions. I argue, however, that these symbols and terms differ from the Sinhalese-Buddhist examples presented above.

First, unlike the Sinhalese-Buddhist symbols, these terms and symbols are not represented as being religious. The LTTE represent these references and symbols as being situated in a secular context. Second, while Sinhalese nationalists represent religious objects and practices as symbols of Sinhalese identity, the LTTE do not represent the references described above (which scholars call religious) as objects of Tamil identity.

We can explain these so-called religious references and symbols by the fact "that most Tigers happen to be Hindu." ${ }^{23}$ Hinduism (or what we anachronistically call Hinduism) informs the world view of Tamils; it is implicated both in their epistemologies and ontologies. Because of this, any Tamil construction of meaning (such as the LTTE's rituals) will be infused by concepts derived from Hindu traditions. This is quite different, however, from the Buddhist symbols, images and concepts, which are not only represented as

\footnotetext{
${ }^{19}$ Margaret Trawick, "Reasons for Violence: A Preliminary Ethnographic Account of the LTTE," in Conflict And Community in Contemporary Sri Lanka: 'Pearl of the East' or the 'Island of Tears'?, ed. Siri Gamage and I.B Watson (New Delhi: Sage Publications, 1999), 160.

${ }^{20}$ Peter Schalk, "Resistance and Martyrdom in the Process of State Formation of Tamil Eelam," http://www.tamilnation.org/ideology/schalkthiyagam.htm (accessed May 13, 2008).

${ }^{21}$ Hellmann Rajanayagam, "And Heroes Die," 118.

${ }^{22}$ Michael Roberts, "Tamil Tiger 'Martyrs:' Regenerating Divine Potency?," Studies in Conflict and Terrorism 28 (2005): 494.

${ }^{23}$ Trawick, "Reasons for Violence," 160.
} 
religious, but which are also venerated as symbols of Sinhalese identity. ${ }^{24}$ The

LTTE's nationalism thus draws on "pre-existing languages and practices including those that we call, anachronistically 'religious.' How could it be otherwise?" 25 Yet, it does not follow that this material is intrinsically the same as the religious material used by Sinhalese nationalists.

As we have seen, Sinhalese and Tamil nationalists differ in how they represent the categories of religion and the secular in relation to national identity. In particular, this difference concerns how religious concerns, identity and objects are represented in relation to national concerns, identity and symbols. On the Sinhalese side, religious interests and identity are closely enmeshed with national interests and identity. Furthermore, Buddhist objects are represented as symbols of Sinhalese identity. In the Tamil case, however, religious interests and identity are distanced from national interests and identity. Moreover, religious objects or practices are not represented as symbols of Tamil identity. Now that we have established the religious difference, we can ask how and why this difference developed. When we undertake this examination, we also expose the substance of Tamil identity - the sorts of concerns, identities and symbols that are represented as being Tamil.

\subsection{Explaining the Religious Difference: A Historical Argument}

Given the scope of my project, I cannot offer an answer that attends to all the complex factors that fed the two developing nationalisms and the religious difference between them. ${ }^{26}$ Yet, despite the enormity of the task, I have still

\footnotetext{
${ }^{24}$ This is not to say, however, that all Buddhist objects, practices and references are treated as objects of Sinhalese identity. For example, former President Jayewardene chose to light 84,000 lamps at a series of meritorious lamp-lighting ceremonies, a number which recalls how Askoa built 84,000 monasteries to equal the divisions of the dhamma. While such symbols and references are used to evoke nationalist sentiment, they are not represented as objects of national identity. These symbols used by Jayewardene function much like the Hindu symbols used by the LTTE. Just as the Tamil worldview is connected to Hinduism, so too is the Sinhalese worldview connected to Buddhism. There is, nonetheless, one difference which remains. While the LTTE's symbols are represented as being situated in a secular context, Jayewardene's symbols are situated in a political context which (as we have seen) is represented as being neither explicitly secular nor religious. Steven Kemper, "J.R. Jayewardene, righteousness and realpolitik," in Sri Lanka: History and the Roots of Conflict, ed. Jonathon Spencer (London: Routledge, 1990), 192193.

${ }^{25}$ Asad, Formations of the Secular, 194.

${ }^{26}$ The second task is worthy of its own investigation. A comprehensive answer would involve a detailed analysis of Sri Lanka's pre-colonial, colonial and post-colonial past, the relationship
} 
decided to tackle it. In short, I believe that the answers that emerge will provide invaluable insights into the contours and overall shape of Tamil nationalism as it exists today.

Thus far I have focussed on both the LTTE and the parliamentarians. This is because I wanted to show that the LTTE is not the first Tamil nationalist group to distance religion from Tamil identity. In this section, I want to understand how this representation of Tamil identity developed. In particular, I want to explain the differences we identified in the preceding discussion. In other words, how did Sinhalese and Tamil group identities come to have such different relationships to religious identity? What conditions prevented Tamil nationalists from representing religious objects and practices as symbols of national identity? And what conditions triggered the reverse for Sinhalese nationalists?

For me to answer these questions satisfactorily, so that my analysis yields valid insights, and yet briefly, so that it fits within the confines of this project, I have carefully limited how and what I investigate in the following ways. First, I have shied away from essentialist arguments that would explain the religious difference (and the conflict more generally) as the inescapable outcome of various immutable features of Hinduism and Buddhism, Sinhalese and Tamil cultures or languages, or even social and cultural institutions like the caste system. ${ }^{27}$ Explanations like these fail to take into account how religious, ethnic and caste identities are constantly rearticulated and reconstituted in new and changing contexts. In contrast, I seek to understand how Sinhalese and Tamil identities, and their representations of religion and the secular, developed in a particular historical context and so, unlike an essentialist, I predicate my entire

between Sri Lankan Tamil nationalism and Indian Tamil nationalism, the relationship between the colonised (Sinhalese and Tamil elites, Sinhala and Tamil masses, Buddhist and Hindu priests etc) and the colonisers (British state, missionaries etc). Such a study must also address theoretical concerns, like the malleability of history. This sort of exhaustive analysis is beyond the scope of my project.

${ }^{27}$ An essentialist might emphasise that the Hindu caste system, unlike the Buddhist caste system, is legitimated by religious texts. As such, they might argue that such a religious ideology, supporting social stratification, is irreconcilable with the nationalist goal to create a homogenous, unifying identity. Tamil nationalists therefore could not mobilise a Tamil-Hindu identity; they had to ground their nationalist project in secular language and ideology. But this argument fails to acknowledge an important fact - Tamil identity in Sri Lanka was predicated on an exclusive (caste) identity. What needs to be explained, then, is how this caste identity came to the forefront of group consciousness and how it came apart from its religious foundations. An essentialist argument would treat Hinduism and the caste system as fixed, demarcated, static categories. Instead, I would ask: what political, ideological, and economic forces coalesced to hinder the development of a Tamil-Hindu identity? 
approach on the flexible, dynamic and constructed character of religious and ethnic identity.

Second, I have confined my investigation to a particular historical period - the Hindu (more particularly Saivite) and Buddhist revivals at the turn of the $20^{\text {th }}$ Century. The Hindu, Buddhist (and also Muslim) revivals occurred when the British established freedom of religion. Freedom of religion enabled Hindus and Buddhists to openly express renewed interest in their religious traditions, traditions which had been suppressed during Portuguese and Dutch rule. ${ }^{28} \mathrm{I}$ chose this period because it is associated not only with the articulation of religious identity, but also with the consolidation of Sinhalese and Tamil group identities. ${ }^{29}$ Because of its associations with both religion and the birth of Sinhala and Tamil group identities, the revivalist period promises to yield insights about how each group identity developed in relation to representations of religion.

Third, in order to elicit these insights, I have chosen to compare the two movements. Here, the Sinhalese-Buddhist material serves merely as a counterpoint to the Tamil-Saivite example. For this reason, I have only adumbrated the character of the Buddhist revival.

Fourth, when I compared the revivalist movements, I actively sought out differences between the two. While the revivalist movements shared many common features, it is the differences that highlight the influences and factors that nudged one group identity towards representations of religion and the other, away from it. In particular, I have attended to two especially influential differences - the roles played by caste identities and language in each revivalist movement.

\subsubsection{Caste Identities in the Revivalist Movements.}

Like ethnic and religious identities, caste structures and identities also develop in and respond to new and changing contexts. I now turn to these

\footnotetext{
${ }^{28}$ Rohan Bastin, "The Authentic Inner Life: Complicity and Resistance in the Tamil Hindu Revival," in Sri Lanka: Collective Identities Revisited Volume I, ed. Michael Roberts (Colombo: Marga Institute, 1997), 389-391. The Hindu and Buddhist revivals were roughly contemporary. The Saivite revival precedes the Buddhist revival by roughly a decade. As such it is not characterised by the fin de siecle sentiments that we see in the Buddhist revival.

${ }^{29}$ Dagmar Hellmann Rajanayagam, "Arumuka Navalar: Religious Reformer of National Leader of Eelam," Indian Economic Social History Review 26 (1989): 236. Scholars concede that these revival movements shaped Sinhalese and Tamil identities, even though they debate the extent of this influence.
} 
constructed caste structures, their place in the revivalist movements and their role in shaping the religious difference between the two group identities.

Both before and during the era of the revivalist movements, Sinhalese and Tamil caste structures were reworked, when certain economic and colonial influences coalesced. In the Sinhalese low country, the British opened up a number of mercantile opportunities. ${ }^{30}$ In particular the Karava and Salagama castes eschewed their traditional occupations and seized these opportunities in transportation, trade, cinnamon production and arrack renting. ${ }^{31}$ These socially mobile castes thus began to form an emerging bourgeoisie. ${ }^{32}$ Through their new found status, they began to resist the hegemony of the dominant Goyigama caste. $^{33}$

In the Tamil north, we observe quite a different set of interactions. Traditionally, the Vellalars, the dominant caste, were at the centre of a social system in which they procured the "salubrious grace" and the "coveted benefit of increase" from Brahman rituals. ${ }^{34}$ These rituals established "the Vellalars in the eyes of the village community as persons saturated with good fortune, the capacity to manage agrarian reproduction, and the right to command the services of non-Vellalar castes." ${ }^{35}$ Like the Brahmans, the untouchable, adimai castes also participated in this social system that hinged upon securing the prosperity of the Vellalar. ${ }^{36}$ They were expected to labour on Vellalar lands and were also responsible for imbibing or removing disordering substances from Vellalar rituals that threatened to disrupt "the very foundation of social order and dignified life." ${ }^{37}$ In return, the adimai possessed rights to Vellalar care and protection. ${ }^{38}$

\footnotetext{
${ }^{30}$ L A Wickremeratne, Religion, Nationalism, and Social Change in Ceylon 1865-1885,

Comparative Studies in Society and History (Colombo: Studies in Society and Culture, 1993), 13.

${ }^{31}$ Bastin, "The Authentic Inner Life," 392.

${ }^{32}$ Richard Gombrich and Ganath Obeysekere, Buddhism Transformed: Religious Change in Sri Lanka (Princeton: Princeton University Press, 1988), 211.

${ }^{33}$ Wickremeratne, Religion, Nationalism, and Social Change in Ceylon 1865-1885, 13.

${ }^{34}$ Pfaffenberger, Caste in Tamil Culture, 149, 227.

${ }^{35}$ Pfaffenberger, "The Cultural Dimension of Tamil Separatism in Sri Lanka," 1151.

${ }^{36}$ Pfaffenberger, Caste in Tamil Culture, 148.

${ }^{37}$ Ibid., 148, 96-7, 198-200

${ }^{38}$ Bastin, "The Authentic Inner Life," 401.
} 
The Dutch, and the Portuguese before them, codified Vellalar dominance to aid their own collection of monies and for agricultural reasons too. ${ }^{39}$ In the process, they rigidified caste relations and amplified Vellalar power. "Elements of Jaffna's caste system probably predate the colonial incursion. However, it would be a serious error to ascribe the system's rigidity to the traditional system of intercaste relations... the Dutch strengthened the dominance of Vellalars for their own revenue-collection purposes."

These reconstituted caste relations greatly influenced the revivalist movements, where group identities were forged. ${ }^{41}$ In the Buddhist case, the revival was tied to the voice and interests of the socially mobile, bourgeois castes. ${ }^{42}$ The revivalists propagated a new Buddhist morality and doctrinal values that fitted their bourgeois lifestyle and aspirations. For example, Angarika Dharmapala, a key figure in the Buddhist revival, authored in 1898 a daily code for the Buddhist laity that openly encouraged bourgeois habits and practices. "In some instances Western norms are directly advocated as, for example, eating with fork and spoon and using toilet paper before water during ablutions."43 Dharmapala's social reform provided a value system to a new class, an emerging bourgeoise. $^{44}$ This newly formulated Buddhism, with its unique ideals and values, responded to Goyigama hegemony in a context of economic change and social mobility: "The Buddhist movement was, at least in part, the religious expression of the improved economic and social status of the major non-

\footnotetext{
${ }^{39}$ Two agricultural methods exist on the Jaffna Peninsula. The first, rice agriculture, is only marginally economic. The Dutch encouraged the second method, of tottam (garden) agriculture, to grow and export cash crops. Tottam agriculture is productive but also very labour intensive. In order to secure labour, the Dutch defined the Untouchable, adimai castes as slaves. As such, they denied the adimai castes their traditional patron-client rights to Vellalar care and protection. "By defining the adimai Untouchables as slaves in the sense of Roman Dutch law, and in particular, as enslaved persons attached to a specific master irrespective of rights to land, the Dutch unleashed forces which were to insulate Vellalar domination from later administrative efforts... to destroy it." Bastin, "The Authentic Inner Life," 400-1; Pfaffenberger, Caste in Tamil Culture, 42 .

${ }^{40}$ Pfaffenberger, "The Political Construction of Defensive Nationalism," 146.

${ }^{41}$ Bastin, "The Authentic Inner Life," 393.

${ }^{42}$ Sarath Amunugama, "Ideology and Class Interest in One of Piyadasa Sirisena's Novels: The New Image of the 'Sinhala Buddhist' Nationalist," in Sri Lanka: Collective Identities RevisitedVolume I, ed. Michael Roberts (Colombo: Marga Institute, 1997), 341. In fact, the epicentre of the revival is the maritime districts where these very castes predominate. Wickremeratne, Religion, Nationalism, and Social Change in Ceylon 1865-1885, 1.

${ }^{43}$ Gombrich and Obeysekere, Buddhism Transformed, 215.

${ }^{44}$ Ibid., 212. In later times these bourgeois ideals were extended to the peasant communities through the Sinhala medium schools. This has led scholars to argue that Sinhalese nationalism and the Buddhist revival are characterised by the embourgeoisement of Sinhala society, the spreading of bourgeois ideals.
} 
Goigama castes in the maritime districts...Implicit was a clear challenge to the traditionally prestigious status of the Goigama caste." 45 Sinhalese identity, which was shaped during the revival, thus came to be tied to this bourgeois Buddhism, a Buddhism which had enabled the revivalists to challenge the hegemony of the Goyigama caste.

In contrast to the Buddhist revival, where traditional caste relations were undermined and the interests of an emerging bourgeoisie were supported, the Saivite revival explicitly celebrated the Vellalar order. As such, it was centred in the Jaffna Peninsula, the preserve of traditional Vellalar domination, and its key instigators were Vellalars. Like their Buddhist counterparts, the Saivite revivalists addressed their peers, who in this case were "the local intelligentsia engaged in the professions and the self employed who were of respectable stock and generally landowners." 46

These Vellalar revivalists extolled Vellalar ideals and values, primarily associated with the ancient Brahman-Vellalar alliance, a feature of Dravidian culture. ${ }^{47}$ As such, Brahmanic rituals, and their prescriptions in the agama texts, were an important facet of the revival. ${ }^{48}$ As Rohan Bastin reminds us, however, this Brahmanical focus should not be misconstrued as a glorification of Brahman status: "In short, agamism is heavily ritualistic, a feature it shares with much Brahmanic Hinduism. It is not, however, pro-Brahmin or more exactly proAdvaita Brahmin in the sense of holding up the person of the Brahmin as an object of veneration, or holding up the Vedas as the most important text." ${ }^{449}$

Instead, revivalists such as Arumuka Navalar (1822-79) celebrated Vellalar identity and openly qualified the pride of place accorded to Brahmans. ${ }^{50}$ While Navalar thought that Brahmanic ritual was important, he also believed that it was the Vellalars who had to ensure that it was performed correctly. In order

\footnotetext{
${ }^{45}$ Wickremeratne, Religion, Nationalism, and Social Change in Ceylon 1865-1885, 13. We can see this even during the early $19^{\text {th }}$ Century when members of the Karava, Salagama and Durava castes introduced a number of Buddhist ordination lines from Burma; up until then, only Goyigamas could be ordained. Bastin, "The Authentic Inner Life," 393.

${ }^{46}$ Bastin, "The Authentic Inner Life," 409.

${ }^{47}$ Pfaffenberger, "The Cultural Dimension of Tamil Separatism in Sri Lanka," 1151.

${ }^{48}$ Bastin, "The Authentic Inner Life," 394-5. Pfaffenberger argues that the Saivite revival, unlike the Buddhist revival, had a strong textual focus: "It is in this respect that Navalar's campaign differs radically from that of other Hindu reformers (and that of Dharmapala): Navalar was simply not interested in reforming Hindu society." Pfaffenberger, "The Political Construction of Defensive Nationalism," 156.

${ }^{49}$ Bastin, "The Authentic Inner Life," 395

${ }^{50}$ Hellmann Rajanayagam, "Arumuka Navalar," 241.
} 
for them to oversee rituals in this way, they must be well versed in the ritual prescriptions. This is one of the main reasons why Navalar pushed for (Vellalar) children to receive a Tamil-Saivite education - as adults, conversant with the ritual prescriptions of the agamas, they could ensure that Brahmans properly executed rituals. "A knowledge of these written rules was also important... to check on whether the Brahmin priests were performing the ritual in the proper way." ${ }^{51}$ Reformers like Navalar were solely intent on preserving the social order, safeguarding Vellalar pre-eminence and keeping Brahmans in their proper place. ${ }^{52}$ Therefore, although the revival is labelled Brahmanic, it was still undoubtedly pro-Vellalar.

In this way, the revival brought Vellalarhood to the forefront of Jaffna Tamil, and then later, a more general Tamil, consciousness. Well into the $20^{\text {th }}$ Century, the term 'Tamil' was used only to refer to Vellalars. ${ }^{53}$ Vellalar ideals, concerns and identity were thus represented as Tamil symbols, concerns and identity. Vellalar-Tamil ideals comprised a number of different values, privileges and practices that were traditionally considered the prerogative of the Vellalars. Some were associated with Saivite tradition (for example the deference given to Brahmans, practices around protecting women's chastity and proficiency in Tamil, the language of Saivite thought). Others, however, had emerged relatively recently as markers of Vellalar- Tamil identity (western education and the cultivation of Tamil dance and music). ${ }^{54}$

Later in this chapter, I will discuss these values and practices in greater detail. Here it is sufficient to say that Tamil national identity eventually came to comprise Vellalar ideals and traditions as its constitutive traits. ${ }^{55}$ This is similar to the way that the bourgeois values (such as the laicisation of Buddhism and the celebration of bourgeois life) of the Buddhist reformers are active in how Sinhalese nationalists understand and articulate their identity.

The material presented thus far might seem to answer our questions about how the religious difference developed. We might argue that, while the Saivite

\footnotetext{
${ }^{51}$ Ibid., 246.

52 Ibid., 243; Bastin, "The Authentic Inner Life," 395.

${ }^{53}$ Pfaffenberger, "The Political Construction of Defensive Nationalism," 149.

${ }^{54}$ K Kaliasapathy, "Cultural and Linguistic Consciousness of the Tamil Community," in Ethnicity and Social Change in Sri Lanka: papers presented at a seminar organised by the Social Scientists Association, December 1979 (Colombo: Social Scientists' Association, 1984), 117.

${ }^{55}$ Bastin, "The Authentic Inner Life," 405-7.
} 
revival exalted values that were explicitly associated with an elite caste, the Buddhist revival implicitly challenged traditional caste relations, focussing instead on religious ideals and values. Consequently, one group identity was founded on ideals that were represented as being caste-based, while the other was predicated on values that were represented as religious. This then influenced the national identities which later developed. Sinhalese national identity was tied to representations of religion, while Tamil identity was distanced from similar representations.

However, this does not satisfactorily answer our questions. In the Saivite revival, Vellalar ideals were firmly anchored to their religious foundations (the Brahmanic rituals). Surely, then, Tamil concerns and identity should have been tied to Saivite-Vellalar concerns and identity. Similarly, we might ask why Saivite-Vellalar practices and objects did not come to be represented as symbols of Tamil identity. What we still need to explain is how these Vellalar ideals came to be distanced from religion, how they came to be represented as cultural, rather than religious traits.

The answer to this question lies in the linguistic dimensions of the Saivite revival. Once again, a comparison with the Buddhist movement is helpful. Amongst the Tamils, language was distanced from Saivite tradition while still privileging Vellalar identity. In the Sinhalese case, however, the linguistic facets of the religious revival supported the primacy of Buddhism as a marker of Sinhalese identity.

\subsubsection{The Impact of Language Missions on the Revivalist Movements.}

We discovered that we cannot understand representations of national identity and their relationship to religion through innate or essential features of Hinduism, Buddhism or caste practices amongst the Sinhalese and Tamils. The same is true of the language elements of the religious revivals. While it would be tempting to explain the religious difference through features of the Sinhalese and Tamil language traditions, we must remember that such arguments can only constitute partial explanations.

For example, we could argue that the Saivite tradition glorifies the Tamil language (in its own right) as a Vellalar accomplishment, and therefore enables a 
Tamil-Vellalar identity founded on language rather than religion. ${ }^{56}$ Similarly, we could argue that the Sinhala Buddhist tradition is dependent on a Pali, rather than a Sinhalese canon. ${ }^{57}$ Consequently, the Sinhalese language developed as a secondary component of Sinhalese identity. While these arguments undoubtedly highlight important truths about each tradition, they cannot solely explain the religious difference. Without looking hard, we can find other factors or features of Sinhalese and Tamil culture and society that contravene the arguments presented above.

For example, while language occupies a place of great importance in the Tamil-Saivite tradition, religious ritual and practice are also valued. In fact, scholars have long designated the Jaffna Tamil peninsula as the most pious and religious corner of the island. ${ }^{58}$ Given this, surely an ethnic identity based on religion was just as likely as one founded on language. In other words, language is in no way intrinsically more important than religion. On the Sinhalese side, I would conversely argue that language is not innately secondary to religion as a marker of group identity. After all, Sinhalese language movements gained a significant following. ${ }^{59}$

In both cases, then, we must seek to understand how language came to function as it did in relation to both group identities. As we did with caste relations, we must look to the ideological, political and economic forces that accentuated particular strands of Sinhalese and Tamil, Buddhist and Saivite traditions while rendering others irrelevant. Here, the role played by the missionaries is important.

While the missionaries had a monopoly on educational facilities both in the north and south, they interacted quite differently with each community and its

\footnotetext{
${ }^{56}$ Hellmann Rajanayagam, "Arumuka Navalar," 243

${ }^{57}$ Gombrich and Obeysekere, Buddhism Transformed, 207-8, 210-11.

${ }^{58}$ Pfaffenberger, "The Cultural Dimension of Tamil Separatism in Sri Lanka," 1148.

${ }^{59}$ K.N.O Dharmadasa, Language, Religion and Ethnic Assertiveness: the Growth of Sinhalese Nationalism in Sri Lanka (Ann Arbor: University of Michigan Press, 1993), 261-289. In the late 1930s there was a Sinhalese language movement known as the Hela Movement. This movement placed language rather than religion at the heart of ethnic identity. Cumaratunge, the founder of this movement, wanted to cleanse the Sinhalese language of its Pali and Sanskrit influences. In this way he was quite different from the religious revivalists before him who had happily accommodated Pali and Sanskrit alongside Sinhalese as the languages of the Sinhala-Buddhist tradition. The movement could not dislodge religion as the most highly mobilised aspect of Sinhalese identity. It did, however, impact upon the form that Sinhalese nationalism took when it erupted into the political arena in 1956 with a linguistic demand - that Sinhalese be made the only official language of the country.
} 
language. The missionaries in the south failed to attend to the nuances of the Sinhalese language. Consequently, they alienated themselves from the Sinhalese elite. Furthermore, because Sinhalese literature was Buddhist, these works were not read in missionary schools, a policy also adopted in government schools. ${ }^{60}$ Instead the missionary and the governmental educational authorities adopted an impoverished Church and Textbook Sinhalese. Even Sinhalese Christian scholars rejected it, arguing that it followed colloquial usage rather than literary conventions. ${ }^{61}$ While the Sinhalese Christian scholars were alienated on this one grievance, their Buddhist counterparts, who formed the majority, were angered on two counts - not only were Buddhist texts not being taught in schools, but the Sinhalese texts that were being taught relied upon a colloquial vocabulary and idiom. The development of the Sinhalese language thus became the responsibility of the Buddhist revivalists. In order to stake out a place for the Sinhalese language, the revivalists had to modernise the language so that it could cope with the new forms of media in the modern world. ${ }^{62}$ They invented a new style of Sinhalese that was a compromise between colloquial usage and literary convention. ${ }^{63}$ They then disseminated this new style of Sinhalese through Sinhalese Buddhist newspapers and journals. ${ }^{64}$

Where the fate of the Sinhalese language had been left almost entirely in the hands of the Buddhist revivalists, in the north, Tamil Christians and even the missionaries were involved in studying and teaching the Tamil language. ${ }^{65}$ Unlike the Sinhalese, the Tamils had a non-religious literature that the missionaries regarded highly. ${ }^{66}$ Consequently the missionaries promoted Classical Tamil and taught Tamil composition in their schools. ${ }^{67}$ The missionaries in the north also had an advantage over their colleagues in the south. They could communicate with the missionaries in Tamil-speaking regions in India, who were also grappling with how to read, speak and generally

\footnotetext{
${ }^{60}$ Ibid., 161.

${ }^{61}$ Ibid., 159-60.

${ }^{62}$ Ibid., 182.

${ }^{63}$ Ibid., 184-5.

${ }^{64}$ Ibid., 115.

${ }^{65}$ Hellmann Rajanayagam, “Arumuka Navalar," 245.

${ }^{66}$ Hellmann Rajanayagam, "Ethnicity and Nationalism - The Sri Lanka Tamils in the Late Nineteenth Century: Some Theoretical Questions," in Nationalism, Ethnicity and Political Development: South Asian Perspectives, ed. D. Weidemann (New Delhi: Manohar, 1991), 31.

${ }^{67}$ Lakshmanan Sabaratnam, Ethnic Attachments in Sri Lanka: Social Change and Cultural Continuity (New York: Palgrave, 2001), 105.
} 
communicate in Tamil. ${ }^{68}$ Because of this, the missionaries working in Jaffna had access to more language resources, and consequently developed a deep understanding and appreciation of Tamil. For example, Reverend Peter Perceival, a missionary based in Jaffna, rendered, with Navalar, a translation of the Bible that was noted for its literary quality. ${ }^{69}$ This is quite different from the reception which the Sinhalese translation of the Bible received. ${ }^{70}$

In the Saivite revival, language was originally represented as a feature of a Saivite-Vellalar concern. ${ }^{71}$ The Vellalars were the preservers and protectors of not only Saivite practices, but also of the Tamil language, which was the vehicle of Saivite thought and practice. But because missionaries and Christians participated in the linguistic facets of the revival, language was distanced from its connections to Saivite tradition, while still retaining a strong connection to Vellalar identity. While Christian Tamil poetry was admitted into the canon of Tamil literature, that same canon of Tamil literature remained a symbol of Vellalar accomplishments. ${ }^{72}$

The missionary involvement in the revival thus enabled Tamil identity to remain firmly tied to Vellalar concerns (of which language was the most important), concerns which were no longer represented as being religious. In particular, Tamil concerns and identity were fused to one particular Vellalar concern - language. ${ }^{73}$ The missionary involvement in the revival thus explains why Tamil national identity came to be aligned with linguistic concerns and identity, and not religious concerns and identity.

\footnotetext{
${ }^{68}$ Ibid., 109.

${ }^{69}$ Hellmann Rajanayagam, "Arumuka Navalar," 237.

${ }^{70}$ Dharmadasa, Language, Religion and Ethnic Assertiveness, 67.

${ }^{71}$ Hellmann Rajanayagam, "The Jaffna Social System," 256. Hellmann Rajanayagam discusses how Tamil identity was connected from early on to Vellalar identity. Language was important then as a status symbol of a Vellalar-Tamil identity. "Thus, from quite early on, an ethnic moment crept into the concept of caste (cati) among the Tamils, and a concept of caste into 'ethnic' differentiations. This had astonishingly little or nothing to do with whether one spoke Tamil or not, a feature that is nowadays so important, and in spite of the fact that even then, Tamil held a high place in the esteem of the Jaffnese, but that was the 'pure' Tamil spoken by high castes."

${ }^{72}$ Hellmann Rajanayagam, "Ethnicity and Nationalism," 31.

${ }^{73}$ Hellmann Rajnayagam notes how language functions as the most potent marker of Tamil identity. Conflict occurs when the Tamil language (and not religion) is threatened. This proves my point that language concerns are aligned with Tamil concerns. Being a Tamil-speaker epitomises what it means to be Tamil. We find further proof in the interactions between the Muslim community and Tamil nationalists. Tamil nationalists have (fairly unsuccessfully) sought to include the Tamil-speaking Muslims. Once again, this shows that Tamil national identity is tied to linguistic, and not religious identity. Ibid., 43; Hellmann Rajanayagam, "From Differences To Ethnic Solidarity," 109-10.
} 
The missionaries' participation in the revival also explains why Hindu practices, temples and texts did not come to be represented as symbols of Tamil identity. When the missionaries participated in the revivial, they enabled not only language, but also other Saivite-Vellalar practices, concerns, and ideals to be distanced from Saivite tradition. The most potent symbols of Tamil identity were thus Vellalar practices and values that were represented as cultural, and not religious, traits.

In the Buddhist case, however, we see a different relationship develop between representations of religion and representations of language. Because the missionaries did not join in the linguistic dimensions of the revival, nurturing and developing the Sinhalese language fell into the hands of the Buddhist revivalists. Those who were promoting the Sinhalese language were also promoting Buddhist interests. This, along with the fact that the Sinhalese language had never been revered in its own right as the sole vehicle of Buddhist thought (Pali and Sanskrit had actually filled this role), meant that language became a secondary marker, which merely reinforced the place of Buddhism as the primary marker of Sinhalese identity. Sinhalese concerns and identity were firmly tied to Buddhist concerns and identity. Consequently, Buddhist objects and practices came to be represented as symbols of Sinhalese identity. Status and ethnic symbols for the Sinhalese were represented as being religious, whereas for the Tamils they were represented as being linguistic and also cultural - hence the religious difference between the two nationalisms.

From this process of identity formation, we can see that the answer to the religious difference does not primarily lie in the raw material that Hinduism and Buddhism or Sinhalese and Tamil cultures (as they were understood and experienced) provided, but in how this raw material interacted with and was reconstituted by historical, social, political, cultural, economic and ideological forces. Religion came to be represented differently in relation to representations of national identity. This is because of how the revivalist movements (which shaped these identities) influenced and were influenced by caste relations and language traditions, which were in turn moulded by colonial ideology, policy and economics.

Perhaps if, historically, a different set of factors had coincided to produce a Saivite revival that pitted Hindus against Christians, rather than lower castes 
against higher castes, then a Tamil religious identity might have emerged. Or if the British had provided entrepreneurial opportunities for the lower Tamilspeaking castes, then a revivalist movement may have been engendered by socially mobile members of these castes, and Tamil nationalism may have become allied to a form of Saivism rather than Vellalarhood. Similarly, if the missionaries had not partaken in the linguistic dimensions of the revival, then perhaps Christians would not have been admitted into the Vellalar, Tamil fold, and Vellalar ideals would have remained firmly embedded within a religious context. But this did not happen, and caste values, divorced from religion, formed the basis of a national identity, where Vellalar Christians were considered as equally Tamil as their Hindu counterparts.

\subsection{Tamil Nationalists: Representing a Vellalar, Tamil Identity}

During the revival, Tamil identity was thus aligned with language, as well as other Vellalar concerns, all of which were distanced from religion. In later years this formulation of Tamil identity lent itself to a policy of secularism. The revival also had other consequences for how Tamil identity came to be represented. I will show how the revival compromised Vellalar identity, while also celebrating it. These compromises enabled Vellalar identity to be extended not only to Christians, but also to Tamil speakers from other castes and regions. Finally, I will discuss how this Vellalar-based formulation of Tamil identity has impacted upon the rhetoric and projects of Tamil nationalists, particularly the LTTE.

While revivalists, such as Navalar, celebrated Vellalar status, they also inadvertently compromised it when they unflinchingly advocated textual prescriptions over popular religious practices. ${ }^{74}$ One example that had lasting consequences was Navalar's opposition to lower-caste, ritual services. On the grounds that they were textually unfounded, Navalar condemned these practices where lower adimai castes removed disordering substances from Vellalar homes and temples. However, in doing so, he unknowingly provided the lower castes with a rationale for temple entry. No longer polluted by these impure tasks,

\footnotetext{
${ }^{74}$ Hellmann Rajanayagam, “Arumuka Navalar,” 239-40.
} 
Untouchable Tamils began to agitate for temple entry and other rights normally denied to them because of their impure status. "In short, if the scriptural language of purity and pollution is privileged above all other forms of status reckoning, then the low rank of Minority Tamils appears to be nothing more than an artifice forced on these castes by Vellalar power.,"75

While some Vellalars resisted Navalar's position, on the whole, these ritual services (and what they implied for the castes that performed them) were increasingly done away with. Consequently, Vellalar status was compromised. These services had traditionally stigmatised the lower castes and so had demarcated Vellalars from non-Vellalars. But now, with the repudiation of these services, lower castes could behave like Vellalars and even claim Vellalar status. $^{76}$

Contemporaneous to these developments, economic forces had also eroded other markers of Vellalar status. ${ }^{77}$ Consequently, the proportion of the Jaffna population professing Vellalar identity swelled from one-third to roughly one-half during the $19^{\text {th }}$ Century. ${ }^{78}$ Even the Madapallis, a caste that claimed higher status than the Vellalars, and had traditionally been rivals of the Vellalars, were amalgamated and integrated into the Vellalar fold as the 'proud' Vellalars of Mannippay. ${ }^{79}$ The Jaffna Peninsula thus faced a situation where "Slowly, slowly they all become Vellalar." 80 The revivalist movement had made it possible for more people to acquire Vellalar status, while simultaneously championing Vellalar ideals. The elite were helpless in the face of such change,

\footnotetext{
${ }^{75}$ Pfaffenberger, "The Political Construction of Defensive Nationalism," 157.

${ }^{76}$ Hellmann Rajanayagam, "The Jaffna Social System," 263.

${ }^{77}$ Bastin, Pfaffenberger and Hellmann Rajanayagam all discuss the erosion of Vellalar status. In contradistinction to the Dutch era when Vellalar status was reinforced and reiterated through colonial policy, the British colonial period coincided with a number of factors that coalesced to erode the basis of Vellalar status. Foremost amongst these was the instability of the market. Vellalars found it increasingly difficult to secure reliable income from the cultivation of cash crops. Consequently, Vellalars no longer required a contingent of adimai workers. Instead it was far more beneficial to hire labourers for cash. But this disturbed the basis of Vellalar hegemony their ownership and cultivation of the land, and their provision for those who laboured on it. Vellalars, deprived of such traditional status markers, fought hard to ensure that they were the sole beneficiaries of English education. They were trying to establish a new domain within which they could continue to predominate and prosper. Bastin, "The Authentic Inner Life," 405-6; Pfaffenberger, "The Political Construction of Defensive Nationalism,"150; Hellmann Rajanayagam, "The Jaffna Social System," 259.

${ }^{78}$ Bastin, "The Authentic Inner Life," 410.

${ }^{79}$ Ibid. This suggests that the situation "was not one of simple upward mobility, but of identification with a numerically, politically and socially dominant caste."

${ }^{80}$ Hellmann Rajanayagam, "The Jaffna Social System," 254. An old Tamil proverb- "mella mella ellam Vellalarkal akinrana."
} 
and so, "Revivalism lost its specifically elite membership, gaining instead more of an elitist orientation." ${ }^{81}$ In this way Vellalar (and therefore Tamil) identity were extended to members of other Tamil-speaking castes and East Coast Tamils also.

This situation caused significant problems. ${ }^{82}$ On the one hand, Vellalar ideals were celebrated and extended, swelling the Vellalar ranks. But on the other, Vellalar status relies on the existence of other subordinate castes. "Thus Jaffna is caught in the dilemma of trying to hold on to high caste status for its elite members, but at the same time defining caste in such a way as to make it impossible for these distinctions to be upheld, constantly extending the range of groups coming under the term "elite." ${ }^{, 83}$ As more people adopted Vellalar deportment, the traditional markers of Vellalar identity eroded, and Vellalars increasingly insisted upon extra-legal measures and outward markers of identity. ${ }^{84}$ Such demands often resulted in brutal and violent caste disputes. ${ }^{85}$

Social stratification is thus firmly entrenched in Sri Lankan Tamil nationalism. ${ }^{86}$ While Vellalar-Tamil ideals have been assumed by more and more Tamil-speaking groups, other loyalties and identities have not been completely obliterated. Pfaffenberger informs us that the Vellalar basis of Tamil identity holds some ambivalence for both East Coast as well as Minority Tamils. ${ }^{87}$ While most East Coast and Minority Tamils would willingly defend and preserve Vellalar-Tamil values as the acme of Tamil achievement, they also fear (although less so after the rise of militant groups) that they would be marginalised in a Vellalar-led state that professed to protect the very values to which they are so deeply attached. ${ }^{88}$

This ambivalence remains unresolved despite the best efforts of both the militants and the parliamentarian nationalists who preceded them. ${ }^{89}$ The 1968 Temple Crisis is an excellent example of how these competing caste agendas and

\footnotetext{
${ }^{81}$ Bastin, "The Authentic Inner Life," 409.

${ }^{82}$ Hellmann Rajanayagam, "The Jaffna Social System," 261.

${ }^{83}$ Ibid., 254.

${ }^{84}$ Pfaffenberger, "The Political Construction of Defensive Nationalism," 148.

${ }^{85}$ Fuglerud, Life on the Outside, 30.

${ }^{86}$ Hellmann Rajanayagam, "The Jaffna Social System," 258-261.

${ }^{87}$ Pfaffenberger, "The Cultural Dimension of Tamil Separatism in Sri Lanka," 1146.

${ }^{88}$ Ibid., 1153-4.

${ }^{89}$ Recently a faction of East Coast Tamils (led by the former LTTE commander Karuna) broke away from the LTTE. This provides another example of how old regional divisions still exist.
} 
identities sat uncomfortably alongside Tamil national unity. Over a week long temple entry campaign, Minority Tamils and Vellalars clashed in violent demonstrations outside the gates of the orthodox, Saivite Nallur temple. Once again, Vellalars sought to safeguard their caste stature by enforcing a status marker, their exclusive right to temple entry.

At the time of the Temple Crisis, the FP was torn between the Vellalars and the Minority Tamils. On the one hand, the FP comprised a mainly Vellalar membership and constituency. On the other, the FP officially supported the abolition of caste. Because it did not wish to alienate itself from either minority Tamil or Vellalar constituents, the FP chose not to form a coherent policy, and instead redirected attention toward ethnic confrontation with the Sinhalese government. ${ }^{90}$

In this case, the FP's stance paid off politically and it was able to present a mostly united Tamil front to the Sinhalese government. However, ruptures and frictions simmered beneath the surface of nationalist politics. These tensions and rivalries have provided the Sinhalese government with grounds for denying a federal option. Prior to the rise of Tamil militancy, the government argued alongside Minority Tamil associations that a Tamil state would merely give Vellalars the opportunity to exploit Minority Tamils. ${ }^{91}$

Eventually, the FP and the TULF failed to effect change both against the government and within Tamil society, and so the LTTE became the successor of their undertaking - to unify and represent the Tamils. The LTTE faced the same predicament - it had to promote an inclusive Tamil identity, when Tamil identity was already tied to an exclusive caste consciousness. Of all the militant groups, the LTTE was perhaps best placed to do this; of all the militant groups it is the most representative of Tamil society. ${ }^{92}$

This brings us to the question which structures the next two chapters of this thesis: how has the LTTE mobilised a group identity that transcends elitist formulations of Tamil identity, without representing religion in the same way as their Sinhalese counterparts? While the following chapters delve into this

\footnotetext{
${ }^{90}$ Pfaffenberger, "The Political Construction of Defensive Nationalism," 158, 160.

${ }^{91}$ Ibid., 159. An association of Minority Tamils had "asked the Prime Minister to stay the implementation of the District councils." The association feared for the human rights and safety of Minority Tamils under a District Council led by Vellalars.

${ }^{92}$ Hellmann Rajanayagam, The Tamil Tigers, 11.
} 
question more thoroughly, the material covered in this chapter offers one piece of the puzzle.

In order to unify its cadres and also the Tamil public, the LTTE challenges Vellalar hegemony. As many scholars have pointed out, the LTTE's battle has been a unique one; it has had to fight a two pronged war. ${ }^{93}$ On one side it has had to oppose the Sinhalese government, but on the other it has struggled against Vellalar dominance. Unlike the FP who only made token attempts to incorporate marginal Tamil groups, ${ }^{94}$ the LTTE has genuinely and consistently tried to reform Tamil caste relations. For example, in 1994 it instituted a penal code that outlawed caste practices. ${ }^{95}$

While the LTTE has challenged Vellalar hegemony, it has not entirely rejected Vellalar values. It has recognised that Vellalar symbols and traditions are evocative; they have long been associated with Tamil identity. While the LTTE does promulgate symbols drawn from other traditions, its formulation of national identity has retained a strong connection to Vellalar symbols. I mentioned these values earlier: honouring the Tamil language, protecting women's chastity (two values originally connected to the Saivite tradition), education, dance and music (traditions that had emerged more recently as markers of Vellalar identity). I will examine each of these values in turn, exploring first, how they were originally tied to Vellalar identity, and second, how they are used by the LTTE to mobilise a group identity. I will begin, first with language, showing both how the LTTE represents it as a symbol of Tamil identity and how it ties linguistic concerns to national concerns.

As already established, during the revival, the Tamil language was distanced from its connections to Saivite tradition while retaining its connection to Vellalar identity. In this way, language concerns came to be represented as Vellalar-Tamil concerns. Language also emerged as a symbol of a non-religious, Vellalar-Tamil identity. ${ }^{96}$

\footnotetext{
${ }^{93}$ Hellmann Rajanayagam, "The Jaffna Social System,” 280.

${ }^{94}$ Pfaffenberger, "The Political Construction of Defensive Nationalism," 162.

${ }^{95}$ Fuglerud, Life on the Outside, 163.

${ }^{96}$ Kaliasapathy, "Cultural and Linguistic Consciousness of the Tamil Community," 117. In particular, Classical Tamil, or Sen Tamil, spoken by the Vellalars was valued as a symbol of Vellalar-Tamil identity. Because of this emphasis of classical literature, revivalists disregarded folk literature and increasingly objectified classical literature. Like the revivalists, the LTTE also promotes a pure Tamil, devoid of influences from other languages. Consequently, it has revived a number of archaisms. Fuglerud, Life on the Outside, 156.
} 
Like the revivalists, the LTTE connects linguistic concerns and identity to Tamil concerns and identity. Writing about Prabhakaran, Adele Balasingham claims that the Tamil language motivates Prabhakaran to fight for Eelam. "His deep love for his people, their culture and - more specifically - their language, fuels his dedication and determination to secure their survival.. ${ }^{, 97}$ When the Tamil language is threatened, so too is Tamil identity.

Like the revivalists, the LTTE also represents the Tamil language as a symbol of Tamil identity. For the LTTE, however, language does not signify an exclusive Vellalar-Tamil identity, but a pan-Tamil identity that includes all Tamils living in the island. Furthermore, the LTTE associates language (as a symbol of Tamil identity) with the liberation struggle: "Artists and literary authors should create novel and revolutionary creations to suit the needs of modern [sic] age and historical evolution. These creations should serve to strengthen our sacred liberation struggle; they should sow the seeds of social revolution." 98 The LTTE promotes Tamil poetry, songs and prose about the liberation struggle. Where Tamil literature was once celebrated as a Vellalar achievement, it is now associated with the liberation struggle and celebrated as an inclusive symbol. When the LTTE presents language in this way, it mobilises a group identity that both depends upon and also challenges former conceptions of Tamil identity.

Protecting the chastity of women, like revering the Tamil language, is another value that came to signify Vellalar-Saivite identity. Protecting women's karpu or chastity traditionally, entailed a number of practices: absolute premarital chastity, chaperoning, female initiation rituals, and the construction of a house to serve as a fortress against the intrusion of strangers. Through these practices, the virgin cultivated a supernatural power, upholding the status of her family and caste. "She will bring to her family an ambience of fertility, power, good fortune, and joy." 100 Traditionally this value was associated with the near supremacy of the Vellalar caste; only Vellalars could afford to uphold the

\footnotetext{
${ }^{97}$ Adele Balasingham, The Will to Freedom: An Inside View of Tamil Resistance (Mitcham: Fairfax Publishing Ltd, 2003), 335. Adele Balasingham is the wife of the recently deceased LTTE theoretician, Anton Balasingham.

${ }^{98}$ LTTE, Reflections of the Leader, http://publications.uu.se/abstract.xsql?dbid=8404 (accessed May 12, 2008), 263.

${ }^{99}$ Pfaffenberger, "The Cultural Dimension of Tamil Separatism in Sri Lanka," 1149.

${ }^{100}$ Ibid., 1149 .
} 
practices associated with protecting women's karpu: "Vellalars advertise the virtue of their women with stout, fenced houses and a remarkable variety of rites... But to claim a high rank on these grounds requires no small wealth, not only to build the houses and sponsor the rites, but also to dispense with the earning power of women outside the house." 101

The LTTE has appropriated and reinterpreted this set of values around karpu. It insists that both male and female cadres abstain from pre-marital relations. ${ }^{102}$ In the context of the struggle, a woman's karpu is no longer believed to maintain the status and prosperity of her family. Instead, women cadres' karpu is now believed to endow them with a power, which enables them to fight fearlessly on the battlefield. ${ }^{103}$ Whereas in the $19^{\text {th }}$ century, the practice symbolised a Vellalar-Tamil identity (that embraced both Saivites and Christians), today it is represented as a symbol of an inclusive Tamil identity. Like language, it is closely associated with the liberation struggle.

Tine practices of honouring the Tamil language and protecting the chastity of women were symbols of Vellalar status originally connected to Saivite tradition. We have seen how the LTTE has appropriated these cultural practices and reshaped them. The LTTE also appeals to Vellalar values and practices of recently relative origin: the pursuit of education and the cultivation of art forms. The LTTE represents both as symbols of Tamil identity.

During the $19^{\text {th }}$ and even $20^{\text {th }}$ Centuries, western education emerged as key feature and symbol of Vellalar identity. Consequently, Vellalar parents fought to prevent children of other castes from obtaining a missionary education. ${ }^{104}$ The LTTE also represents the pursuit of education as a key trait and symbol of Tamil identity: "Education is basic to the life and development of our ethnic community; it is the foundation to the progress of our society." ${ }^{105}$ Where education was once associated with Vellalars, the LTTE now associates it with the liberation struggle: "As the struggle of liberation is the armour for education,

\footnotetext{
101 Ibid., 1150.

${ }^{102}$ Balasingham, The Will to Freedom, 79.

${ }^{103}$ Peter Schalk, "Women Fighters of the Liberation Tigers in Tamil Ilam. The Martial Feminism of Atel Palacinkam," South Asia 14:2 (1994): 177-8.

${ }^{104}$ Hellmann Rajanayagam, "The Jaffna Social System," 258-9.

${ }^{105}$ LTTE, Reflections of the Leader, http://publications.uu.se/abstract.xsql?dbid=8404 (accessed May 12, 2008), 287.
} 
education should also stand the [sic] fortress of our struggle."106 Yet again, a once elitist value is associated with the liberation struggle and represented as a symbol of an inclusive Tamil identity.

Finally, during the revival, two art forms, dance (Bharata Natyam) and music (carnatic music), emerged as symbols of a Vellalar-Tamil identity. Only affluent Vellalars could afford to acquire these art forms. ${ }^{107}$ The LTTE also encourages the cultivation of these Tamilian arts. Even though the LTTE employs a Marxist rhetoric, it does not represent these art forms as being in the least bourgeois. ${ }^{108}$ Instead it values and promotes them, Bharata Natyam in particular. Bharata Natyam performances are an integral part of LTTE ceremonies and rituals. I witnessed one of these performances at the Mavirar Nal ceremony which I attended in Melbourne in 2006. I was told that the dance depicted the struggle for Eelam. Yet again, the LTTE has appropriated a Vellalar value as a symbol of national identity. It is associated with the liberation struggle, and not an elite status.

While the LTTE has eschewed Vellalar domination, ${ }^{109}$ it has also continued the process begun in the $19^{\text {th }}$ Century where Vellalar ideals were appropriated, reshaped, and, most importantly, extended to non-Vellalar, Tamilspeaking peoples. These reshaped Vellalar values are an important part of how the LTTE depicts and mobilises a Tamil identity: "The pillars that bear the superstructure of our ethnic community are education, language, culture and land. The enemy is trying to demolish these pillars. His aim is to destroy the individuality of the ethnic community." 110 According to Hellmann Rajanayagam,

\footnotetext{
${ }^{106}$ Ibid., 265.

${ }^{107}$ Kaliasapathy, "Cultural and Linguistic Consciousness of the Tamil Community," 116.

${ }^{108}$ Daniel, Charred Lullabies, 27. Several scholars have noted that the LTTE's Marxist rhetoric is not as potent as its references to Tamil culture. Hellmann Rajanayagam suggests that the Marxist references are merely a veneer for an ultra-nationalist rhetoric: "This ideology creates great doubts about LTTE's alleged Marxist and socialist allegations." Adele Balasingham discusses why the LTTE has turned away from Marxism: "Although many of the cadres had an inherent sympathy with socialist views, none of them ever articulated Marxist positions; neither did any of them 'look' like Marxist revolutionaries in the classical sense... But more deeply than that, over the years we were to learn that Marxism had no real mass appeal in the Tamil social formation where religion, particularly Hinduism, has become a deeply entrenched ideology steeped in the socio-cultural life of the Tamil people." Hellmann Rajanayagam, The Tamil Tigers, 68; Balasingham, The Will to Freedom, 45.

${ }^{109}$ Hellmann Rajanayagam, "The Jaffna Social System," 265-269.

${ }^{110}$ LTTE, Reflections of the Leader, http://publications.uu.se/abstract.xsql?dbid=8404 (accessed May 12, 2008), 294.
} 
the LTTE's success lies in its capacity to usurp Vellalar values and meld them with social reforms.

At times, the LTTE claims to have stripped Vellalar practices and ideals of all that is not true Tamil culture - dowry practices, caste practices and so on. The LTTE thus claims to uphold some kind of cultural essence: "We should identify and get rid of reactionary qualities, customs and ideologies which have penetrated our social life in the guise of culture."111 At other times, however, the LTTE seems remarkably self-aware of how it is formulating a new conception of Tamil identity. It explicitly admits to combining old values with new ones: "Arts, fine arts and culture which flourish by shedding the old and by incorporating the new bring honour to our ethnic community; it will produce a revolutionary awakening in the mentality of our people." ${ }^{\prime 12}$ This reveals an important insight about how the LTTE mobilises a group identity: while the LTTE draws on Tamil traditions, it is also explicit about how it transforms these traditions. This notion of transformation and becoming is important to how the LTTE mobilises a group identity, and we will see it appear in the following chapters.

In this chapter I have shown that Sinhalese and Tamil nationalists differ in how they represent the categories of religion and secular. In particular, I have looked at how religious concerns, identity and objects are represented in relation to national identity. I have also inquired into how these representations developed. I employed a historical argument, structured by a comparison of the Saivite and Buddhist revival movements. I argued that during the revivals Sinhalese identity was fused to Buddhist concerns, identity and symbols. Tamil identity, on the other hand, became enmeshed with Vellalar concerns, identity and symbols, which were eventually represented as separate from religion. This argument thus explains how Sinhalese nationalist identity came to be represented as a religious identity when Tamil identity came to be distanced from religion.

In the rest of this study, I discuss how the LTTE mobilises a group identity. From the material covered in this chapter, we can appreciate what a difficult task this is for the LTTE. On the one hand, the LTTE has had to mobilise a group identity without representing religion as their Sinhalese

\footnotetext{
${ }^{111}$ Ibid., 285.

112 Ibid., 280.
} 
counterparts do. On the other, the LTTE has had to diverge from the traditional Vellalar-based conception of Tamil identity.

In the following chapters, I move from the comparative framework and historical arguments employed here. Instead, I analyse LTTE discourses and show how they are involved in the LTTE's efforts to mobilise a group identity. While my approach changes between this chapter and the ones which follow, I continue to pursue the two interests discussed here. Chapters Three and Four, like this chapter, discuss representations of national identity and representations of the secular. 


\section{Chapter Three}

\section{The Construction of History}

The authentic story of immense suffering and heroic struggle of our people. ${ }^{1}$

In the previous chapter, we established that Tamil identity has long been represented, first, as a non-religious identity and, second, as an elite, Vellalarbased identity. This elitist formulation of Tamil identity presented difficulties for the parliamentarian nationalists who sought to mobilise a unifying identity. Caste disputes ensued in which Vellalars would fight to protect their status markers from being appropriated by members of other castes. As the 1968 Temple Crisis demonstrates, these symbols proved to be too divisive. Using Vellalar symbols, the parliamentarians could not sustain the nationalist illusion that the nation consists of a homogenous body of individuals. Consequently, they failed to mobilise a convincing group identity and thus laid the foundations for the militant groups that were soon to erupt on the Sri Lankan political scene.

Because they promised results, the militants generated much enthusiasm amongst the Tamil public. But this enthusiasm did not make them immune from the challenges that confronted their parliamentarian predecessors. They too had to mobilise nationalist sentiment through values, ideals and symbols that were evocative, but also inclusive. Furthermore, this formulation of Tamil identity needed to be robust enough to contend with the Buddhist claims to pre-eminence

As we saw in the last chapter, the LTTE has usurped and reshaped Vellalar values, extending them to all Tamils. This is one way in which it has mobilised a group identity. There are others also. In the following two chapters, I move from the religious difference to the discourses through which the LTTE mobilises a group identity. When I examine these discourses, I seek out the values, experiences, ideals, claims and traditions which the LTTE promotes. From my analysis I conclude that the LTTE mobilises a group identity through shared experiences of suffering and liberation, reworked Tamil traditions and practices, and claims and arguments which are represented as secular. I also discuss how scholars assess these LTTE discourses (or aspects within them). I argue that when scholars apply the category of religion in self evident ways, they

\footnotetext{
${ }^{1}$ LTTE, Towards Liberation, 22.
} 
obscure or neglect important aspects of the discourses. In this chapter I focus on the LTTE's historical discourse, and in the following, on their discourse pertaining to violence and death.

I have identified three strands to the historical narrative promulgated by the LTTE: the militant past (comprising a further three strands: the Maravars, Cholas and the Sangam era), the Jaffna Kingdom and finally the LTTE's postcolonial history. The LTTE shares the latter two (the Jaffna Kingdom and postcolonial narrative) with its parliamentarian predecessors, while the former (the militant past) is unique to the LTTE's formulation of national identity.

I argue that while all three are important to the LTTE's project, it is the third strand, the post-colonial narrative, which fulfils all the functions and criteria of a nationalist history. As such, it provides the most evocative basis of Tamil identity.

I begin the chapter with an overview of the characteristics of nationalist histories in general. I also provide some background about the introduction of this sort of history to Sri Lanka. This task enables me to establish the key characteristics of nationalist histories, and thereby frames my analysis. I then discuss the militant strands and the Jaffna Kingdom, showing how they do not possess the characteristics of national histories. I follow this with an examination of the post-colonial narrative. I argue that it functions as a true nationalist history which enables the LTTE to mobilise a group identity. Finally, I turn to the scholarly discussion of the LTTE's historical discourse.

\subsection{Enlightenment History in the Sri Lankan Context}

Nationalist histories are a key ingredient of how any nationalist group mobilises an evocative and convincing sense of national identity. Not any kind of past, however, will suffice; nationalist histories are characterised by the assumptions and traits of Enlightenment History. I thus begin this chapter with an outline of the Enlightenment History. From this discussion, I will establish the criteria of nationalist histories. I use these criteria to substantiate my argument that it is the recent past that provides the LTTE with its most potent mobilisation tool. 
Enlightenment History arose during the Western Enlightenment. It is a modern phenomenon, originally propounded by German scholars. Closely associated with nations, territories and states, ${ }^{2}$ Enlightenment History is seen both in the academic discipline of history and also in nationalist histories. National histories, which are crucial to national identity, are thus one kind of Enlightenment History.

We can characterise Enlightenment History through a number of features. First, and most important, Enlightenment History is always narrated. Its narration is predicated on the logic of cause and effect. ${ }^{3}$ Consequently, Enlightenment History is very future-orientated. It seeks potentialities in actualities, ${ }^{4}$ creating a chronological chain of events that explain a series of transformations or changes. Enlightenment History is thus predicated on a linear conception of time; the past is distinct from the present and the future. ${ }^{5}$ The past is thus represented as an object that is recovered by the historian, who is a subject. ${ }^{6}$

History, in its Enlightenment form, is also a theoretical discourse structured around the dichotomy of true and false. ${ }^{7}$ The historian aims to not just uncover the past, but to reveal or elicit the 'true' past (and there can be only one true past). Some historians define this inquiry and project in terms of attaining a strict correspondence between what is written and what is being written about. Others nurture a less ambitious project - to paint a picture to the truth of which a community of inquirers can concur. ${ }^{8}$ Whatever the scope of the project, Enlightenment History is concerned with truth and creating a verifiable version of the past. Because of this concern with truth, Enlightenment History claims authority, a feature which has important political consequences. ${ }^{9}$ As Qadri Ismail points out, if all that Enlightenment History offered was a powerfully structured story about the past, then its implications for nationalist claims would be less

\footnotetext{
${ }^{2}$ Dagmar Hellmann Rajanayagam, "Tamils and the Meaning of History," In The Sri Lankan Tamils, ed. Chelvadurai Manogram and Bryan Pfaffenberger (Colorado: Westview Press, 1994), 58.

${ }^{3}$ Oivind Fuglerud, "Time and Space in the Sri Lanka-Tamil Diaspora," Nations and Nationalism 7:2 (2001): 201.

${ }^{4}$ Daniel, Charred Lullabies, 52.

${ }^{5}$ Qadri Ismail, Abiding by Sri Lanka: On Peace, Place and Postcoloniality (Minneapolis: University of Minnesota Press, 2005), 38.

${ }^{6}$ Daniel, Charred Lullabies, 28.

${ }^{7}$ Fuglerud, "Time and Space in the Sri Lanka-Tamil Diaspora," 201.

${ }^{8}$ Daniel, Charred Lullabies, 52.

${ }^{9}$ Ismail, Abiding by Sri Lanka, 109.
} 
potent. If all history did was to produce stories of the past, then "one could call the stories empiricist and proceed to ignore them, or enjoy them if well crafted, use the paper to wrap fish or whatever. Unlike fiction, however, the stories of history don't enable such a response, because they are authoritative, taken to be true, as bearing some relationship to the real." ${ }^{, 10}$

Its insistence on truth has other consequences also. ${ }^{11}$ When Enlightenment History claims to present an unbiased, objective narration of the past, it erases its own epistemological production. ${ }^{12}$ And so, as Fuglerud puts it, the nation and its uniqueness appear as an accident of fact. ${ }^{13}$ In reality, however, Enlightenment History is a literary activity. It is reliant on ellipsis, repetition and elision. Events that are not believed to enter the chain of relevant transformations are excluded from the telling of history. ${ }^{14}$

This sort of history was brought to Sri Lanka by the British. This is not to suggest, however, that the pre-colonial inhabitants of the island had no awareness or interest in the past. Prior to the advent and hegemony of Enlightenment History, other ways of approaching the past existed, all of which were grounded in a particular ontology, a way of being. In contrast, Enlightenment History is an epistemological enterprise that approaches the past as a way of seeing, rather than a way of being. ${ }^{15}$

Valentine Daniel refers to the ontic-based orientation to the past as heritage and the epistemic consciousness of the past (Enlightenment History) as history. ${ }^{16}$ Heritage, unlike history, tolerates multiple and often contradictory versions of the past. Heritage emphasises participation, whereas history is characterised by its aboutness. As such, heritage is a holistic discourse, whose verity is affirmed in the experience of intersubjective being; heritage collapses

\footnotetext{
${ }^{10}$ Ismail, Abiding by Sri Lanka, 165.

${ }^{11}$ Fuglerud, "Time and Space in the Sri Lanka-Tamil Diaspora," 209.

${ }^{12}$ Ismail, Abiding by Sri Lanka, xxxvii.

${ }^{13}$ Fuglerud, "Time and Space in the Sri Lanka-Tamil Diaspora," 209.

${ }^{14}$ Ismail, Abiding by Sri Lanka, 70, 111.

${ }^{15}$ Daniel, Charred Lullabies, 55, 53. This is not to say that enlightenment histories do not have ontological implications: "a narrative, even an imported one, that begins as theory, providing a people with a way of seeing the world, can, however, in time, become embodied in practice." History, as a way of seeing, impacts on people's ways of being in the world. For example, Daniel argues that epistemic history (enlightenment history) lends itself to particular kinds of violence: "In history's very thinning out of the multiplex in the record of the past, in the reduction of its manifold forms to a single strand, communal violence finds its raison d'etre." Daniel's epistemic history, like Asad's reconstructed secular, claims to apprehend (or see) the world as it is. Both, however, offer another conception of the world, another way of being in the world.

${ }^{16}$ Ibid., 23-5.
} 
what was then and now. The past thus becomes present enactment. ${ }^{17}$ In precolonial cultures, the emphasis shifted from being to seeing in different contexts, but ultimately traditional historic consciousness was always grounded in ontology. $^{18}$

When the British came to Sri Lanka, they found a Sinhalese-Buddhist text, the Mahavamsa, which had an affinity to modern, disciplinary history; it displayed a traditional historic consciousness. Despite this affinity, the Mahavamsa nonetheless entertained a way of being. ${ }^{19}$ For example, the colonisers regarded the Mahavamsa as an authentic history because it recorded dates. Recent scholarly work, however, shows that the dates in the Mahvamsa are connected to astrological calculations, not to a concern to establish a true, verifiable chronology: "The presentation of the chronicles as authentic history is not the result of some irreducible facet of the text itself. The chronicles are transformed from a poetic basis for multiple versions of the past into a chronological narration where all motions of incalculable time were excluded.,20

On the Tamil side, the British struggled to find any sources comparable to the Mahavamsa. Because of this, the Tamils were perceived as a people without a history - an unfavourable assessment. ${ }^{21}$ The Sinhalese, a people with history, were regarded as the descendents of the original settlers, whereas the Tamils were cast as the progeny of invaders (from South Indian empires) and pirates. ${ }^{22}$

Initially the Tamils did not seem perturbed by the British claims that they had no history. Even Arumuka Navalar, the great proponent of Tamil-Saivite tradition, never once alluded to Tamil history. ${ }^{23}$ This began to change slowly in the late $19^{\text {th }}$ and early $20^{\text {th }}$ centuries. Leaders from the Tamil community realised that they required a history to justify the Tamils' right to be in the island. And so, they began to show an interest in the history of the Jaffna Kingdom, a precolonial kingdom that was conquered by the Portuguese. ${ }^{24}$

\footnotetext{
${ }^{17}$ Ibid., 50-3.

${ }^{18}$ Ibid., 43.

${ }^{19}$ Ibid., 47.

${ }^{20}$ Fuglerud, "Time and Space in the Sri Lanka-Tamil Diaspora," 209.

${ }^{21}$ Hellmann Rajanayagam, "Tamils and the Meaning of History," 58.

${ }^{22}$ Ibid., 78.

${ }^{23}$ Ibid., 60.

${ }^{24}$ Ibid., 70.
} 
Hellmann Rajanayagam and Daniel discuss this development of a historical consciousness amongst the Tamils. Both argue that whilst the first Tamil historians employed an enlightenment (or epistemic) history to legitimate political arguments, they did not require this sort of history for their identity as Tamils. Instead, Tamil identity depended upon Tamil art, sculpture, dance and literature. ${ }^{25}$ A third scholar, Oivind Fugelrud, argues that while Enlightenment History might have once been marginal to Tamil identity, it now plays an important role in the rhetoric of the militants. Given that the militants are trying to mobilise a national identity, and given that national identities depend on enlightenment histories, it seems likely that Fuglerud is correct. ${ }^{26}$ The question, then, is: which of the LTTE's three pasts is the history most important to the organisation's depiction of Tamil identity?

As I have argued, nationalist identities are predicated on nationalist histories. And nationalist histories are one kind of Enlightenment History. As such, the LTTE's formulation and mobilisation of national identity will depend most on the history which possesses the criteria of Enlightenment History. In this chapter I argue that it is the LTTE's post-colonial history that fulfils all the criteria of Enlightenment History. In other words, the post-colonial narrative is a narrated history predicated on a linear conception of time. It is a history which attends to chronology and which also presents a causal chain of events. Finally, in the post-colonial narrative all these elements coalesce, revealing a past that is presented as true. Because the post-colonial narrative is an Enlightenment History, it is the 'past' which is most important to how the LTTE depicts and mobilises a group identity.

I will begin my discussion with the other strands of the LTTE's historical discourse: the militant past (the Maravars, the Cholas and the Sangam era) and the Jaffna Kingdom. I will demonstrate how the LTTE uses these pasts for its nationalist project, while also highlighting how these pasts are not enlightenment histories. Against this analysis, I will then delineate the post-colonial narrative.

\footnotetext{
${ }^{25}$ Daniel, Charred Lullabies, 27.

${ }^{26}$ When Fuglerud substantiates his claim that history is now important to the militants, he discusses both the post-colonial narrative as well as the militant past. I argue, however, that it is the post-colonial narrative that is most important to how the LTTE depicts and mobilises a group identity. This is because it is the post-colonial narrative which possesses the traits of Enlightenment History.
} 


\subsection{A Militant Presentation of the Past:}

\section{The Maravars, Cholas and the Sangam Era}

According to the LTTE, the Tamil people possess a long history of martial valour. The LTTE claims to embody and revive the martial tradition of this period, a tradition which has been largely forgotten by the Tamil people: "A hidden heroic tradition in the long glorious history of the Tamil ethnic community has been revived again."27

As far as I have seen, no accounts exist (whether from the LTTE or other militant groups) which chronologically narrate this militant past. I have, however, found an account which details the process by which the martial tradition (associated with this past) was lost and then found. Detailed in a series of articles, this account was written by D.S. Sivaram and published in the Lanka Guardian, a Colombo magazine. While I have not read these articles in their entirety, I have read significant excerpts which are included in Fuglerud's book. These articles are not an LTTE source. In fact, Sivaram was a member of a rival militant group in conflict with the LTTE during the $1980 \mathrm{~s} .{ }^{28}$ I have nonetheless chosen to discuss Sivaram's articles here. They present a view of the past which the LTTE implicitly holds.

Sivaram begins his account in the colonial era. He claims that the British felt threatened by the martial values of the Maravar, a caste that embodied the martial tradition of the Tamils. Consequently, to consolidate their rule, the British suppressed the Maravar and instead favoured non-military castes, particularly the "peace loving" Vellalars, a caste "who had "no other calling than the cultivation of the soil." ${ }^{29}$ During the colonial encounter the Tamil militant tradition (embodied by the Maravars) was thus suppressed, and the Vellalarbased conception of Tamil identity was celebrated. ${ }^{30}$

\footnotetext{
${ }^{27}$ LTTE, Reflections of the Leader, http://publications.uu.se/abstract.xsql?dbid=8404 (accessed May 12, 2008), 268.

${ }^{28}$ Fuglerud, Life on the Outside, 157-160. Sivaram used to write military analysis in AngoSinhala newspapers under the alias Taraki. If you want to know more about Sivaram/Taraki, you can read Whitakers' article. Mark P. Whitaker, "Learning Politics From Taraki: A Biographical Fragment," in Sri Lanka: Collective Identities Revisited-Volume II, ed. Michael Roberts (Colombo: Marga Institute, 1997).

${ }^{29}$ Fuglerud, Life on the Outside, 158.

${ }^{30}$ Ibid.,159. Sivaram argues that the colonial intervention brought two distinct depictions of Tamil identity to the fore. While the Vellalars claimed that the 'pure Tamils' were Vellalars, the
} 
From the examples presented by Fuglerud, it seems that Sivaram is primarily concerned with South India. There is, however, an underlying assumption that his analysis of Tamil society in India applies equally to Sri Lankan Tamil society. Sivaram ends (or at least in Fuglerud's excerpts) by making a more explicit connection. He claims that the village of Valvettithurai, on the Jaffna peninsula, was given to a Maravar chieftain by the founder of the Jaffna Kingdom.

This village, where the Karaiyar caste predominates, has long been associated with militant activity. Several militant leaders, including Prabhakaran, are from this village. ${ }^{31}$ As such, Sivaram's history connects the coastal Maravar of Tamil Nadu to the Karaiyar and the Tamil militant groups of Sri Lanka. The Karaiyar and the militant groups are quite literally presented as the offspring and heirs of the Maravar. ${ }^{32}$ Like the Maravar, they too embody the militant Tamil tradition which has been suppressed by the colonial powers and which is now being revived by the militant groups.

The LTTE does not narrate this history (of a militant tradition which has been lost and found) as explicitly as Sivaram does. But a presentation like Sivaram's, is nonetheless implicit in how the LTTE presents its militant past: "Heroic tradition which died among the Tamils long ago has taken rebirth again." 33

The LTTE evokes this militant past, when it invokes the Maravars, Cholas and the Sangam era. These three strands are presented as evidence of the Tamils' militant past and of the militant tradition which flourished there. While the militant past is undoubtedly important to the LTTE's project, it is not an enlightenment history. As we will see, the LTTE does not narrate events

\footnotetext{
Maravar asserted that all Tamils were Maravar and that the Tamil nation was distinguished by its ancient martial heritage. Where these depictions had once been equal and contending, under British rule, the militant Maravar conception of Tamil identity was suppressed and the Vellalar conception, promoted.

${ }^{31}$ Ibid., 160; Hellmann Rajanayagam, The Tamil Tigers, 34.

${ }^{32}$ Fuglerud, Life on the Outside, 160. Some scholars have postulated a historical link between the Maravars and the Karaiyar, but for the most part this is fairly uncertain. What is interesting, however, are the resemblances between the Maravar and Karaiyar traditions. For example, the Karaiyar, like the Maravar (but independent of any connections with the Maravar), possess a claim to Kshatriya status through their myths of origin. Peter Schalk, "Historisation of the Martial Ideology of the Liberation Tigers of Tamil Ealam (LTTE)," South Asia 20:2 (1997): 51-3; Hellmann Rajanayagam, The Tamil Tigers, 29. Oivind Fuglerud, "Time and Space in the Sri Lanka-Tamil Diaspora," 203.

${ }^{33}$ LTTE, Reflections of the Leader, http://publications.uu.se/abstract.xsql?dbid=8404 (accessed May 12, 2008), 292.
} 
pertaining to the Maravars, Cholas and the Sangam era. Consequently the militant past is not the history on which Tamil identity depends. In the following discussion, I show how the LTTE invokes (rather than narrates) each strand of the militant past. I will begin with the Maravars, proceed to the Cholas and then finish with the Sangam era.

Maravar literally means one who has maram (valour). ${ }^{34}$ In 1911 the government of India declared the Maravar a criminal caste. As part of their efforts to dispel this reputation, the Maravar have developed a tradition about a glorious past where they were free warriors. ${ }^{35}$

The LTTE taps into this presentation of a Maravar past, suggesting that it is reviving the glory of the former Maravar. Prabhakaran frequently refers to his cadres as 'Maravar. ${ }^{36}$ When Schalk translates an excerpt from one of Prabhakaran's speeches, he retains the reference to the Maravar: "These great heroes do not die in [normal] time; (they are) artisans of independence (cutantiram), heroic maravar who have sown the seeds for the rise of a very great liberation (struggle) on our soil." 37 Another reference to the Maravar, once again rich in allusions, comes from a poem translated by Hellmann Rajanayagam: "The bodies of the cruel ones speaking / courage / Turns into dust defeated [by] the / glorious Maravar." ${ }^{38}$ When the LTTE refers to its cadres as 'Maravar,' it connects them to a long militant past, suggesting that its cadres embody the ancient martial tradition of this past.

The LTTE invokes the Cholas in a similar way. The Chola kingdom was one of three major South Indian kingdoms that existed during the Sangam period (300BCE to 300CE). ${ }^{39}$ Its rise to imperial glory, however, came much later in the middle of the ninth century $\mathrm{CE}{ }^{40}$ It is interesting that the LTTE has chosen to allude to the Cholas (and not another Dravidian kingdom) first, because the Cholas invaded Sri Lanka, and second, because they are connected through

\footnotetext{
${ }^{34}$ Schalk, "Historisation of the Martial Ideology of the Liberation Tigers of Tamil Ealam (LTTE)," 45.

${ }^{35}$ Ibid., 45-6.

${ }^{36}$ Schalk, "The Revival of Martyr Cults Among Ilavar," 165.

${ }^{37}$ Peter Schalk, "Beyond Hindu Festivals," 402.

${ }^{38}$ Pantitar Vi. Parantaman, "A King born from Humanity," trans. by Hellmann Rajanayagam,

"And Heroes Die," 140.

${ }^{39}$ Fuglerud, Life on the Outside, 155.

${ }^{40}$ K.A. Nilakanta Sastri, A History of South India: From Prehistoric Times to the Fall of Vijayanagar (Delhi: Oxford University Press, 1975), 5, 124. Hellmann Rajanayagam also provides an overview of the Cholas. Hellmann Rajanayagam, "The Jaffna Social System," 274.
} 
tradition to the East Coast and not the Jaffna kingdom. ${ }^{41}$ The LTTE refers to the Cholas in several ways. First, the Tiger symbol, used by the LTTE and from which their name comes, is the royal insignia of the Chola dynasty. ${ }^{42}$ Also, Prabhakaran's nom de guerre, 'Karakalan,' is the name of the first Chola king. We see this reference in LTTE poetry: "All of this will go on the path / shown by Karikalan / Before the Tigers it will be crippled."

The LTTE also connects its naval unit (the Sea Tigers) to the military exploits and seamanship of the Cholas. We see this in the following speech translated by the Fuglerud:

In those days all the deep seas were ruled by Chola kings. The ships flying the Tiger flags spread the news of Tamil heroism to the world. All these things were washed away by the flood of time, and the Tamils became slaves and refugees [akathi]. Now the Sangam period has come back. The Liberation Tigers make the world focus on Tamil Eelam. The boats of Sea Tigers flying Tiger flags are anew roaming in the seas. ${ }^{44}$ The Sea Tigers thus continue the seafaring, military victories of the Cholas. ${ }^{45}$ As with the Maravars, the LTTE does not narrate events pertaining to Chola history. Instead it invokes the Cholas, and thus evokes an ancient militant past where the martial tradition of the Tamils flourished.

The excerpt above also introduces the third and final militant strand of the LTTE's militant past: the Sangam period. Alongside other Tamil nationalist groups, the LTTE presents the Sangam era as a period in Tamil history when martial values were upheld, a period when mothers willingly sent their sons to

\footnotetext{
${ }^{41}$ The Cholas had fiefs in the East whereas the Kings of the Jaffna Peninsula were drawn from the rival Pandyan dynasty. In her book, Hellmann Rajanayagam discusses possible reasons why the LTTE has chosen to allude to the Cholas. Hellmann Rajanayagam, The Tamil Tigers, 56-7. ${ }^{42}$ Hellmann Rajanayagam, "The Jaffna Social System," 274. According to Hellmann Rajanayagam, rival militant groups have vied for the title 'Tigers,' showing the huge symbolic significance of the name. I have not been able to find any LTTE source where the LTTE explicitly connect the Tiger symbol to the Cholas. Several Tamil nationalist websites, however, make this connection and I assume that the LTTE do so also in their Tamil sources. Hellmann Rajanayagm, The Tamil Tigers, p.43; TamilNet, "Rules guide on use of Tamileelam National flag published," http://www.tamilnet.com/art.html?catid=13\&artid=16423 (accessed May 16, 2008) ${ }^{43}$ M Icaialakan, "Time Collects in Our Hand (The Opportunity is in our Hands)," trans. by Hellmann Rajanayagam, "And Heroes Die," 133.

${ }^{44}$ Fuglerud, Life on the Outside, 155-6.

${ }^{45}$ R. Cheran, The Sixth Genre: Memory, History and the Tamil Diaspora Imagination (Colombo: Marga Institute, 2001), 20-21. The speech connects the Cholas with the earlier Sangam period, and not with the $9^{\text {th }}$ Century, when they achieved the height of their power. The later Cholas of the $9^{\text {th }}$ Century were associated with Brahmanical reforms and reputed to have persecuted nonSaivite religions. This may explain why the LTTE, pursuing a policy of secularism, connect themselves to the earlier Cholas of the supposedly pre-religious Sangam era.
} 
battle. ${ }^{46}$ In particular, the LTTE draws on the Purananuru, an anthology of poems, written during the Sangam era, which celebrates this militant depiction of life. 47 "Almost all the material available on Great warriors' day has references to one of the Sangam anthologies, puranaanooru that celebrated maram (valour).",48 As with the Maravars and Cholas, the LTTE invokes the Sangam era, thus alluding to a Tamil militant past. ${ }^{49}$

While the LTTE claims to embody the Tamil militant tradition of the ancient past, it also celebrates its divergence from this tradition. We see this in a statement written by Adele Balasingham. She first depicts the role traditionally played by women during the militant past: "Early Tamil literature is full of episodes which glorify the self-less, sacrificing mothers and wives encouraging bravery and heroism in their sons and husbands." ${ }^{50}$ Balasingham then claims that the LTTE's female fighters have diverged from this traditional role. By choosing to fight, the women cadres "Have altered the trajectory of Tamil women." 51 This statement intimates an important feature of how the LTTE presents the militant past. The LTTE does not present itself as simply embodying the militant tradition of the past. Instead, it explicitly celebrates its reformulation of tradition.

In the last chapter, we saw how the LTTE celebrates its reformulation of another Tamil tradition - Vellalar values. We also saw how these reformulated Vellalar values are sometimes presented as upholding a cultural or traditional essence. In the case of the militant tradition, however, no cultural essence is postulated. Instead, the LTTE represents the militant tradition as a precedent which it embodies but also betters: "In the history of Tamils one thousand years ago, mothers from home - women - bid farewell to men who went for war, 'Son, go forward! Come back with victory! In today's history of the Tamils one thousand years later, I, on behalf of all mothers, bid farewell to you, women, who

\footnotetext{
${ }^{46}$ Hellmann Rajanayagam, "And Heroes Die," 126.

${ }^{47}$ Ibid., 117. According to Hellmann Rajanayagam, the LTTE claims that secularism was an ideology constituent of Purananuru society.

${ }^{48}$ Cheran, The Sixth Genre, 18.

${ }^{49}$ Thus far, all the references to the Maravars, Cholas and the Sangam era are drawn from scholarly translations of LTTE sources. In the English language sources, we see no references to the fighting prowess of the Tamil people. The only exception is in Adele Balasingham's statement above. She alludes to a Tamil martial society when she discusses how women in early Tamil literature (i.e. Sangam literature) used to support their war-bound sons and husbands. ${ }^{50}$ Adele Ann Balasingham, Women Fighters of Liberation Tigers (Jaffna: LTTE, 1993), 17. ${ }^{51}$ Ibid.
} 
go for war, 'Daughter, go forward! Come back with victory!" 52 The LTTE thus celebrates a tradition which it explicitly claims to transform. Once again, we see how notions of becoming are important to how the LTTE mobilises a group identity.

Clearly the Maravar, Chola and Sangam pasts are important to the LTTE. The LTTE present these pasts as constitutive of a long martial history and tradition, forgotten by the Tamil people. This militant past presents a depiction of Tamil identity that diverges from former elitist conceptions. The militant past emphasises a horizontal depiction of Tamil identity; all Tamils throughout the ages have possessed a martial spirit. In this way, the LTTE celebrates and mobilises a Tamil identity which is not connected to any one caste.

Although the militant past is important, it is not the history on which Tamil identity depends. This is because it does not bear the hallmarks of Enlightenment History. It is not a narrated history. As we saw, the LTTE does not chronologically recount events pertaining to the Maravars, the Cholas or the Sangam era. Unlike Sivaram, the LTTE does not even narrate the history of how the militant tradition (embodied in the militant past) was lost and then found. Instead it evokes a long forgotten militant past when it invokes (rather than narrates) the pasts of the Cholas, Maravars and the Sangam era.

The Jaffna kingdom, like the militant past, is another strand of the LTTE's history that is invoked but not narrated. Unlike the militant past, however, the Jaffna Kingdom is a source that the LTTE has borrowed from the parliamentarians. I will now turn to the Jaffna Kingdom and its place in LTTE rhetoric and claims.

\subsection{The Jaffna Kingdom: Legitimating the Claim to Eelam}

The tradition of the Jaffna Kingdom is drawn from a text, the Yalppana Vaipava Malai (YVM), written by a Jaffna local during the early eighteenth century at the request of a Dutch governor. ${ }^{53}$ Early Tamil politicians and

\footnotetext{
${ }^{52}$ LTTE, Reflections of the Leader, http://publications.uu.se/abstract.xsql?dbid=8404 (accessed May 12, 2008), 294.

${ }^{53}$ Dagmar Hellmann Rajanayagam, "The Politics of the Tamil Past," in Sri Lanka: History and the Roots of Conflict, ed. Jonathon Spencer, (London: Routledge, 1990),110. According to Pfaffenberger, the Jaffna Kingdom is strongly connected to Vellalar hegemony. Pfaffenberger, "The Cultural Dimension of Tamil Separatism in Sri Lanka," 1152.
} 
nationalists deployed the kingdom to advance political arguments. Before independence, G.G. Ponnambalam deployed the Jaffna Kingdom in his fifty-fifty proposal, ${ }^{54}$ arguing that the Tamils had historically had a political influence in the island's affairs and were therefore entitled to political rights equalling those given to the Sinhalese majority. ${ }^{55}$ After independence, the TULF argued that the Jaffna kingdom proved that the Tamils were a politically autonomous nation in pre-colonial times. On this basis, the TULF claimed that the Tamils were entitled to first, a federal, and then a sovereign state. ${ }^{56}$

While the kingdom was invoked to legitimate political arguments, it did not function as an enlightenment history, animating the national life and heritage. Early Tamil nationalists did not narrate the history of the Jaffna kingdom; no attention is paid to the events, dates and kings of the Jaffna Kingdom. For the parliamentarians, Tamil identity clearly did not depend on the Jaffna Kingdom. As we will see, the LTTE's invocations of the kingdom are not a great deal different from those of their predecessors.

In the LTTE's English language sources, the Jaffna Kingdom is usually mentioned at the beginning of a historical survey. The reader is told that there was a stable, autonomous Tamil kingdom in the north of Sri Lanka: "From the $13^{\text {th }}$ Century onwards, until the penetration of Portuguese colonialism, Tamil Eelam lived as a stable national entity, ruled by its own kings." 57

At times, the LTTE seems to suggest that the boundaries of the Jaffna Kingdom correspond exactly with the boundaries of their proposed Eelam: ${ }^{58}$ "The proponents of Tamil Eelam argue that the northern and eastern provinces of Sri Lanka coincide with the historic boundaries of the kingdom of Jaffna and

\footnotetext{
${ }^{54}$ Please see the introduction

${ }^{55}$ Hellmann Rajanayagam, "The Politics of the Tamil Past," 115.

${ }^{56}$ Ibid., 117.

${ }^{57}$ LTTE, Towards Liberation, 4.

${ }^{58}$ This claim, that the boundaries of Eelam (or the areas where Tamils traditionally live) coincide with the Jaffna Kingdom, is a highly contestable one. In fact, areas that now fall within the boundaries of the Eastern province were loyal to Kandy in pre-colonial times. And Trincomalee, also on the East Coast, has fiercely retained a tradition of autonomy. This information is available in the traditions of the East Coast Tamils. It sometimes makes it way into some Tamil nationalist websites in interesting ways that emphasise a homogenous Tamil identity where scholars would postulate difference. Hellmann Rajanayagam, "The Concept of a Tamil Homeland in Sri Lanka," 89-90; Eelam Web, "Tamil Eelam History," http://www.eelamweb.com/history/te/\#2 (accessed May 16, 2008).
} 
argue a case that seeks to establish that sovereignty over these territories..."59 In most instances, however, the concept of a Tamil homeland is introduced alongside the Jaffna Kingdom:

The British divided the island into 9 provinces for their administrative convenience. In so doing, they recognised the Tamil ethnic character of the territory and population of the old Jaffna Kingdom and ensured its continuity by carving out 2 separate provinces out of the territory where the population would not be mixed but entirely Tamil speaking. They are the northern and eastern provinces, now recognised as the North-East province consequent to the Indo-Sri Lanka pact of 1987 which among other things, took cognizance of the historical contiguity of the Tamil habitat. ${ }^{60}$

Together the Jaffna Kingdom and the Tamil homeland legitimate the

LTTE's claim to Eelam. While the Tamil homeland justifies the borders of Eelam (as the area where Tamils have always lived), ${ }^{61}$ the Jaffna kingdom proves that the Tamil people have always had a political presence in the island and are therefore entitled to the mechanisms of a state.

The Jaffna Kingdom is thus an important part of how the LTTE legitimates its claim to Eelam. It is not, however, crucial to how the LTTE mobilises a group identity. Like the militant past, the history of the Jaffna Kingdom is invoked and not narrated. ${ }^{62}$ The LTTE displays no interest in the chronology of the Jaffna kingdom. Because it is not narrated, the Jaffna Kingdom, as the LTTE uses it, is not predicated on the principles of cause and effect, nor is it dependent upon a linear conception of time. In other words, it does not function as a true nationalist history, replete with the assumptions of Enlightenment History. Consequently, it is not the history on which Tamil

\footnotetext{
${ }^{59}$ International Federation of Tamils, "Tamil Eelam - A Reversion to Sovereignty," http://www.eelam.com/introduction/reversion.html (accessed May 16, 2008). According to the website, this paper, along with two others also cited in this study ("Tamil Eelam Demand in International Law" and "The Legitimacy of the Armed Struggle of the Tamil People"), was presented by International Federation of Tamils at a conference in 1992 which was held at the School of Oriental and African Studies, University of London. According to my original printout of these webpages (2006), the papers were also published in the Official Tamil periodical of the LTTE International Secretariat - Kalathil. The statement, however, connecting these papers to the periodical, has since been removed.

${ }^{60}$ LTTE Peace Secretariat, "Historical Background," http://www.ltteps.org/list.ltte?folder=11 (accessed May 16, 2008).

${ }^{61}$ Stokke and Ryntveit, "The Struggle For Tamil Eelam in Sri Lanka," 292.

${ }^{62}$ The Jaffna Kingdom is invoked only once in the English translations of Prabhakaran's Heroes' Day Addresses: "The Sinhala chauvinistic gangs in the South may light crackers in jubilation assuming that they have captured the kingdom of Jaffna." Velupillai Prabhakaran, "English translation of Martyrs' Day Speech 1995," http://www.ltteps.org/?view=419\& folder=9 (accessed May 16, 2008).
} 
identity depends. While the Jaffna Kingdom is important to how the LTTE legitimates Eelam, it is not the history most important to how the LTTE depicts and mobilises a group identity.

\subsection{The Post Colonial Narrative: Mobilising a Group Identity}

This history, the history on which Tamil identity depends, is the postcolonial narrative. Amongst other things, the narrative is important, because it has ritual implications. All the ritual days in the LTTE's calendar mark the deaths of significant individuals or events within the post-colonial narrative. ${ }^{63}$ The narrative is also important because the LTTE's representations of violence and death (which we look at in the following chapter) build upon this past. Most importantly, the narrative is an example of Enlightenment History. It is presented as a true account of the past. Furthermore, it is predicated on a linear conception of time. The LTTE carefully narrates the post-colonial narrative, chronologically sequencing and linking events. The narrative is thus structured by the principles of cause and effect. As such, it is a true nationalist history. In the LTTE's postcolonial narrative, we have found the LTTE's most potent 'past,' the past which is most important to how the LTTE depicts and mobilises a group identity.

Like the Jaffna Kingdom, the post-colonial narrative is a source that has been borrowed from the parliamentarians. For both the LTTE and the TULF, the post-colonial narrative demonstrates that the Tamils will never be safe in a united Sri Lanka. In this way, the post-colonial narrative legitimates both the TULF's and the LTTE's demand for a state apparatus. The LTTE has, however, developed the post-colonial narrative beyond simple legitimation. Now, the postcolonial history is a unifying narrative that mobilises a Tamil identity through experiences of shared suffering. In the following discussion, I will delineate the LTTE's post-colonial narrative, showing how it functions as an enlightenment history. ${ }^{64}$ In the process, we will also see how the LTTE weaves together the

\footnotetext{
${ }^{63}$ Schalk, "Beyond Hindu Festivals," 406-8.

${ }^{64}$ It is not my intention to adjudicate the veracity of the LTTE's post-colonial narrative. Instead, I want to understand how the LTTE presents the events within this narrative. Where the scholarly presentation of events adds to the discussion by bringing into relief elements of LTTE's narrative, then I have included it.
} 
events of this history in a way that enables it to both mobilise a group identity and legitimate its claims to Eelam.

The LTTE's post-colonial narrative usually begins in 1948, the year that Sri Lanka won independence. One of the first sets of acts passed after independence effectively disenfranchised the Estate Tamils, depriving them of citizenship rights:

The first victims of the Sinhala racist onslaught were the Tamil plantation workers. A million of this working people, who toiled for the prosperity of the island for more than a century, were disenfranchised by the most infamous citizenship legislation in Sri Lankan political history, which robbed these people of their basic human rights and reduced them to an appalling condition of statelessness. ${ }^{65}$

While scholars agree that this event was based on class rather than ethnic distinctions, the LTTE generally presents the legislation as evidence of the government's anti-Tamil bias. ${ }^{66}$

The next major event described in the narrative is the 1956 Sinhala Only Act, passed by the Bandaranaike led government: "The Sinhala Only Act put an end to the equality of status enjoyed by the Tamil language and made Sinhala the only state language. This infamous legislation had disastrous consequences. It forced the Tamil public servants to learn the Sinhala language or leave employment." ${ }^{, 67}$ The outrage which followed from the Tamil side was not solely about the inconvenience of not having Tamil recognised as an official language.

The LTTE expresses this in quite strong terms. It argues that the act was an attack on the Tamil language, one of the facets of Tamil national identity. It is on this, and other similar claims, that the LTTE bases its accusations of genocide:

This genocidal oppression, which spans a period of fifty years, is based on a calculated strategy implemented by successive Sri Lankan governments with a deliberate intention of destroying the essential foundations of the Tamil nation i.e. the land, the language, culture, economic, social and political life. The ultimate objective is to destroy the national or ethnic identity of the Tamil people. ${ }^{68}$

\footnotetext{
${ }^{65}$ LTTE Peace Secretariat, "Historical Background," http://www.ltteps.org/list.ltte?folder=11 (accessed May 16, 2008).

${ }^{66}$ In fact, several Sri Lankan Tamil politicians supported the passing of the act. At the time, the greatest concern of the British-educated, English-speaking intelligentsia was that extreme leftist parties (for whom the Estate Tamils voted) would come into power; nationalist or ethnic sentiment was far from anyone's mind. Bass, Landscapes of Malaiyaha Tamil Identity, 10; Nissan and Stirrat, "The Generation of Communal Identities," 34.

${ }^{67}$ LTTE, Towards Liberation, 24.

${ }^{68}$ Balasingham, The Will to Freedom, 283.
} 
Other 'genocidal' events in the narrative include the annexation of Tamil lands and policy, and acts of parliament that discriminate against Tamil youth in both education and employment. Land in particular has become a fraught issue in Sri Lanka. The 'annexation' or 'colonisation' of the Tamil homelands thus plays an important role in the narrative of historical grievances.

Prior to independence, the British opened up the Vanni region for settlement, an initiative continued by the Sri Lankan government after independence. ${ }^{69}$ Increasingly, these plans became a sore point between the Sinhalese and Tamils. As Sinhalese settlers were moved into areas traditionally dominated by Tamils, the demographics of the region began to change. The LTTE views this as a colonisation scheme which attacks the territorial integrity of Tamil Eelam. The schemes are thus construed as acts of genocide: "This planned occupation of Tamil lands by hundreds of thousands of Sinhala people aided and abetted by the state was aimed to annihilate the geographical entity of the Tamil nation." 70

The discrimination against the Tamils in education and employment includes a number of acts, policies and schemes. The most significant act, however, is the standardisation policy introduced by Sirimavo Bandaranaikne's government during the 1970s: "In the sphere of education a notorious discriminatory selective device called 'standardisation' was introduced in 1970, which demanded higher marks from the Tamil students for university admissions whereas the Sinhalese students were admitted with lower grades." ${ }^{, 11}$ With the introduction of standardisation, an already competitive schooling system became even more competitive, and many bright Tamils were turned away. According to the LTTE this led to increasing discontent and angst with the government, which boiled over into activism.

\footnotetext{
${ }^{69}$ Hellmann Rajanayagam, "The Concept of a Tamil Homeland in Sri Lanka," 79, 93-4, 99. Interestingly, the Tamils were given first choice to settle the area. The Jaffna Tamils, with their high regard for education, were reluctant to cultivate the largely uninhabited Vanni, despite the intense overpopulation in the Jaffna peninsula and the pressure on the arid land that this caused. ${ }^{70}$ LTTE, Towards Liberation, 23-4.

${ }^{71}$ LTTE Peace Secretariat, "Historical Background," http://www.ltteps.org/list.ltte?folder=11 (accessed May 16, 2008). According to Hellmann Rajanayagam, students studying in the Tamil stream had to gain higher marks than their Sinhalese counterparts if they were to obtain university entrance. This was then complemented with district quotas, disadvantaging Tamils further. Little offers a slightly different account of the standardisation policy. He says that the policy instituted regional (and not ethnic) quotas and therefore did not discriminate against the Tamils per se. Either way, many Tamils perceived the policy to be anti-Tamil. Hellmann Rajanayagam, The Tamil Tigers, 10-11; Little, Sri Lanka: The Invention of Enmity, 72.
} 
The 1972 Constitution is another seminal point in the narrative. The Sirimavo Bandaranaike government created a constituent assembly to establish a new constitution for Sri Lanka. Amongst other things, the LTTE presents the constitution as illegal (because it revokes an entrenched clause in the previous constitution which protected minorities), ${ }^{72}$ and discriminatory (Buddhism is made the foremost religion and Sinhala, the only official language) ${ }^{73}$ The LTTE's grievance is not only with the constitution, but also with the circumstances surrounding the inception and establishment of the Constitution. According to the LTTE, Tamil concerns were blatantly dismissed by the assembly: "Sinhala national chauvinism reigned supreme in the deliberations of the Assembly which resulted in most of the Tamil members of Parliament walking out in utter frustration and hopelessness."74

According to the LTTE, this series of events frustrated the Tamil leadership, compelling them to pursue a separate state for the Tamils. In the 1977 elections the Tamil United Front (TUF) demanded a clear mandate from the Tamil people: "This election took the character of a referendum and the Tamil people voted overwhelmingly in favour of secession." ${ }^{\text {,5 }}$ The LTTE argues that its national liberation project is based on this mandate given to the Tamil politicians at the 1977 elections: "The LTTE holds the view that the Tamil people had invoked the right to self determination at the 1977 general elections and opted to fight for political independence and statehood. The national liberation project of the LTTE is based on the people's mandate for self determination." ${ }^{, 76}$

In the events described thus far, we can see how the LTTE's narrative is predicated on the principles of Enlightenment History. In particular, we see how events are narrated in a linear fashion with careful attention to chronology. Furthermore, each event is linked to the next and thus progressively strengthens the LTTE's claim that the Tamil people can only be safe in a Tamil state. The

\footnotetext{
${ }^{72}$ International Federation of Tamils, "Tamil Eelam - A Reversion to Sovereignty," http://www.eelam.com/introduction/reversion.html (accessed May 16, 2008).

${ }^{73}$ International Federation of Tamils, "Tamil Eelam Demand in International Law, http://eelam.com/introduction/eelam_demand.html\#RTFToC2 (accessed May 16, 2008).

${ }^{74}$ LTTE, Towards Liberation, 41.

${ }^{75}$ Ibid., 27-8.

${ }^{76}$ LTTE, "A Struggle For Justice," http://eelam.com/freedom_struggle/ltte_publ/strug_for_just/armed.html (accessed May 16, 2008).
} 
narrative thus creates a sequence of cause and effect which enables the LTTE to justify its claim to Eelam.

The events outlined thus far are consistently mentioned across a variety of LTTE texts, if not in every single text. However, the episodes of most importance are those which involve acts of violence, particularly the violence of the state. We have already seen how the LTTE laces its description of postcolonial events with accusations of genocide and violence. In this way, the LTTE presents its own violence as a necessary counter to the violence of the government. The events involving actual violence, however, provide the ultimate proof that the LTTE's violence is necessary; without it, the Tamil people would be destroyed, or so the LTTE claims.

This emphasis on violence distinguishes the LTTE's narrative from the parliamentarians' narrative. In particular, the LTTE emphasises the postindependence riots, which, according to Ismail, are not even mentioned in the parliamentarians' version. ${ }^{77}$ For the LTTE, the riots are described as the "worst of all" the atrocities perpetrated against the Tamil people. ${ }^{78}$ The government is held responsible for inspiring and even instigating the anti-Tamil riots in 1956, 1958, 1961, 1974, 1977, 1979, 1981 and July $1983 .{ }^{79}$ Through these riots, the state forces are said to have unleashed "mass murder, looting, arson and rape, with abominable crimes of genocide in which the State police openly colluded with the vandals." ${ }^{80}$ Prabhakaran himself speaks about the riots in an interview with Anita Pratrap. When asked about events that had shaped his journey towards militant politics, he describes his childhood encounter with a widowed mother whose husband had been burnt alive during the 1958 riots. $^{81}$

The LTTE also discusses how the government employed violence to silence the non-violent campaigns of the Tamils. The Tamil leadership protested against discriminatory, government policies through non-violent methods organised satyagrahas and a civil disobedience campaign. ${ }^{82}$ The LTTE

\footnotetext{
${ }^{77}$ Ismail, Abiding by Sri Lanka, 144.

${ }^{78}$ LTTE, Towards Liberation, 5.

${ }^{79}$ LTTE Peace Secretariat, "Historical Background," http://www.ltteps.org/list.ltte?folder=11 (accessed May 16, 2008).

${ }^{80}$ LTTE, Towards Liberation, 5.

${ }^{81}$ LTTE, Towards Liberation, 79.

${ }^{82}$ LTTE Peace Secretariat, "Historical Background," http://www.ltteps.org/list.ltte?folder=11 (accessed May 16, 2008)
} 
highlights the government's response to these protests: "The Sinhala

Government reacted with military violence and terror, brutally crushing the nonviolent peaceful campaigns of the Tamils." ${ }^{, 83}$

The LTTE emphasises the violence of the government because it vindicates the LTTE's own violence. Once again, we see the principles of cause and effect at work. Based on this presentation of events, the LTTE claims that it is the government and not the LTTE who are the terrorists. ${ }^{84}$ Born of the people's frustration, the LTTE claims to have only pursued violence as a last resort, and even then, only after careful consideration. ${ }^{85}$ In this way the LTTE's violence becomes reactive, rather than proactive. "The strategy of armed struggle was formulated by us after a careful and cautious appraisal of the specific concrete conditions of our struggle, with the fullest comprehension of the historical situation in which masses of our people have no choice other than to fight decisively to advance the cause of national freedom." $" 86$

The LTTE cites these events involving violence not only to justify its violence, but also to emphasise a key theme of the narrative: shared suffering. While government policies and legislations have caused the people to suffer, the people's greatest suffering has been at the hands of government troops. This suffering is an experience shared by Tamils; it is constitutive of what it means to be a Sri Lankan Tamil today. In this way, the LTTE's post-colonial narrative goes beyond mere legitimation. It posits a shared experience of suffering which the LTTE emphasises in order to mobilise a group identity: "Only when we share the suffering of our people, the people will unite with us." ${ }^{, 77}$ This suffering exists not only in the past but also in the present. ${ }^{88}$

Thus far, we have seen how the post-colonial narrative functions as an enlightenment history, animating the LTTE's efforts to mobilise a group identity. It is predicated on a linear conception of time. It is narrated chronologically and

\footnotetext{
${ }^{83}$ LTTE, "A Struggle for Justice," http://eelam.com/freedom_struggle/ltte_publ/strug_for_just/whydid.html (accessed May 16, 2008).

${ }^{84}$ LTTE, Towards Liberation, 13.

${ }^{85}$ LTTE, “A Struggle for Justice," http://www.eelamweb.com/publication/justice/whydid.shtml (accessed May 16, 2008).

${ }^{86}$ LTTE, Towards Liberation, 28.

${ }^{87}$ LTTE, Reflections of the Leader, http://publications.uu.se/abstract.xsql?dbid=8404 (accessed May 12, 2008), 265.

${ }^{88}$ Velupillai Prabhakaran, "English Translation of Martyrs' Day Speech 2006," http://www.ltteps.org/?view=1776\&folder=9 (accessed May 16, 2008).
} 
consequently, is animated by the logic of cause and effect. We still have to test the post-colonial narrative against one final criterion: is the post-colonial narrative presented as a true account?

The LTTE depicts the post-colonial narrative as true, when it also depicts the narrative as secular. We see this in the following quote, where Prabhakaran contrasts the post-colonial narrative (the true, secular account) with the Mahavamsa (a mythical history). "The Sinhala nation continues to be entrapped in the Mahavamsa mindset, in that mythical ideology... It is because of this ideological blindness the Sinhalese people and their political and religious leaders are unable to grasp the authentic history of the island and the social realities prevailing here." ${ }^{~} 99$ The LTTE thus presents its post-colonial narrative as a verifiable, secular account, uncomplicated by religious or mythical details. It claims that if others (including the Sinhalese and the international community) read and understood this history, then they would understand the LTTE, and, more notably, its violence. ${ }^{90}$ The LTTE thus ascribes history with an important function. It is transparent. ${ }^{91}$ The post-colonial narrative thus meets the last criterion of enlightenment history: it is presented as a true, verifiable account of the past.

As stated earlier, nationalist identities depend on histories which fulfil the criteria of Enlightenment History. The LTTE's post-colonial history clearly fulfils these criteria. Therefore, it is the LTTE's post-colonial narrative, and not the militant past or the Jaffna Kingdom that provides the LTTE with its most potent formulation of Tamil identity. It is the LTTE's post-colonial narrative that is most important to how the LTTE mobilises a group identity.

The post-colonila narrative is strikingly modern and so too, therefore, is the formulation of Tamil identity which arises out of it. When the LTTE emphasises recent experiences of suffering, it almost suggests that Tamil identity was forged only in opposition to the government's violence: "Tamil nationalism arose as a historical consequence of Sinhala chauvinistic oppression." ${ }^{92}$ This

\footnotetext{
${ }^{89}$ Velupillai Prabhakaran, "English Translation of Martyrs' Day Speech 2005," http://www.ltteps.org/?view=996\& folder=9 (accessed May 16, 2008).

${ }^{90}$ Balasingham, The Will to Freedom, 279-80.

${ }^{91}$ Asad would identify this as a secular, modern sensibility. The secular is concerned with the apprehension of the real. When the LTTE identifies its history as true, transparent and non religious, it draws on a universal modern discourse.

${ }^{92}$ LTTE, Towards Liberation, 33.
} 
emphasis on a recent history fits well with how the LTTE sees itself as shaping and reformulating Tamil tradition. The recent past and the present is a period of great transformation where the LTTE assesses and refines Tamil tradition and identity.

When scholars analyse the various strands of the LTTE's historical discourse, they too identify what we have established here - the post-colonial narrative and the notion of a militant tradition and past are important to the LTTE's project. I turn now to these scholarly arguments, focussing particularly on how scholars apply the categories of religion and the secular.

\subsection{History or Myth?}

\section{Reading Religion into the LTTE's Historical Discourse}

When scholars analyse the LTTE's historical discourse (or aspects within it), they do not overtly or pervasively apply the category of religion. This is perhaps because the discourse conforms to our ideas about what constitutes a secular history. While the references to religion are few, they are nonetheless there.

I examine two scholars here: Fuglerud and Schalk. Fuglerud implicates the category of religion when he discusses the LTTE's postcolonial narrative. Schalk however, assesses the LTTE's nationalism in relation to a functionalist definition of religion. ${ }^{93}$ He concludes that the LTTE's nationalism performs a religious function. While Schalk does not explicitly discuss the LTTE's historical discourse, we can surmise that his analysis applies to aspects of the LTTE's militant past.

When Fuglerud discusses the LTTE's post-colonial narrative, he does not explicitly invoke the category of religion. He does, however, apply the term myth, a category long associated with religion:

\footnotetext{
${ }^{93}$ Hellmann Rajanayagam and Trawick also suggest that the LTTE's nationalism is a religion. Hellmann Rajanayagam argues that the militants' expression of Tamil nationalism is a new secular religion that has "strong integrative power precisely because it syncrestically uses religious symbolism and quasi-religious terms to unite Sri Lankan Tamils into a Tamil nationalism based on its very own concept of culture and tradition." Trawick similarly suggests that the LTTE's nationalism evokes a reverence that is religious in tone: "The LTTE are not religious fanatics or fundamentalists. Its members practice the religions of their choice. If there is an LTTE religion, it is devotion to Tamil Eelam, which like many other homelands is depicted metaphorically as a mother." Hellmann Rajanayagam, "Religious Ideology Among the Tamils," 82; Trawick, "Reasons For Violence," 160.
} 
This explanation goes beyond scientific history and represents a 'mythico-history.' Not because it is untrue but because the Tamils as a people are here heroised and placed within a more encompassing moral ordering of the world (Malkki 1990) where relationships and processes are reinterpreted within a dichotomy of good and evil. It is with reference to this binary moral framework that the significance of different levels of communication must be sought. While internally there is a continuous ordering and reordering of events and actors, externally most people will project an image of the world in categorical terms where Tamils are locked in an oppositional relationship with their surroundings. Many, in fact, express the opinion that Tamils are a 'cursed people', abandoned by gods and men alike. When asked about their background, Tamil refugees tend to slip from the story of their own lives into the field of collective history. The individual and the collective fuse into one standardised discourse explaining 'why I am here now. ${ }^{94}$

Here, Fuglerud says that the LTTE's history is mythic not because it is untrue (a definition often given to myth), but because it departs from scientific history. In other words, the post-colonial narrative does not just narrate facts; it is also involved in how Tamils understand their identity as Tamils. Fuglerud is saying what we have already established - the post-colonial narrative plays an important role in how the LTTE mobilises a group identity.

Of course, Fuglerud's observation is true of all nationalist histories. All nationalist histories are involved in the creation and maintenance of identity, even though they claim to be 'scientific.' So what does Fuglerud imply when he uses the category of myth? I think he suggests that identity formation belongs to the religious domain. Science, on the other hand, has no agendas; it wants nothing more than to provide a straightforward account of (historical) reality. Science, unlike religion, is not involved in how people shape their identities. While Fuglerud does not explicitly say that the LTTE's history is religious (because it is involved in the creation of identity), he nonetheless implies this. Fuglerud's use of the term myth shows us that the category of religion is firmly entrenched in modern thought and epistemology.

While Fuglerud implicitly connects religion to the post-colonial narrative, Schalk explicitly applies functionalist definitions of religion to the LTTE's nationalism. Although Schalk writes polemically when he applies this definition, I have chosen to include his analysis here. His argument captures an important connection that people often make between nationalism and religion.

\footnotetext{
${ }^{94}$ Fuglerud, Life on the Outside, 179-80.
} 
In his article "The Revival of Martyr Cults Among Ilavar," Schalk argues that the LTTE is a religious organisation because it employs tradition. ${ }^{95}$ According to Schalk, established religions (Christianity, Hinduism etc.) possess tradition: "It is part of our concept of religion itself that it appeals to a long tradition going back to a founder or original revelation that rationalises its norms." Schalk argues that new political movements climb towards the status of a religion when they incorporate tradition (which can include language purism or reviving factual or mythical incidents of the past). ${ }^{96}$ In this way, Schalk presents tradition as being inherently religious.

From Schalk's argument, I presume that he would accept the militant tradition (which we discussed in relation to the militant past) as evidence for his argument - the LTTE relies on tradition and is therefore a religious organisation. Because all nationalisms depend on tradition, we can also presume that Schalk would deem all nationalisms religious.

When we deconstruct the scholarly arguments discussed above, we see how they point to important observations about the LTTE's nationalism. Fuglerud is arguing that the LTTE's post-colonial history is important to how Tamils understand their identity. Similarly, Schalk indicates that tradition is important for the LTTE: the ancient past evokes a sense of tradition.

These insights, however, are obscured, when Fuglerud and Schalk try to explain them through the category of religion. In the scholars' analyses, these observations - that the LTTE requires tradition and that its post-colonial narrative is important for Tamil identity - become secondary to assertions about the role that religion plays in the LTTE's nationalism. When scholars become fixated on the categories of religion and the secular, they neglect, as well as obscure, important insights. For example, Schalk does not discuss how the LTTE celebrates its divergence from tradition, an important and fascinating facet of how the LTTE presents tradition. Asad's observation thus becomes clear: when we apply the category of religion (as it is conventionally understood), we provide a muddled analysis that says little about the subject being examined.

\footnotetext{
${ }^{95}$ Schalk also argues that the LTTE is a religious organisation because it stipulates an ultimate aim (for which cadres are willing to die). Schalk, "The Revival of Martyr Cults Among Ilavar," 153.

${ }^{96}$ Schalk, "The Revival of Martyr Cults Among Ilavar," 154.
} 
In this chapter I have argued that nationalist identities depend on histories which exhibit the characteristics of Enlightenment History. This includes, amongst other things, a concern with truth, a narration of events predicated on a linear conception of time and structured by the logic of cause and effect. I have shown that it is the LTTE's post-colonial narrative, and not the Jaffna Kingdom or the militant past, which exhibits these characteristics. Consequently, it is the post-colonial narrative which is most important to how the LTTE depicts and mobilises a group identity. In particular, the narrative mobilises a group identity through shared experiences of suffering.

Alongside these recent experiences of suffering, the LTTE also presents a glorious, martial past. The LTTE quite extraordinarily celebrates its divergence from the martial tradition of this past. In this departure from tradition, we once again see how the LTTE emphasises a sense of constant becoming and transformation, a theme which reappears in the next chapter. 


\section{Chapter Four}

\section{Violence and Death- Liberating the Self and the Nation}

At no time and nowhere in world history, except in our motherland, has occurred such wonderful abandonment (from life) and astonishing dedication (of life). ${ }^{1}$

In the previous chapter we established that the LTTE mobilises a shared Tamil identity by invoking a recent past of shared suffering and an ancient past where martial values flourished. In this chapter, we turn our attention to another LTTE discourse: violence and death. I ask the same questions of this discourse as I did of the last: how does the LTTE use the discourse to mobilise a group identity? How is the discourse structured by the claim to be secular? And how do scholars implicate or apply the categories of religion and the secular when they analyse the discourse? In addition to the commonalities between how I approach the two discourses, there are several continuities between the discourses themselves.

The LTTE's discourse around violence and death is intimately connected to the historical narrative of suffering. In fact, violence and death point to the

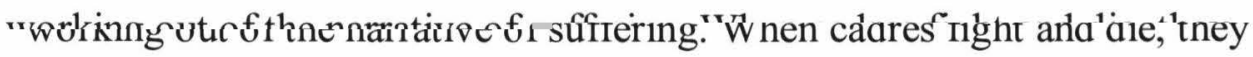
channel and transform their experiences of suffering into battle. In the process, they liberate not only the self, but also the nation from experiences of suffering. And so, in this chapter, I argue that the LTTE mobilises a group identity through shared experiences of liberation, experiences which are presented as the answer to suffering.

In this chapter, as in the last, we observe an LTTE discourse structured by the claim to be secular. We similarly observe a scholarly discussion around the discourse that involves the categories of religion and the secular. I focus on one aspect of the debate: the deification of the dead. Some scholars argue that LTTE rituals are commemorative only, while others claim that the rituals encourage the public to approach the dead as deities. For each scholar 'religion' and the 'secular' implies something slightly different. These meanings shift between one study and another, and sometimes even within a single study.

\footnotetext{
${ }^{1}$ LTTE, Reflections of the Leader, http://publications.uu.se/abstract.xsql?dbid=8404 (accessed May 12, 2008), 265.
} 
When we engage with this lively discussion and all its flaws and inconsistencies, new questions and approaches emerge. The scholarly debate provides us with rich material that enables us to better understand how the LTTE represents the secular and mobilises a group identity. I begin not with the scholarly discussion, but with the discourse itself. I show how it is structured by the claim to be secular. This will lead me into a discussion about how the LTTE constructs meaning around violence and death. In particular, I identify how the LTTE presents fighting and dying as creative acts through which its cadres transform and liberate both themselves and the nation. Finally, I will discuss the scholarly debate. I will offer three alternative readings of the deification of the dead. Unlike the scholars whom I discuss, I do not assume that the deification of the dead is a religious act. Instead, I inquire into what the practice might tell us about how the LTTE represents the secular.

\subsection{Violence and Death: The Claim to be Secular}

In the previous chapter, we saw how the LTTE presents its post-colonial narrative as secular. It distinguishes its own 'factual' account from the religious history of its Sinhalese adversaries. We see similar assertions in the LTTE's discourse around violence and also death. For example, the LTTE refers to its cult of martyrs as 'secular.' The organisation's burial practices offer us another example of how it asserts its secularity. Finally and perhaps most importantly, the LTTE's cause, for which it is willing to fight and die, is depicted as a secular one.

Let us begin with the first example. The LTTE collectively refers to the dead cadres as a secular cult of martyrs. Furthermore, it claims to honour the dead through secular, civil ceremonies and not religious rituals. On appointed days, the LTTE conducts these secular ceremonies throughout the North-east. The ceremonies are an opportunity for living cadres and the Tamil public to honour the contribution made by all who have died. Most of the ceremonies mark the death anniversaries of notable cadres. One such ceremony is Mavirar Nal. It commemorates the death anniversary of Shankar, the first LTTE martyr. Other days in the LTTE's ritual calendar mark the 1983 riots, the fasts to death by Pupati and Thileepan against the Indian occupation, and the death of the first 
Black Tiger (suicide bomber). The biggest of these ceremonies, however, is Mavirar Nal. These ceremonies are considered solemn, formal occasions. On the marked day, ritual prescriptions are carried out fastidiously. ${ }^{2}$

The LTTE feels that the dead are most appropriately honoured through these secular rituals and in a secular cult:

It [the LTTE] feels that it would not be possible to have a specific Hindu, Muslim or Catholic cult of martyrs ... for the simple reason that death should not separate; the unity achieved in battle... should be continued, and unity can be maintained only in a 'secular' cult... in the sense of a cult, which does not interfere in any of the religions already practised, and also in the sense of a rationalistic commemorative cult. ${ }^{3}$

The LTTE thus asserts its secularity, when it classifies as secular both its commemoration of the dead and its cult of martyrs.

In the LTTE's burial practices we find another instance where the LTTE presents itself as a secular organisation. In Tamil Hindu society, the dead are usually cremated. Burial is a practice generally associated with Christians, Muslims and even lower castes. Up until the early 1990s, the LTTE returned the bodies of dead cadres to their families who chose to either bury or cremate their dead in a kin-based, religious ceremony. In the early 1990s, however, the LTTE established tuyilum illam (war cemeteries). When cadres die, they are now buried here. The LTTE effected another change also - the body of a cadre was no longer to be inhumed in a ceremony particular to the cadre's religious tradition. Instead, all dead cadres were to be buried in a secular ceremony. The practice is thus innovative for two reasons: first, the dead are buried (rather than cremated), and second, their burial is conducted as part of a 'non-religious' ceremony. ${ }^{4}$

Scholars speculate about how the LTTE has managed to convince the Tamil public to adopt this practice, when it diverges so drastically from Hindu custom. Scholars point to alternative Hindu traditions that permit burial, arguing that the LTTE has only been able to adopt the practice on account of these traditions. I will survey these arguments later, but here, I am interested in exploring how the LTTE itself justifies its decision to bury the dead. Does the LTTE explain it as a return to a Hindu practice? Or has the LTTE chosen an explanation that asserts its secularity?

\footnotetext{
${ }^{2}$ Schalk, "Beyond Hindu Festivals," 406-9.

${ }^{3}$ Schalk, "The Revival of Martyr Cults Among Ilavar," 186.

${ }^{4}$ Ibid., 183.
} 
According to Schalk and Natali, LTTE leaders claim that they decided to bury the dead when they observed the practices of countries like Britain and America: "They saw that they used to bury their soldiers. Then they decided to proceed in the same way." ${ }^{, 5}$ While the LTTE does not explicitly delineate the practice as a secular one, it nonetheless distances the practice from possible religious explanations. Instead, the LTTE aligns the practice with those of nations that are perceived as civil and secular. It too hopes to be perceived as a secular movement.

Thus, we have seen how the LTTE presents its commemorative ceremonies as secular events. We have also explored how the LTTE associates its burial practices with the practices of nation-states that are generally deemed secular. In addition, violence and death presents us with a third instance where the LTTE asserts its secularity. This last instance concerns how the LTTE represents its reasons for fighting and dying.

The LTTE contrasts its own reasons for fighting and dying with those of religious organisations. In this way, the LTTE suggests that its violence is driven by moral, secular motivations: "We are not mentally demented as to commit blind acts of violence impelled by racist and religious fanaticism. We are fighting and sacrificing our lives for the love of a noble cause." ${ }^{6}$ Secularists, the LTTE included, often regard religious violence as gratuitous. This does not mean, however, that secularism is incompatible with violence. Asad challenges theorists who designate religious origins for the violence perpetrated by secular governments. He argues that violence is entirely compatible with liberal, secular values. In fact, it is characteristic of it. Violence is disavowed on principle, but enlightened violence, the violence of universalising reason, is legitimised for the liberal project of redeeming the world. ${ }^{7}$ When the LTTE presents its cadres' violence (and deaths) as just, rational and necessary, it draws on this tradition, distinguishing its violence from the violence of religious organisations and simultaneously asserting the secularity of its own. So how does the LTTE represent its cadres' violence and deaths as just, rational and necessary?

\footnotetext{
${ }^{5}$ Natali, "Building Cemeteries, Constructing Identities. Funerary Practices and Nationalist Discourse Among the Tamil Tigers of Sri Lanka," http://www.basas.ac.uk/conference05/natali,\%20cristiana.pdf (accessed April 26, 2008).

${ }^{6}$ Velupillai Prabhakaran, "English Translation of Martyrs' Day Speech 2001," http://www.ltteps.org/?view=414\& folder=9 (accessed May 16, 2008).

${ }^{7}$ Asad, Formations of the Secular, 7-8.
} 
The LTTE advances three interrelated claims pertaining to its cause, Eelam. All three demonstrate that Eelam is a rational, just, necessary cause. Consequently, when LTTE cadres fight and die for this cause, their violence and deaths are also construed as rational, just and necessary. First, the LTTE claims that Eelam is guaranteed to the Tamil people as a universal right. Here it draws on UN documents about the rights of nations, showing how Sri Lankan Tamils constitute a nation. Based on this position, the LTTE argues that the Tamils are entitled to live as a nation, determining their own political and economic life. ${ }^{8}$ Second, the LTTE represents its cause, Eelam, as embodying the collective aspirations of the Tamil people. The LTTE emphasises that it does not just represent the people; it is the people: "The Liberation Tigers are not separate from the people. The Liberation Tigers are a people's movement. The Tigers, indeed, are the people. The people, indeed, are the Tigers." ${ }^{9}$ Third, the LTTE represents Eelam as a historical necessity. Eelam was only pursued when it became clear that the Tamil people would never be safe in a united Sri Lanka. ${ }^{10}$ These three arguments coalesce to form a strong moral claim: Eelam is a just, rational and necessary cause. Because cadres fight and die for such a cause (as opposed to a religiously motivated cause), the cadres' acts of violence and death are also construed as just, rational and necessary.

Because secularists repudiate violence on principle, when they do resort to it, they must demonstrate that they are fighting and dying for a moral cause. But they must do more than this. While a cause might be just, rational and necessary, an onlooker might ask whether it is just, rational and necessary to kill and die for that cause. The moral foundation of the LTTE's cause thus only partly convinces a secularist that the LTTE's violence is enlightened. Consequently, the LTTE advances a further three arguments, all of which demonstrate that its violence, like its cause (but independent of it), is driven by secular, moral motivations. These claims strongly echo the three arguments enumerated above.

\footnotetext{
${ }^{8}$ The International Federation of Tamils, "Tamil Eelam Demand in International Law," http://eelam.com/introduction/eelam_demand.html\#RTFToC2 (accessed May 16, 2008).

${ }^{9}$ LTTE, Reflections of the Leader, http://publications.uu.se/abstract.xsql?dbid=8404 (accessed May 12, 2008), 258.

${ }^{10}$ LTTE Peace Secretariat, "Historical Background," http://www.ltteps.org/list.ltte?folder=11 (accessed May 16, 2008).
} 
First, the LTTE deploys a universalist discourse, claiming that it is a historical law that people must fight and die for freedom. ${ }^{11}$ In this way, the LTTE claims that it is necessary (and therefore rational and just) for its cadres to fight and die for Eelam. Second, the LTTE claims that its violence represents the collective aspirations of the people. ${ }^{12}$ Its violence is not a tyrannical, violence imposed upon the people, but a democratic one that emanates from the people. Here, the LTTE presents its violence as just. Third and finally, the LTTE employs a historical argument: fighting and dying for Eelam (like Eelam itself) were only opted for, when all other options were exhausted. It was only after careful consideration that the LTTE decided to attain Eelam through violent methods. ${ }^{13}$ Yet again, the LTTE asserts the necessity of its violence. As with the previous three claims, the LTTE uses these arguments to present its violence and deaths as just, necessary and rational. Unlike the previous three arguments, however, these claims are not connected to the LTTE's cause.

When the LTTE shows that its violence and deaths are motivated by these moral motivations and considerations, it distinguishes its own violence and deaths from those of religious organisations. This moral basis is crucial to how the LTTE presents itself as a secular organisation. It is also important, however, for how the organisation constructs meaning around violence and death. We see this in how the LTTE distinguishes its own violence from the government's violence. Because it is not predicated on moral motivations, the government's violence is futile and meaningless. It brings unnecessary suffering to the people. In contrast, the LTTE's own violence is liberating and just: "The Sinhala nation is engaged in a war of injustice where as we are engaged in a liberation struggle in which justice is on our side."14 Because the LTTE's violence is just, any suffering that is experienced because of it (whether by the Sinhalese, Tamil public or LTTE cadres) is necessary.

\footnotetext{
${ }^{11}$ Velupillai Prabhakaran, 'English Translation of Martyrs' Day Speech 1992, http://www.ltteps.org/?view=422\&folder=9 (accessed May 16, 2008).

${ }^{12}$ LTTE, Towards Liberation, 47-8.

${ }^{13}$ Ibid., 28. Because the LTTE presents its violence as necessary, it continually affirms its commitment to peace and peaceful modes of resolution: "We are not warmongers who love violence. In actually fact, spiritually, we love peace. We want a permanent, stable and honourable peace." Velupillai Prabhakaran, "English Translation of Martyrs' Day Speech 1992," http://www.ltteps.org/?view=422\& folder=9 (accessed May 16, 2008).

${ }^{14}$ Velupillai Prabhakaran, "English Translation of Martyrs' Day Speech 1998," http://www.ltteps.org/?view=416\&folder=9 (accessed May 16, 2008).
} 
The moral basis of the LTTE's cause similarly imbues its cadres' deaths with meaning: "Our heroes have sacrificed their lives for a just cause. Their demise does not constitute an ordinary event of death. Rather their death signifies a profound spiritual aspiration for national freedom." 15 Just as the moral basis of the cause provides a counterpoint between the LTTE's violence and the violence of the government, it also provides a contrast between the deaths of LTTE cadres and the deaths of others. LTTE cadres die for the cause, and hence "They lie buried as seeds." ${ }^{\prime 16}$ The deaths of Tamil civilians, however, are pointless. In one LTTE poem it is made clear that while cadres become seeds, innocent bystanders (i.e. Tamil civilians) do not: "Not all who fell became seeds." ${ }^{17}$ In a similar way, the LTTE distinguishes its own deaths from the deaths of government soldiers: "We, motivated by an unceasing yearning for national liberation, are forced to oppose you, a puppet of the state...As we walk the path of national liberation, our deaths will acquire dignity, meaning. But yours will become meaningless and absurd." ${ }^{18}$ Unlike Tamil civilians and government soldiers, LTTE cadres die for a just, secular cause and this is why only their deaths are presented as meaningful.

The LTTE thus employs a moral argument to establish its secularity and to imbue violence and death with meaning. The LTTE's discourse around violence and death, however, concerns more than just its moral foundation: "Right and justice alone on our side is not enough. We need strength. We must have excellence for fighting. We must have determination without hesitation." 19 How the cadres fight (and presumably die) is also important. When we address how cadres approach fighting and dying, we discover how the LTTE represents violence and deaths as transformative, liberating acts.

\footnotetext{
${ }^{15}$ Velupillai Prabhakaran, "English Translation of Martyrs' Day Speech 1993," http://www.ltteps.org/?view=421\& folder=9 (accessed May 16, 2008).

${ }^{16}$ Katiravan, "One Foot Above the Ground," trans. by Hellmann Rajanayagam, "And Heroes Die," 38.

${ }^{17}$ Arts and Culture Association, "How You Alone...," trans. by Hellmann Rajanayagam, "And Heroes Die," 137.

${ }^{18}$ LTTE, Towards Liberation, 16.

${ }^{19}$ LTTE, Reflections of the Leader, http://publications.uu.se/abstract.xsql?dbid=8404 (accessed May 12, 2008), 271.
} 


\subsection{Violence and Death: Liberating the Self}

Before cadres can fight (and die) on the battlefield, they are required to undertake ascetic practices. They subject themselves to an abstemious lifestyle.

Furthermore, they undertake gruelling training where they learn to master themselves physically and emotionally. In the process, they transcend and liberate the self from physical discomfort, everyday fears and, most importantly, experiences of suffering. This ascetic training also enables them to fight in a liberated way on the battlefield. While fighting involves liberating the self in some degree, dying on the battlefield represents the ultimate liberation of self.

The LTTE expects its cadres to adopt a disciplined, ascetic lifestyle, ${ }^{20}$ abstaining from worldly goods and pleasures, such as smoking, drinking and premarital relations. ${ }^{21}$ It thus refers to its cadres as ascetics. ${ }^{22}$ As ascetics, cadres embrace this ascetic lifestyle and renounce their own personal desires, committing all their energies to the liberation struggle: "A liberation warrior should transcend the borders of his ego and dedicate (his life) totally to the struggle. ${ }^{23}$ In this way, the LTTE suggests that its cadres liberate themselves when they undertake ascetic training in preparation for the battlefield.

In other ways also, cadres undertake ascetic practices. Their training regime is rigorous.

This is a period when elbow skin turns to calluses; when barbed wire treats the soles of the feet as a pin cushion; when ropes burn off the palm of the hands. It is the time when cadres bathe in their sweat; when dust replaces talcum powder; where clothes become rags. This is the time when your rifle becomes your friend; when alertness becomes a life saver; the moon and stars your light. ${ }^{24}$

Through this training, cadres liberate themselves, learning to tolerate extreme physical deprivation and discomfort.

Cadres are also taught to master their emotions, another aspect of their ascetic training. For example, they are taught to approach killing as a job that

\footnotetext{
${ }^{20}$ Ibid., 267.

${ }^{21}$ Balasingham, The Will to Freedom, 78-81. For some time cadres were not allowed to marry at all. Those who breach the code of conduct are severely punished.

${ }^{22}$ Schalk, "The Revival of Martyr Cults Among Ilavar," 166. Living cadres are referred to as tavan (ascetics)

${ }^{23}$ LTTE, Reflections of the Leader, http://publications.uu.se/abstract.xsql?dbid=8404 (accessed May 12, 2008), 266.

${ }^{24}$ Balasingham, Women Fighters of Tamil Eelam, 19-20.
} 
must be undertaken without emotion. ${ }^{25}$ They also learn to individuate themselves so that they can overcome their fears, especially the fear of death. ${ }^{26}$ When cadres overcome their fear of death, they transcend, transform and liberate the self: "Fear of death is the cause of every human fear. Who conquers this fear of death, conquers over himself. This person also reaches liberation from the prison of his mind.,"27

While cadres are taught to overcome certain emotions, they learn to harness others. For example, cadres are trained to channel their experiences of suffering. On the battlefield, they marginalise their fears and then focus on experiences of suffering, such as the loss of a comrade or the collective suffering of the Tamil people. They then harness this experience of suffering and cultivate a martial rage. ${ }^{28}$ As we noted in the previous chapter, the LTTE mobilises a group identity when it appropriates and emphasises shared experiences of suffering. In this chapter, we see how the LTTE offers a solution to the postcolonial narrative of suffering. Cadres liberate the self from suffering when they channel their experiences of suffering into battle.

Cadres thus undertake ascetic training, liberating the self from worldly desires, physical discomfort and emotional states. This ascetic training also enables cadres to fight in a liberated way on the battlefield: "In poverty you lived / Without pretensions your inner self / On the battlefield your courage surged."29 Through living ascetically, cadres cultivate a power which they unleash on the battlefield. Men cultivate tapas (strength through abstinence) and women, karpu (chastity). ${ }^{30}$ In battle they channel this power and fight ferociously. Liberated through ascetic practices, the self is able to fight without fear and kill without emotion. Most importantly, when the 'liberated self' takes to the battlefield, it transforms experiences of suffering: "Every drop of blood... that our people shed in their day to day agonies will transform into arms against your Government. We will raise a revolutionary army of thousands of liberation fighters from the

\footnotetext{
${ }^{25}$ Trawick, "Reasons for Violence," 159.

${ }^{26}$ E. Valentine Daniel, "The Semeiosic Economy of Fear," Social Reseach 71:4 (2004): 1093.

${ }^{27}$ LTTE, Reflections of the Leader, http://publications.uu.se/abstract.xsql?dbid=8404 (accessed May 12, 2008), 258.

${ }^{28}$ Schalk, "Beyond Hindu Festivals," 400.

${ }^{29}$ Warrior Icaiyalakan, "Distant Star," trans. by Hellmann Rajanayagam, “And Heroes Die," 131.

${ }^{30}$ Schalk, "Women Fighters of the Liberation Tigers in Tamil Ilam," 177.
} 
very ashes of those innocents who were murdered for no reason by your armed forces." $" 31$

Thus, cadres signify that they have liberated the self when they adopt ascetic practices and fight on the battlefield. Dying on the battlefield, however, connotes the ultimate renunciation and liberation of the self. Consequently, the dead are seen as the ultimate renunciators. The term tiyaki (ascetic) refers only to dead cadres. When a cadre dies in battle, his death is understood as an act of tiyakam or abandonment. ${ }^{32}$ The term tiyakam has strong connotations of renunciation. It generally refers to the sacrifice or devotion of someone who has freed the self from all earthly bonds. ${ }^{33}$ The cadre who voluntarily abandons his or her life for the realisation of the cause is thus similar to the renouncer who abandons worldly life. ${ }^{34}$

The dead cadre, more so than the living, has truly transcended and liberated the self: "To be courageous to annihilate oneself for the happy living of others is godly asceticism." 35 Consequently death does not defeat the cadre: "The hawk risen into the air / Devours our bodies / As leftovers only / No power can contain the power inside us." ${ }^{36}$ When a cadre dies, he or she transcends and liberates the self, and concomitantly defeats death. Violence and death are thus interpreted as creative acts which are necessary for the individual to liberate the self. As we will see in the next section, violence and death are liberating for another reason also: they bring the liberation of the nation one step closer.

\subsection{Violence and Death: Liberating the Nation}

When cadres fight in an empowered, agentive way, they bring the liberation of Eelam closer. The LTTE is clear that Eelam cannot be realised without the willingness of cadres to fight relentlessly and fearlessly. Only then can government forces be dispelled from the Tamil homeland: "We will continue to

\footnotetext{
${ }^{31}$ LTTE, Towards Liberation, 18.

${ }^{32}$ Schalk, "The Revival of Martyr Cults Among Ilavar," 166-8.

${ }^{33}$ Hellmann Rajanayagam, "And Heroes Die," 123.

${ }^{34}$ Schalk, "The Revival of Martyr Cults Among Ilavar," 166.

${ }^{35}$ LTTE, Reflections of the Leader, http://publications.uu.se/abstract.xsql?dbid=8404 (accessed May 12, 2008), 275.

${ }^{36}$ M Icaialakan, "Time Collects in Our Hand (The Opportunity is in our Hands)," trans. by Hellmann Rajanayagam, in “And Heroes Die," 132.
} 
fight until your armed forces are chased out from our homeland." ${ }^{37}$ The LTTE thus advances its journey to Eelam, each time a cadre takes to the battlefield, cultivating a martial rage: "Our fighters have today become historic personages and are impelling history forward." ${ }^{38}$ Because of its liberating quality, the LTTE celebrates its violence: "The speed of our strikes, the ability of rapid deployment, the unified command, the high discipline, the spectacular offensive tactics and the tremendous courage displayed by our fighting formations have astounded the world military experts." 39

While fighting brings Eelam closer, dying signifies the ultimate way of liberating the nation (just as it is signifies the ultimate means of liberating the self). According to the LTTE, it is necessary for cadres to die: "Only in return for death, destruction and grief as gifts can we see the paradise of independence."40 Their deaths push forward the liberation struggle, bringing liberation to the land. Consequently their deaths are considered proof that progress is being made towards Eelam: "If you are afraid of losses in war you cannot conduct (a war). Losses should be evaluated as support for progress." ${ }^{~} 41$ The LTTE claims that it could not advance towards Eelam unless cadres were willing to put themselves in situations where they can and will die. The Black Tigers exemplify this. The Black Tigers are the wing of the LTTE that are trained to conduct suicide bombing missions. They undertake missions knowing that there is no chance of survival. When they die fulfilling these missions, they eliminate obstacles that would otherwise hinder the realisation of Eelam. ${ }^{42}$ When cadres die, whether they be Black Tigers or not, they impel the liberation struggle onwards, enabling the LTTE to take yet another step towards the actualisation of its goal - Eelam. ${ }^{43}$

\footnotetext{
${ }^{37}$ LTTE, Towards Liberation, 18.

${ }^{38}$ Velupillai Prabhakaran, "Tamil National Leader Hon. V. Prabhakaran's Interview," http://www.eelamweb.com/leader/interview/in_199404/(accessed May 16, 2008).

39 Velupillai Prabhakaran, "English Translation of Martyrs' Day Speech 1999," http://www.ltteps.org/?view=415\&folder=9 (accessed May 16, 2008).

${ }^{40}$ LTTE, Reflections of the Leader, http://publications.uu.se/abstract.xsql?dbid=8404 (accessed May 12, 2008), 263.

${ }^{41}$ Ibid., 268.

${ }^{42}$ LTTE, Reflections of the Leader, http://publications.uu.se/abstract.xsql?dbid=8404 (accessed May 12, 2008), 261.

${ }^{43}$ Eelam is thus shaped by the dead: "For the liberation of the motherland, many thousands of tiger heroes have battled and fell. We have buried these heroes by opening the breast of our heroic earth. They have not disappeared as lifeless corpses inside land. We have buried them as seeds of liberation in the lap of our mother. Mother history has embraced them. Many thousands of individual lives have entered the womb of history. Those lives have become the foetus, and have assumed a shape in course of time. They assume the form of independence of the nation. As
} 
The deaths of cadres bring Eelam closer in another way also. They replenish the struggle. We can best see this in the LTTE's commemorations of the dead. When the dead are commemorated through ritual ceremonies, the people's passion for the struggle is renewed. During the ceremonies, attendees experience a range of emotions which end in them recommitting themselves to the struggle. First, they are reminded that the dead died for them: "Our martyrs have died for the liberation of his land so that our people could live in our land with freedom, dignity and security." 44 Those attending the ceremonies feel sorrow and guilt for this: "As dogs with contempt / We existed oh Tiger / Only yesterday... / We forgot to guard / The soil that was mother... / Full / of empty talk / We were mouth... / As deed you came." ${ }^{45}$ Consequently the people express grief, wailing and sobbing: "Crying crying every day / The eyes have dried up. / Each waking day / Breaks with the hero's death." 46

The LTTE, however, also reminds the public that these occasions are not solely about mourning: "Today is not a day of mourning to weep for the dead nor a sad day to plunge into sorrow." ${ }^{, 47}$ Once again, experiences of suffering and grief (this time, over the loss of a cadre) are transformed: "Hearts exploding in sobbing, a sorrow / unbent. / Impossible to stop crying, such a / sorrow indeed and yet... / Relatives who beat their breast / trembling... / And yet...therein the germ of bravery / sprouting." 48 The deaths of cadres incite the living to renew their commitment to Eelam: "On this sacred day when we remember our martyrs who have sacrificed their lives for national freedom and attained historical immortality, let us pledge to commit ourselves to the cause for which thousands of our freedom fighters laid down their lives." ${ }^{49}$ The living thus strengthen their

the child of history, that independent nation called Tamililam will be born soon." LTTE, Reflections of the Leader, http://publications.uu.se/abstract.xsq1?dbid=8404 (accessed May 12, 2008), 294.

${ }^{44}$ Velupillai Prabhakaran, "English Translation of Martyrs Day Speech 1995" http://www.ltteps.org/?view=419\& folder=9 (accessed May 16, 2008).

${ }^{45}$ Kaci Anantan, "You Were Mouth, You Came As Deed," trans. by Hellmann Rajanayagam, "And Heroes Die," 134.

${ }^{46}$ Putuvai Irattinaturai, "Supporters of the Soil," trans. by Hellmann Rajanayagam, "And Heroes Die," 145 . The burial of cadres is referred to as a 'planting' and the dead cadres are referred to as seeds.

${ }^{47}$ Velupillai Prabhakaran, "English Translation of Martyrs Day Speech 1996," http://www.ltteps.org/?view=418\& folder=9 (accessed May 16, 2008).

48 Jeya, "He Guards the 'We', Having Destroyed the 'I' (Having Destroyed Himself, He Will Guard Us)," trans. by Hellmann Rajanayagam, "And Heroes Die," 135.

${ }^{49}$ Velupillai Prabhakaran, "English Translation of Martyrs Day Speech 1995" http://www.ltteps.org/?view=419\&folder=9 (accessed May 16, 2008). 
resolve to pursue Eelam, not wanting the efforts of the dead to be in vain. ${ }^{50}$ In this way, cadres' deaths bring the liberation of the nation closer.

The LTTE has developed a range of metaphors to capture how dying contributes toward the liberation of Eelam. Once again, the cadres are said to defeat death - as seeds that replenish the struggle ${ }^{51}$ and as historical architects that live on in history. ${ }^{52}$ They also defeat death because they live on in those who take up the struggle: "He exhaled national fire in slow breaths / and passed vigour and fierce velocity to Tamil cubs, / once timid and shy as mice, / And now lives as the sinew and blood / of armies of pouncing Tigers / pursuing national pride and peace and a national paradise." ${ }^{53}$

Violence and death are thus construed as liberating acts. In particular, dying is considered the ultimate articulation of liberation. When cadres die in battle, they demonstrate that their self is not shackled to worldly desires and objects. Furthermore, dying is the ultimate way in which a cadre can contribute to the nation's liberation. When cadres die they first, make strategic advances that could not be won otherwise, and second, they replenish their comrades' commitment to Eelam. We thus see how the LTTE mobilises a group identity through notions of liberation. Once again, the theme of becoming emerges - the Tamil nation is in a process of becoming. This involves not only attaining the mechanisms of a state, but also liberating and transforming individuals. Being Tamil is thus tied up with this process of transformation of liberation and transformation.

As we have seen, the LTTE most potently communicates this 'becoming' through a series of metaphors and images. When cadres die in this liberated way, they conquer death and become something else (history, seeds etc.). Several of the images suggest some sort of metaphorical immortality.

In some LTTE poems the cadres seem to live on in a more literal sense too. The dead are referred to as "children of god" or even gods. ${ }^{54}$ In one poem,

\footnotetext{
50 Velupillai Prabhakaran, “English Translation of Martyrs' Day Speech 1992, http://www.ltteps.org/?view=422\& folder=9 (accessed May 16, 2008).

${ }^{51}$ Trawick, "Reasons For Violence," 140.

52 Velupillai Prabhakaran, "English Translation of Martyrs' Day Speech 1993," http://www.ltteps.org/?view=421\& folder=9 (accessed May 16, 2008).

${ }^{53}$ Professor Kopan Mahadeva, "Martyr Thileepan," http://www.sangam.org/ANALYSIS/Thileepan_5_12_03.htm (May 16, 2008).

${ }^{54}$ Hellmann Rajanayagam, "And Heroes Die," $13 \overline{9}$.
} 
the dead watch the struggle from beyond the grave, showing no interest in the offerings laid before them: "For us there are no flowers... / For us there are no lamps... / For us there is not even this song... / For us there is only freedom / For us there is only the liberation of the / country." 55 In another poem, the dead influence the struggle from beyond the grave: "There in the flower world he creates / new works / A storm of rays spreading, the thunder / of a volcano." 56 The dead heroes thus seem to live on in a literal as well as a metaphorical sense.

Amongst other things, this notion of living on leads scholars to conclude that the Tamil public approach the tiyaki as deities. It is to this notion, the deification of the dead, that scholars impute the category of religion. I now turn to these scholarly claims and arguments.

\subsection{The Deification of the Dead: Evidence of Religion?}

Scholars draw on a wide range of evidence to suggest that Tamils attending LTTE rituals approach the dead as deities. Several argue that the LTTE has formatted its rituals in such a way that it subtly encourages the people to worship and propitiate the dead. In their analyses, scholars implicate the category of religion and draw conclusions which impact upon how they assess not only LTTE rituals and culture, but also the organisation itself. In these analyses, the meaning of religion is generally taken for granted. In the following discussion, I will investigate each scholar's position on the deification of the dead. Finally, I will suggest an alternative reading of the practice, focussing on the nadukal tradition.

Schalk, the first of our scholars, sees the deification of the dead as a religious act. But for Schalk, the people's deification of the dead does not compromise the LTTE's assertions of secularity, unless the LTTE officially endorses the practice. ${ }^{57}$ Schalk is thus not interested in trying to determine whether the Tamil public regard the mavirar as deities. He only wants to

\footnotetext{
${ }^{55}$ Putuvai Irattinaturai, "Supporters of the Soil," trans. by Hellmann Rajanayagam, "And Heroes Die," 146.

${ }^{56}$ Pantitar Vi. Parantaman, “A King Born From Humanity, ” trans. by Hellmann Rajanayagam, "And Heroes Die," 140.

${ }^{57}$ Schalk, "Beyond Hindu Festivals," 391. Schalk argues that the LTTE's secularity places them beyond traditional religion and also beyond religion in principle. For Schalk, the cult of martyrs would no longer be rationalistic (or beyond religion in principle) if the LTTE explicitly encouraged people to approach the dead as deities.
} 
establish how the LTTE officially refers to the dead: "What goes on in the mind of the individual is... another matter. We focus here only on the official ideology of the members of the movement." 58 Schalk maintains that the LTTE does not conflate the Great Heroes with deities: "Nobody expects the Great Hero to react to prayers and offerings. He is and remains dead. Furthermore, there is no concept of intercession... The flowers laid on the grave are according to the official norm commemorative tokens, and not offerings forcing the other party to reciprocal action." ${ }^{59}$

When Schalk argues that the LTTE does not officially deify the dead, he discusses the nadukal (literally, planted stone), the headstones in LTTE cemeteries. The term is crucial to how scholars construct their arguments about the deification of the dead. ${ }^{60}$ I will briefly digress and discuss the nadukal before returning to Schalk's argument.

The LTTE has revived the term nadukal from Sangam poetry. In the Sangam era, the nadukal referred to a stone that was erected to honour a dead hero. The hero was believed to reside within the stone and could be propitiated through offerings: "The spirit of the dead hero was identified with the stone and was worshipped and sacrificed to." ${ }^{61}$ The nadukal of the Sangam era were always erected on the outskirts of the village.

Schalk argues that the LTTE does not represent its nadukal as auspicious stones that house deified heroes. ${ }^{62}$ Instead, he claims that the term nadukal has been appropriated for other reasons. Like the Sangam nadukal, the LTTE's nadukal potently marks a territorial claim. ${ }^{63}$ Furthermore, the LTTE's nadukal, like the ancient nadukal, is public property. By calling the headstones nadukal, the LTTE has been able to present its funerals and graveyards as public events and spaces and thus distinguish its own rituals from kinship rituals. ${ }^{64}$ With this argument, Schalk affirms his position - the LTTE officially endorses only the commemoration, and not the deification of the dead. The LTTE does not

\footnotetext{
${ }^{58}$ Ibid., 398.

${ }^{59}$ Ibid., 398.

${ }^{60}$ Schalk, "The Revival Of Martyr Cults Among Ilavar," 183. The LTTE also refer to these stones by other names: camati and kallarai.

${ }^{61}$ Ibid., 183.

${ }^{62}$ Ibid., 185 .

${ }^{63}$ Ibid., 184.

64 Ibid.
} 
represent the nadukal as deified stones. Instead, the LTTE employs the term because it evokes a strong sense of territorial allegiance, and because it alludes to public ways of honouring the dead.

Unlike Schalk, Roberts focuses on how people participate in LTTE ceremonies. He claims that the LTTE is not completely in control of their cultural compositions - partly because people are free to interpret them as they please, and partly because the LTTE leaders, like all Tamils, have been conditioned by deeply ingrained Tamil or Hindu traditions. ${ }^{65}$ The LTTE leadership thus believes in its own productions, and is not completely aware of what makes its compositions so powerfully evocative. ${ }^{66}$

Because the LTTE is not completely autonomous in how it handles tradition, Roberts argues that we must not attend merely to what the LTTE say about their rituals. ${ }^{67}$ If we want to understand why these rituals resonate with the Tamil people and how they evoke the response they do, we must investigate the rituals themselves and their connections to Tamil tradition. ${ }^{68}$ When we do this, Roberts argues that we heed (what he calls) the "cosmological conditioning" of Tamils, "a grounding that goes back many centuries." 69

Roberts argues that LTTE rituals resemble entrenched Tamil practices. He suggests that these similarities (between LTTE rituals and Tamil traditions) predispose the Tamil public to approach the mavirar as deities. For Roberts, the deification of the dead is part of a greater argument about the regenerative quality of LTTE rituals: "Some Tamils (including some Tigers) may renew their faith and derive sakti from their sincere acts of devotion to the dead - dead who may even be regarded as deities., ${ }^{, 70}$ Roberts does not definitively argue that the Tamil public approach the dead as deities. He offers it as a suggestion only. ${ }^{71}$ In stronger terms, however, he argues that LTTE rituals possess a regenerative dynamic that also pervades traditional Tamil Hindu practices.

\footnotetext{
${ }^{65}$ Michael Roberts, "Saivite Symbols, Sacrifice, and Tamil Tiger Rites," Social Analysis 49:1 (2005): 68-9.

${ }^{66}$ Michael Roberts, "Filial Devotion in Tamil Culture and the Tiger Cult of Martyrdom," Contributions to Indian Sociology 30:2 (1996): 258.

${ }^{67}$ Roberts, "Tamil Tiger 'Martyrs,", 498.

${ }^{68}$ Ibid., 505. In another article, Roberts argues that this cosmological conditioning applies to both Hindu and Christian Tamils. Roberts, "Saivite Symbols, Sacrifice, and Tamil Tiger Rites," 69.

${ }^{69}$ Michael Roberts, "Tamil Tiger 'Martyrs,"” 505.

${ }^{70}$ Ibid., 503.

${ }^{71}$ Ibid., 505.
} 
In order to advance his suggestion that the dead are being deified, Roberts offers three pieces of evidence. ${ }^{72}$ All three involve Tamil or Hindu traditions: votive rituals, the nadukal and the tradition of burying sannyasins (ascetics). Roberts focuses particularly on the votive rituals in which Tamils partake. He suggests that the similarities between LTTE rituals and votive rituals induce Tamils to approach the dead cadres as deities, asking for their succour and blessing. Just as Tamils perform votive rituals to seek favour from the deities, so too do the Tamil public propitiate the mavirar while they pay homage, seeking arul (grace or divine presence) or darsanam ("the act of seeing and being seen by a deity, an exchange of vision, an auspicious sight, or a blessing deriving from the gaze of a deity"). ${ }^{73}$

Roberts also refers to the nadukal to support his claims about the deification of the dead. Roberts argues that when the LTTE uses the term nadukal, it either deliberately or unintentionally suggests that its nadukal, like the Sangam nadukal, houses a deified hero. ${ }^{74}$ While Schalk refers to how the LTTE officially represents the nadukal tradition, Roberts thus discusses the evocative power of the term nadukal.

The final piece of evidence that Roberts offers pertains to ascetics. Roberts connects the Hindu tradition of burying ascetics to the LTTE's decision to bury its dead. As explained earlier, the LTTE has chosen to bury its mavirar, a practice that departs from the Hindu tradition of cremating the dead. While cremation was and is the norm in Hindu society, Roberts alerts us to how sannyasins (ascetics) were traditionally buried. "Sannyasins are a special category of persons: the path to the status of exemplary ascetic involves the burning away of one's former life, a form of death in other words. So sannyasins are buried and their shrines are regarded as a locus of divine power." $" 75$ Traditionally, ascetics were buried and then revered as supernatural beings that could effect change from beyond the grave. Once again, Roberts demonstrates how a Tamil practice converges with the LTTE's practice. He argues that the LTTE induces the Tamil people to approach the dead as deities, when it refers to

\footnotetext{
${ }^{72}$ Roberts also uses all three pieces of evidence (alongside other evidence) to support his claim that LTTE rituals have a regenerative dynamic.

${ }^{73}$ Roberts, "Pragmatic Action and Enchanted Worlds," 91-2.

74 Roberts, "Tamil Tiger 'Martyrs," 500.

${ }^{75}$ Ibid., 499.
} 
its dead - dead that are buried - as ascetics. Roberts thus conducts a threefold analysis where he elicits similarities between LTTE rituals and Tamil traditions. Based on this he concludes that the mavirar are "perhaps deified dead like those reposing in nadukal in the Tamil past."

Roberts argues that the deification of the dead, like the regenerative dynamic, is evidence that the LTTE's symbolism and rhetoric has non-rational, enchanted facets. The connection between religion and the 'enchanted' is not always clear in Roberts' writings. Sometimes Roberts connects the enchanted to votive rituals or Hindu practices, and other times to anything which holds some kind of symbolic or non-rational meaning. ${ }^{77}$ While Roberts is ambiguous about what the enchanted is, he is clear that the enchanted can and does coexist alongside the rational facets of LTTE practice. The deification of the dead is evidence of this. As mentioned in the Introduction, Roberts uses this analysis to claim that the LTTE resembles Al Qaeda. Both organisations draw on a combination of enchanted sensibilities and rational considerations.

Natali, the third scholar whom I discuss, has conducted fieldwork in the North-east and has interviewed LTTE cadres and members of the Tamil public. She argues that the Tamil people regard the tuyilum illam as temples and the mavirar as deities. "When I asked if Tuillum Illam were cemeteries, all the people replied saying 'How can you say such a thing? Tuillam Illam are temples, gods are seeded [buried] there." ${ }^{78}$ Natali assumes that this interpretation (that the dead are deities and the tuyilum illam are temples) is incongruous with the LTTE's interpretation of the graveyards as secular places. Furthermore, she assumes that the LTTE is aware, as she is, of this discrepancy. According to Natali, the LTTE leaders choose not to reject this religious interpretation "because it allows them to include the tuillum illam in the mainstream of Hindu tradition." ${ }^{79}$ Elsewhere she says: "I would argue that the attitude of the LTTE with regard to the identification of the Maaveerar with gods emerges as an ambiguous but necessary one...the idea that Tuillum Illam are temples where the

\footnotetext{
${ }^{76}$ Roberts, "Pragmatic Action and Enchanted Worlds," 92.

${ }^{77}$ Ibid., 94, 87. At one point, Roberts discusses how the LTTE uses jasmine flowers in their ceremonies. He claims that this is evidence of the enchanted.

${ }^{78}$ Natali, "Building Cemeteries, Constructing Identities. Funerary Practices and Nationalist Discourse Among the Tamil Tigers of Sri Lanka," http://www.basas.ac.uk/conference05/natali,\%20cristiana.pdf (accessed April 26, 2008) 79 Ibid.
} 
Maaveerar/gods are worshipped allows the LTTE to avoid a break with the religious feelings of civilians, guaranteeing popular consent to the new project of nation-building., $\$ 0$

Of the three scholarly analyses, Natali's conclusions worry me the most. She claims that the LTTE does not dissuade the people from this 'religious' interpretation, because it enables the organisation to represent burial as an acceptable, Tamil practice. ${ }^{81}$ Natali thus suggests that the leaders of the LTTE turn a blind eye to this religious interpretation, knowing that it contravenes the organisation's secular proclamations. One might pursue her line of reasoning further and argue that the LTTE is not serious about its secularity. But is it necessary to derive such conclusions? If people are propitiating the dead, this certainly adds something to how the LTTE officially presents the rituals. But does it necessarily follow that the LTTE really see it as a divergence?

When all three scholars analyse the deification of the dead, they apply the categories of religion and the secular as self-evident, descriptive categories. Schalk assumes that the deification of the dead is an inherently religious act that would compromise the LTTE's secularity if the organisation officially endorsed the practice. On the other hand, Roberts argues that the deification of the dead is an enchanted practice. Because LTTE rituals implicitly encourage the practice, the LTTE should not be understood (from an analytical perspective) as a secular organisation. Natali, like Schalk, also sees the deification of the dead as an inherently religious practice. Unlike Schalk, however, she argues that the people's deification of the dead compromises the LTTE's secularity because the LTTE ignores the practice.

These arguments all assume that religion is a self-evident phenomenon when, in fact, it is defined and redefined in different contexts. When we expose how these arguments rely upon conventional understandings of religion and the secular we begin to realise the true limitations of these scholarly analyses. In sum, the three scholars inform us of only two things: that the Tamil public possibly approach the dead as deities; and that the LTTE does not officially or explicitly refer to the dead as deities. While these scholars assess the deification of the dead as a religious or enchanted practice, I want to investigate how the

\footnotetext{
${ }^{80}$ Ibid.

${ }^{81}$ Ibid.
} 
deification of the dead might be involved in the LTTE's representation of a secular, national identity.

\subsection{Deification of the Dead: An Alternative Reading}

Before I advance an alternative reading, I want to discuss three key issues pertaining to the deification of the dead which highlight where further research needs to be done.

First, I am not completely convinced that the Tamil public definitely approach the dead as deities. More research needs to be conducted into whether Tamils regard the mavirar as deities who can interact with and influence the living. Second, we need to better understand what the LTTE mean when they describe their cult of martyrs as a secular one. Unfortunately, I have no independent statements from the LTTE which explain how and why its cult of martyrs is secular. Consequently, I have had to rely on reported statements from scholars. Because scholars assume that the meaning of the secular is self-evident, they do not specifically focus on what the LTTE's declarations of secularity mean. Consequently, they confuse their own analysis of the LTTE's secular proclamations with the actual proclamations. Third, we require more information about how the LTTE regards the deification of the dead. Does the organisation perceive the practice as a threat to its secular proclamations? Does it therefore avert attention from the practice? The answers which emerge can be used to determine how the LTTE represents the secular. For example, we might discover that the LTTE is aware that the international community would not regard the practice as a secular one. We might thus find that the LTTE, influenced by the opinion of the international community, regards the practice as a threat to its secularity. If this is the case, we can conclude that the LTTE's representations of the secular are influenced by how powerful, Western secular nations understand what it means to be secular.

As I do not know what the LTTE's position is on the factors presented above, I will assume a possible position and then propose interpretations based on it. I assume that there are Tamils who approach the dead mavirar as deities. I also postulate that the LTTE's notion of the secular does not preclude the deification of the dead. Consequently, I assume that the deification of the dead 
does not impinge on the LTTE's declarations of secularity. From these premises I offer three readings. In the first two, I suggest how the deification of the dead might be represented as a secular practice, and in the last, I demonstrate how the deification of the dead might be represented as a religious practice which enables the people to practise their religious freedom.

These suggestions are obviously contradictory. But the point of the exercise is not to provide definitive conclusions, but rather to suggest alternative ways of approaching the deification of the dead. In doing so, I follow Asad's exhortation to repudiate the categories of religion and the secular as they are conventionally understood. I do not assume that the deification of the dead is an inherently religious practice. Instead, I analyse how the practice is involved in representing a secular, national identity. ${ }^{82}$

My first suggestion (that the deification of the dead may be represented and mediated as a secular practice) is connected to Schalk's observation that the LTTE is selective in how it uses the nadukal concept. Schalk shows how there are significant differences between how the LTTE's concept of the nadukal is employed by the LTTE and the nadukal of the Sangam era. But the LTTE has been selective not only in how it applies the term, but also in its choice of the concept.

The LTTE has derived the term nadukal from Sangam literature. ${ }^{83}$ Historians as well as nationalists refer to this literature when they discuss Tamil culture and customs during the Sangam era. The Sangam era is depicted by the LTTE and others as a pre-caste, pre-religious era in Dravidian history ${ }^{84}$ where egalitarian, secular values flourished. "The argument that the Sangam society was secular and caste-free and the social and religious divisions among the present day Tamils are due to the 'Aryan' influence is a favourite one advanced by Tamil nationalist groups in Tamil Nadu and the Tigers." 85 Given that the nadukal is drawn from Sangam literature, it is possible that the LTTE represents

\footnotetext{
${ }^{82}$ My investigation is highly speculative. I cannot speak or read Tamil which makes it difficult for me to carry out any conclusive examination. I thus qualify all my conclusions as suggestions only!

${ }^{83}$ The Purananuru anthology (discussed in the previous chapter) is one anthology within this body of literature.

${ }^{84}$ Cheran, The Sixth Genre, 20. Cheran argues that Sangam society cannot be said to be caste free except perhaps for in a relative sense, "relative to early north Indian society as evidenced by literature and the later Tamil society."

${ }^{85}$ Ibid.
} 
the worship of the dead at the nadukal as a non-religious act drawn from the prereligious Sangam era. The practice may be considered a cultural, rather than a religious practice.

There is a second way in which the practice might be represented as a secular one. If we leave aside its connection to the Sangam era, we might argue that the deification of the dead is represented as a religious idiom transferred into a secular context. Just as Western nationalists reposition sacrificial, Christian vocabulary in a secular context, so too do the LTTE reformulate a Saivite idiom (the worship of the dead as deities) within a new context. Western secular nationalists do not see this vocabulary as compromising their secularity. Similarly the people's deification of the dead may be represented and mediated as a secular practice that has religious origins but no religious meaning.

Because we as Westerners do not associate the deification of the dead with secular ideals, it does not mean that the LTTE cannot represent and mediate the practice as a secular one. If we recall Asad's example of France, Britain and America, the secular can be represented in diverse ways. The deification of the dead certainly adds another dimension to the LTTE's commemorative rituals. But the LTTE need not necessarily turn a blind eye to the practice. Instead, the organisation may represent the deification of the dead as a secular practice which complements (rather than contradicts) its official commemorations.

My third proposition is that the deification of the dead is represented and mediated as a religious practice through which the people express their religious freedom. I offer this suggestion based on a statement which Schalk makes: "It is not unusual to divinise a dead prominent person in South India, and in some cases a living person also. A dedication of one's person to a divinised person is natural... Many of them [Sri Lankan Tamils] are (just normal) Caivas...What else could they do than express their grief in a Caiva idiom?" 86

Here, Schalk does discuss the deification of the dead as a Saivite practice. Perhaps, then, the deification of the dead is represented as a Saivite practice through which Saivites express their religious freedom. The LTTE has long proclaimed that the Tamil people are at liberty to practise their own religious traditions. For the LTTE, being religious (whether Hindu or Christian) is not

\footnotetext{
${ }^{86}$ Schalk, "Historisation of the Martial Ideology of the Liberation Tigers of Tamil Ealam," 66.
} 
antithetical to being Tamil. In this case, the deification of the dead is not part of the LTTE's official nadukal concept. But the LTTE does not repress or artfully ignore the practice, even though the practice may diverge from its focus on commemorating the dead. Instead the practice is represented and understood as an expression of the people's religious freedom - a representation which is entirely in keeping with the LTTE's secularism.

I have offered three readings of how the deification of the dead could be understood alongside the LTTE's secular proclamations. On the one hand, I have suggested how the deification of the dead might be regarded as a secular practice, and on the other, I have delineated how it might be represented and mediated as an expression of the people's religious freedom, guaranteed to them through the LTTE's policy of secularism. Either way, the practice has a strong egalitarian emphasis. The deities are fellow Tamils who have died fighting for the realisation of Eelam. This powerfully reinforces the horizontal comradeship which characterises all nationalist discourses. The deification of the dead also underlines the liberating quality of death which we identified earlier. Dying unleashes a powerful transformation where the dead liberate the self, bring Eelam closer, replenish the cause, and possibly influence the struggle from beyond the grave. The theme of becoming and transformation emerges once again. When scholars analyse the deification of the dead as a religious practice, they miss how the practice complements the LTTE's depiction of death and violence as creative, transformative, liberating acts. In other words, they miss this potent sense of becoming which is integral to how the LTTE mobilises a group identity. 


\section{Conclusion}

\section{Exploring Becoming and Suggestions for Future Research}

This study has been structured by two interrelated interests: the religious difference between Sinhalese and Tamil nationalisms and the LTTE's representations of national identity. With regards to the first issue, I argued that the LTTE's nationalism does have content that we might anachronistically call religious. But this content differs in important ways from the Buddhist rhetoric and symbols of the Sri Lankan government. The religious difference thus does not pertain to the content itself but to how Sinhalese and Tamil nationalists represent the categories of religion and the secular through this content. In this study, I also discussed how scholars implicate the categories when they assess Sinhalese, and more particularly Tamil nationalism. When scholars apply the categories of religion and the secular in self-evident ways, they often ignore how Sinhalese and Tamil people perceive the government and the LTTE. How useful is it to argue that the LTTE's nationalism has religious facets, when LTTE cadres see their movement as a secular one? "When we die, we have no religion."

With regards to the second issue, I argued that the LTTE mobilises a group identity through a variety of claims, traditions and experiences. I explored these mobilisation tools when I discussed two LTTE discourses: history, and violence and death. I focussed on how the LTTE mobilises a group identity through claims, practices and arguments that are represented as being secular; reworked Tamil traditions and shared experiences of suffering and liberation. As I discussed these features, it became clear that these discourses emphasise experiences of becoming and transformation. The LTTE promises to radically transform individuals (who partake in the struggle), Tamil society (caste and dowry practices, and gender relations) and finally, Tamil culture (Vellalar values and Tamil martial traditions). The LTTE thus acknowledges that Tamil identity is in a state of change. This sense of becoming is an important facet of how the LTTE mobilises a group identity; being part of this current process of transformation is an important part of what it means to be a Tamil.

\footnotetext{
${ }^{1}$ Trawick, "Reasons for Violence," 155.
} 
As I have discussed, this focus on transformation is quite extraordinary. It enables the LTTE to both draw on and explicitly diverge from Tamil traditions. Furthermore, it enables the LTTE to celebrate this divergence. We expect nationalists to choose and modify tradition. We do not, however, expect nationalists to explicitly celebrate this process of selection and revision. Nationalists usually appeal to the essence of a tradition or culture, claiming that they are stripping tradition of all accretions, of all that is not truly culture. The LTTE sometimes advances this claim. For the most part, however, it explicitly celebrates its revision of and divergence from tradition.

The LTTE's emphasis on becoming and transformation manifests in other equally unexpected ways. For example, the LTTE promises to transform the people's suffering in the post-colonial past; it thus emphasises a strikingly recent history. In doing so, the LTTE implies that Tamil identity is grounded in the recent past. Once again, this is quite extraordinary. We do not expect nationalists to locate national identity in recent events. Instead we expect nationalists to argue that the nation, and therefore national identity, extend back to the furthest reaches of time. The LTTE's emphasis on becoming is thus an unusual, but important part of how the LTTE mobilises a group identity. Scholars miss this insight, in part, because they depend on conventional understandings of religion and the secular.

Here, in the conclusion, I will elaborate on the LTTE's process of 'becoming.' Finally, I will suggest how future studies on the LTTE or Sri Lanka might draw on the conclusions arrived at in this study. Here, I return to Asad's theory.

\subsection{Tamil Identity: A Secular State of Becoming}

Given that the LTTE does not seem to posit a cultural essence, we might ask how the LTTE justifies the transformation that it promises. The following extract from an LTTE text gives us some insights into this question:

The monumental growth in knowledge and the resulting global outlook is taking humanity into a new era. Ideas, views and philosophies are changing in tandem with this growth in knowledge and this is resulting in changes in society. Yet within the Sinhala nation, there is little change in its ideas and philosophies... The Sinhala nation remains mislead by the 
mythical ideology of the Mahavamsa and remains trapped in the chauvinistic sentiments thus created. ${ }^{2}$

The LTTE suggests that its transformation of society (and all that it entails) is based on enlightened choices. This is how the LTTE explains its selection and revision of Tamil tradition; it retains and even betters all that is enlightened, and discards all that is backward.

In the quote above, we see the LTTE imply that the Sinhalese are blinded by a fanatical, religious ideology, an ideology which prevents them from making enlightened choices. The LTTE thus connects its transformation, its process of becoming, to enlightened, secular decisions and arguments. We have seen these connections elsewhere in this study. For example, in Chapter Four, we saw how the LTTE asserts its secularity when it presents its violence (and the transformation it entails) as just, rational and necessary. In this way, the LTTE connects its violence (and the transformation which its violence brings) to secular, enlightened choices.

The LTTE also presents its transformation of Tamil society as being predicated on enlightened choices. As I mentioned in Chapter Two, the LTTE wants to liberate the nation not only from government oppression, but also from oppressive cultural traditions and practices: "Only by making fundamental changes in social relations, we [sic] can get rid of oppressive forms prevalent in society and establish firmly equality and social justice."3 As discussed in Chapter Two, the LTTE has challenged the hegemony of the Vellalars. It has banned caste and dowry practices, which Vellalars have long employed to assert their elite status. The LTTE severely punishes those who defy such interdictions. ${ }^{4}$ Like liberation from government oppression, this social liberation thus emanates "from the barrel of a gun."

The eradication of gender discrimination is another part of the societal transformation that the LTTE promises. Once again, this transformation is presented as an enlightened choice: "Oppression of women is a complicated social problem; social cruelty has deep entrenched roots in our cultural life from

\footnotetext{
${ }^{2}$ Velupillai Prabhakaran, "English Translation of Martyrs' Day Speech 2006," http://www.ltteps.org/?view=1776\&folder=9 (accessed May 16, 2008)

${ }^{3}$ LTTE, Reflections of the Leader, http://publications.uu.se/abstract.xsql?dbid=8404 (accessed May 12, 2008), 290.

${ }^{4}$ Schalk, "Women Fighters of the Liberation Tigers in Tamil Ilam," 169.

${ }^{5}$ Hellmann Rajanayagam, "The Jaffna Social System," 277.
} 
antiquity. Our movement is determined to throw out this social injustice root and branch." ${ }^{\prime 6}$ Some scholarly work suggests that the LTTE has been inconsistent in how it has represented the role of women. ${ }^{7}$ Previously, the traditional roles ascribed to women have been represented as an integral part of Tamil tradition which should be retained. More recently, however, the LTTE has repudiated many traditional practices towards women, asserting that these practices are oppressive.

We have thus seen how the LTTE emphasises a secular state of becoming - not only through experiences of suffering and liberation, and reworked Tamil tradition, but also through the societal transformation that it promises. In this process of transformation, the Tamil people are refined along with Tamil society, culture and tradition: "Our people have been (like gold) purified in the smithy of Sinhala communal suppression; they have faced the extreme heat of state terrorism; they are used always [sic] to carry the cross of suffering; they live, lying down and sleeping under the shadow of death." 8

In this study, I have argued that scholars neglect this sense of becoming that pervades LTTE discourses. ${ }^{9}$ This oversight occurs at least partly because they are fixated on the categories on religion and the secular. Hellmann Rajanayagam, Roberts and Natali apply self evident definitions of religion to the LTTE's nationalism. In particular, they miss how the LTTE represents itself as selecting and shaping Tamil tradition.

Schalk does assert that the LTTE is autonomous in how it employs tradition. Unfortunately, he words this as an analytical statement. He argues that the LTTE picks and chooses aspects of tradition, consequently it is not influenced by the traditions on which it draws: "These producers of martial

\footnotetext{
${ }^{6}$ LTTE, Reflections of the Leader, http://publications.uu.se/abstract.xsql?dbid=8404 (accessed May 12, 2008), 290.

${ }^{7}$ Hellmann Rajanayagam, The Tamil Tigers, 69-70. According to Hellmann Rajanayagam, the LTTE's position on the role of women in the struggle has changed considerably: "While in former years, their criticism consisted mainly in deriding the dowry system for the burden it puts on brothers and in denouncing the rape of Tamil girls by the Sinhalese army because this renders them unfit for marriage to respectable Tamil men, remarks have become somewhat more... 'heroic' now... in stark contrast to a release of the Voice of Tigers some years ago, where the contribution of the women fighters seemed to consist not least in dancing Bharatnatyam in battle dress!"

${ }^{8}$ LTTE, Reflections of the Leader, http://publications.uu.se/abstract.xsql?dbid=8404 (accessed May 12, 2008), 279.

${ }^{9}$ Roberts does identify this sense of becoming when he discusses the regenerative dynamic that pervades LTTE discourse.
} 
concepts in the Office of Great Heroes seem to be sovereign and not predisposed and predetermined in their approach to the cultural heritage. They are not 'outpourings' of it." ${ }^{10}$ Hellmann Rajanayagam and Roberts argue against Schalk, claiming that the LTTE is influenced by Tamil traditions in ways that its leaders are not aware of.

Of course, Hellmann Rajanayagam and Roberts are right. The LTTE is influenced by Tamil traditions which shape Tamil people's ontologies and epistemologies. And the organisation may not always be aware of these influences. What Hellmann Rajanayagam and Roberts miss, however, is the way in which the LTTE claims to handle tradition. While the LTTE might not be entirely autonomous in how it employs tradition (as Schalk claims it is), it nonetheless represents itself as handling Tamil tradition in an autonomous, explicitly selective way.

\subsection{Suggestions for Future Research: Returning to Asad}

From the foregoing discussion, we can see that Asad's notion of representation is useful for discussing not only the categories of religion and the secular, but also the notion of tradition. Future studies must thus distinguish how the LTTE represents tradition from how it is influenced by tradition. This is one way in which future research on the LTTE would benefit from an Asad-based approach.

Asad's analytical approach can be applied to the Sri Lankan situation in many other ways that I have been unable to cover in this thesis. As I suggested in the previous chapter, I believe that further research needs to be done to determine how the LTTE understands its declarations of secularity. This is an important part of how the LTTE represents the secular. I also believe that a more comprehensive comparative study between Sinhalese and Tamil nationalisms is required. Perhaps future studies might be done which focus on the explicitly secular character of Tamil nationalism and the implicitly religious character of Sinhalese nationalism.

In addition to this, I think a comparative study must examine the key sensibilities which underpin Sinhalese and Tamil nationalisms. Here I return to

\footnotetext{
${ }^{10}$ Schalk, "Historisation of the Martial Ideology of the Liberation Tigers of Tamil Ealam (LTTE)," 63.
} 
Asad's reconstructed secular. For Asad, the reconstructed secular is characterised by particular modern sensibilities which emphasise a sense of this-worldliness and an apprehension of the real.

Asad makes a valuable point through his reconstructed secular: while modern discourses, institutions and organisations claim to depict the world as it truly is, they actually present another conception of the world. In other words, modern discourses do not really apprehend the world as it is, although the claim that they do is an important part of how they are structured. We can yield interesting insights when we approach the modern depiction of the world as just that - one possible conception of the world. I think there are two possible applications of this for future research on Sri Lanka. First, we can specifically examine how modern sensibilities structure LTTE discourses. And second, we can more generally compare how Sinhalese and Tamil nationalisms draw on these modern sensibilities.

I would like to provide one example of how we might analyse LTTE practices in such a way. This suggestion provides a counterpoint to an argument advanced by Michael Roberts. After I have given an overview of Roberts' argument, I will provide this alternative analysis that attends to modern sensibilities, rather than Tamil tradition.

Roberts claims that LTTE rituals, like Tamil traditions, have a regenerative quality. As part of his argument, he identifies how the people's suffering is transformed during LTTE rituals: "Grief and suffering are not the only motifs that run through these ceremonies and their contexts... the homage to the dead on 27 November every year since 1989 is a gathering of strength and an act of renewal. It mobilises, remembers, respects, legitimizes, transcends, and inspires." 11 Roberts argues that this regenerative dynamic arises out of similarities between Tamil traditions and LTTE ceremonies; the Tamils who participate in LTTE ceremonies are renewed in much the same way as those who partake in traditional rituals.

Roberts classifies this regenerative dynamic as an enchanted facet which coexists alongside the rational facets of LTTE practice (strategic thinking etc). ${ }^{12}$ While the enchanted facets concern symbolic meanings and intangible

\footnotetext{
${ }^{11}$ Roberts, "Saivite Symbols, Sacrifice, and Tamil Tiger Rites," 82-3.

${ }^{12}$ Roberts, "Tamil Tiger 'Martyrs,"” 494.
} 
possibilities, Roberts seems to assume that the rational facets of LTTE practice apprehend the world as it is. He does not, however, consider whether the modern, so-called rational facets of LTTE practice also reflect a particular conception of the world.

I would argue that the regenerative dynamic (which Roberts attributes to Hindu concepts and rituals) could easily be attributed to modern sensibilities which Asad describes as secular (in the reconstructed sense). I will present some of the modern, secular sensibilities that Asad identifies pertaining to pain and suffering, agency and resistance, and history and empowerment. I will show how we can explain the regenerative dynamic that Roberts identifies through these modern, secular sensibilities.

In the modern era, new sensibilities (which Asad identifies as secular) arose around pain: "Pain was increasingly regarded as having an origin entirely internal to a mechanistic world, and therefore susceptible only to the action of elements in that world." 13 This has retrospectively been referred to as the secularisation of pain. But Asad argues that those who classify this new conception of pain as 'disenchanted' or 'secular' fail to attend to the presence of new patterns of sensibility and different ways of objectifying pain. ${ }^{14}$ In the secular ontological world, pain is perceived as an external force that represses and subjugates the individual. ${ }^{15}$ In the form of suffering, it is also a human condition that secular agency seeks to eliminate universally. ${ }^{16}$ In secular discourse, pain is thus intimately connected to agency.

Asad argues that the secular formulation of agency is not a natural category (a way of cognising the real), although academic and medical discourses treat it as such. ${ }^{17}$ The secular formulation of agency is only one depiction of what it means to be an agent; and, like other depictions, it too makes possible different ways of acting and being. In the secular formulation,

\footnotetext{
${ }^{13}$ Asad, Formations of the Secular, 46.

${ }^{14}$ Ibid., 46-8.

15 Ibid., 71.

${ }^{16}$ Ibid., 67.

${ }^{17}$ Ibid., 73, 68. "Even in the growing field of medical anthropology, where innovative work has given us a cultural understanding of health and disease, the standard meaning of agency is taken too much for granted. The sick body is often represented no differently from the healthy body in that for both resistance to power is the form that agency typically takes. I find such views troubling because they attribute individual agency to the sick body translating all its states and movements directly into 'dissent."”
} 
individuals are considered either victims or agents. ${ }^{18}$ While external forces like power and pain oppress the individual, the individual, as an agent, has a responsibility to resist subjugation, become powerful and overcome suffering. Agents must strive to empower themselves and replace pain with pleasure. As a form of agency, resistance to pain or power is a response to an implied metaphysical question: "What should human beings do to realise their freedom, empower themselves and choose pleasure (given that they are essentially free, naturally sovereign and given to their own desires and interests)?"19

The LTTE's discourse on violence and death seems to conform strikingly to these formulations of suffering and pain, and agency and resistance. The LTTE constitutes and explains its cadres' agency in relation to the people's historical and continued suffering. LTTE cadres are the agents and the people are the victims whose suffering they are fighting to eradicate. This is why the deaths of LTTE cadres are meaningful in a way that civilians' deaths are not. Even though both LTTE cadres and Tamil civilians die at the hands of the government, the LTTE's deaths are empowered, agentive acts, whereas the deaths of the Tamil people are in vain. Through their acts of violence and death also, cadres empower themselves and thus transform suffering. Because they die in an empowered, agentive way, death cannot conquer LTTE cadres.

Asad connects agency to history (or what I called Enlightenment History in Chapter Three). In this regard too, we can see how LTTE discourses might be shaped by modern, secular sensibilities. Secular, modern ideas about agency are tied to a progressivist history; individuals and nations journey towards truth and freedom when they act as agents, realising their freedom, empowering themselves and choosing pleasure. In the context of the nation state, men and women of each national society make and own their history. ${ }^{20}$ We can thus see that the cadres' deaths are considered agentive not only because they are evidence of resistance or empowerment, but also because they are connected to history making. This explains why the LTTE discuss the cadres' contribution as a historical one.

\footnotetext{
${ }^{18}$ Ibid., 79.

${ }^{19}$ Ibid., 71.

${ }^{20}$ Ibid., 192-3.
} 
The regenerative dynamic which Roberts attributes to Tamil, Hindu traditions and practices can thus be explained by these modern sensibilities. When living cadres (and members of the public) attend LTTE ceremonies, they overcome their experiences of suffering (the loss of comrades), becoming agents who are inspired to go forth and make their own contribution to Eelam, a contribution which is depicted as a historical achievement. This explanation does not necessarily disprove Roberts' argument. LTTE rituals may very well imply notions of regeneration. What I want to suggest, however, is that we must recognise that modernity presents yet another conception of the world and is thus characterised by its own ontological and epistemological assumptions. When we recognise this we can assess how modern sensibilities might be involved in LTTE practices.

When we attend to the sensibilities which underpin discourses as well as the representations of religion and the secular which these discourses promulgate, we obtain important insights into the evocative power of the discourses. This point brings me to my second suggestion for how Asad's reconstructed secular might be useful for future research.

We can compare Sinhalese and Tamil nationalisms not only in terms of how they represent the secular, but also in terms of the sensibilities and concepts which underlie them. When we attend to how Sinhalese and Tamil nationalists represent the categories of religion and the secular, we identify key differences between them. But when we pinpoint how Sinhalese and Tamil nationalists draw on modern sensibilities, we elicit some key similarities between them.

When Asad characterises nationalism as secular, he points to an interesting insight about nationalism which stands regardless of whether we agree with his proposition that nationalism is inherently secular. Nationalism requires both a universal discourse as well as other particularising discourses. On the one hand, nationalisms appeal to both the universal discourse of nations (which Asad would say is an implicitly secular one), which contains an overlap between what we (anachronistically) call religion and the secular. For example, the nation arouses sentiments often associated with religious sensibilities, and yet, it is grounded in this world. But alongside this universal discourse, nationalisms must also cultivate particularising discourses which guarantee the uniqueness of the nation. It is these particularising discourses that can be 
represented as either secular or religious. Both the Sri Lankan government and the LTTE must use history and shared experiences to mobilise a national identity. They differ, however, in how they choose to represent the categories of religion and the secular within their particularising discourses. In this way, we can say that Sinhalese and Tamil nationalisms rhyme. ${ }^{21}$ They comprise both sameness and difference - and this difference concerns how the categories of religion and the secular are articulated in relation to national identity.

This Asad based approach, which I have outlined above, is useful not only for studying Sri Lanka, but any situation where representations of religion and the secular are involved. Using Asad's ideas, we can redirect our inquiry. Rather than determine whether an object is inherently religious or secular, we can focus on a number of other inquiries: how do particular representations of religion and the secular shape people's identities and their discourses? What are the genealogies of particular terms? Has the grammar of particular concepts changed? And if so, what does this tell us about representations of religion and the secular? What sorts of sensibilities and concepts characterise the discourses being examined?

This analytical framework opens up new, exciting possibilities for research on nationalism, and more particularly on nationalism in Sri Lanka. It enables us to take the LTTE's declarations of secularity seriously, assessing the implications they have for Tamil identity in Sri Lanka. When we focus on how religion and the secular are represented, we elicit rich insights, otherwise only partially uncovered or entirely overlooked. Such an analysis enables us to appreciate how and why the LTTE's depiction of Tamil identity resonates deeply amongst the Tamil public. Such a framework thus enables us to understand how the LTTE, only one of many militant groups, has risen to power against all odds and won the support of many Tamils belonging to different castes, regions and socio-economic groups across the island of Sri Lanka.

\footnotetext{
${ }^{21}$ Ismail, Abiding by Sri Lanka, xv, 85-6. Ismail uses the term 'rhyme' to describe two approaches, positions or objects which hold both sameness and difference. "rhyme in the OED: "Agreement in the terminal sounds of two or more words or metrical lines, such that... the last stressed vowel and any sounds following it are the same, while the sound or sounds preceding are different."”
} 


\section{Bibliography:}

Amunugama, Sarath. "Ideology and Class Interest in One of Piyadasa Sirisena's Novels: The New Image of the 'Sinhala Buddhist' Nationalist." In Sri Lanka

Collective Identities Revisited Volume I, edited by Michael Roberts, 335353. Colombo, Marga Institute, 1997.

Asad, Talal. Formations of the Secular: Christianity, Islam, Modernity.

California:

Stanford University Press, 2003.

Balasingham, Adele Ann. Women Fighters of Liberation Tigers. Jaffna: LTTE, 1993.

Balasingham, Adele. The Will to Freedom: An Inside View of Tamil Resistance. Mitcham: Fairfax Publishing Ltd, 2003.

Balasingham, A.S. Liberation Tigers and Tamil Eelam Freedom Struggle. n.p: LTTE, 1983.

Bass, Daniel. Landscapes of Malaiyaha Tamil Identity. Marga Monograph

Series on Ethnic Reconciliation 8. Colombo: Marga Institute, 2001.

Bastin, Rohan. "The Authentic Inner Life: Complicity and Resistance in the Tamil

Hindu Revival." In Sri Lanka: Collective Identities Revisited Volume I, edited by Michael Roberts, 385-438. Colombo: Marga Institute, 1997.

Bush, Kenneth D. The Intra-Group Dimensions of Ethnic Conflict in Sri Lanka: Reading to Read between the Lines. Hampshire: Palgrave Macmillan, 2003.

Cheran, R. The Sixth Genre: Memory, History and the Tamil Diaspora Imagination,

Marga Monograph Series on Ethnic Reconciliation 7. Colombo: Marga Institute, 2001.

Daniel, E. Valentine. Charred Lullabies: Chapters in an Anthropography of Violence.

Princeton: Princeton University Press, 1996.

Daniel, E. Valentine. "The Semeiosic Economy of Fear." Social Research 71:4 (2004): 1087-1110.

De Votta, Neil. Blowback: Linguistic Nationalism, Institutional Decay and Ethnic

Conflict in Sri Lanka. Stanford, Stanford University Press, 2004.

Dharmadasa, K.N.O. Language, Religion and Ethnic Assertiveness: The Growth of

Sinhalese Nationalism in Sri Lanka. Ann Arbor: University of Michigan Press,

1993.

Dissanayake, T.D.S.A. War or Peace in Sri Lanka. Mumbai: Popular Prakashan, 2005.

Emmanuel, S.J. Let My People Go: The Tamil Struggle for Survival and Self Determination in Sri Lanka. Germany: Tamil Catholic Chaplaincy, 1997.

Fuglerud, Oivind. Life on the Outside: The Tamil Diaspora and Long Distance Nationalism. London: Pluto Press, 1999. 
Fuglerud, Oivind. "Time and Space in the Sri Lanka-Tamil Diaspora." Nations and

Nationalism 7:2 (2001): 195-213.

Ghosh, Partha S. Ethnicity versus Nationalism: The Devolution Discourse in Sri Lanka. New Delhi: Sage Publications, 2003.

Gombrich, Richard, and Ganath Obeysekere. Buddhism Transformed: Religious Change in Sri Lanka. Princeton: Princeton University Press, 1988.

Gunasingam, Murugar. Sri Lankan Tamil Nationalism: A Study of its Origins.

Sydney: M.V. Publications, 1999.

Hasbullah, S. H. "Justice for the Dispossessed: The Case of a Forgotten Minority" in

Sri Lanka's Ethnic Conflict." In Sri Lankan Society in an Era of Globalisation: Struggling to Create a New Social Order, edited by S.H. Hasbullah and Barrie M. Morrison, 221-240. New Delhi: Sage Publications, 2004.

Hellmann Rajanayagam, Dagmar. "Arumuka Navalar: Religious Reformer of

National Leader of Eelam.” Indian Economic Social History Review 26 (1989): 235-257.

Hellmann Rajanayagam, Dagmar. "The Concept of a Tamil Homeland in Sri Lanka -

its Meaning and Development." South Asia 13:2 (1990): 79-110.

Hellmann Rajanayagam, Dagmar. "The Politics of the Tamil Past." In Sri

Lanka: History and the Roots of Conflict, edited by Jonathon Spencer, 107-122. London: Routledge, 1990.

Hellmann Rajanayagam, Dagmar. "Ethnicity and Nationalism - The Sri Lanka Tamils

in the Late Nineteenth Century: Some Theoretical Questions.” In Nationalism,

Ethnicity and Political Development: South Asian Perspectives, edited by

D.

Weidemann, 25-49. New Delhi: Manohar, 1991.

Hellmann Rajanayagam, Dagmar. "The Jaffna Social System: Continuity and Change

under Conditions of War.” Internationales Asienforum 24 (1993): 251 281.

Hellmann Rajanayagam, Dagmar. "Tamils and the Meaning of History." In The Sri

Lankan Tamils, edited by Chelvadurai Manogram and Bryan

Pfaffenberger, 54-83. Colorado: Westview Press, 1994.

Hellmann Rajanayagam, Dagmar. The Tamil Tigers: Armed Struggle For Identity.

Stuttgart: Franz Steiner Verlag, 1994.

Hellmann Rajanayagam, Dagmar. "From Differences To Ethnic Solidarity." In Sri

Lankan Society In An Era of Globalization: Struggling To Create a New

Order, edited by S.H. Hasbullah and Barrie M. Morrison, 102-119. New

Delhi: Sage Publications, 2004.

Hellmann Rajanayagam, Dagmar. "Religious Ideology Among the Tamils." In Sri

Lankan Society In An Era of Globalization: Struggling To Create a New 
Order, edited by S.H. Hasbullah and Barrie M. Morrison, 72-84. New

Delhi: Sage Publications, 2004.

Hellmann Rajanayagam, Dagmar. “And Heroes Die: Poetry of the Tamil Liberation

Movement in Northern Sri Lanka." In South Asia: Journal of South Asian Studies XXVIII:1 (2005): 112-153.

Ismail, Qadri. Abiding by Sri Lanka: On Peace, Place and Postcoloniality.

Minneapolis: University of Minnesota Press, 2005.

Kaliasapathy, K. "Cultural and Linguistic Consciousness of the Tamil

Community."

In Ethnicity and Social Change in Sri Lanka: papers presented at a seminar organised by the Social Scientists Association, December 1979,

107- 120. Colombo: Social Scientists' Association, 1984.

Kearney, Robert. "Ethnic Conflict and the Tamil Separatist Movement in Sri Lanka."

Asian Survey 25:9 (1985): 898-917.

Kemper, Steven. "J.R. Jayewardene, righteousness and realpolitik." In Sri Lanka: History and the Roots of Conflict, edited by Jonathon Spencer, 187-204. London: Routledge, 1990.

LTTE. Towards Liberation. n.p: LTTE, 1984.

Little, David. Sri Lanka: The Invention of Enmity. Washington: United States Institute

of Peace Press, 1994.

McGilvray, Dennis. Tamil and Muslim Identities in the East. Marga Monograph

Series on Ethnic Reconciliation 24. Colombo: Marga Institute, 2001.

McGowan, William. Only Man Is Vile: The Tragedy of Sri Lanka. New York:

Farrar,

Straus and Giroux, 1991.

Nesiah, Devanesan. Tamil Nationalism. Marga Monograph Series on Ethnic

Reconciliation 6. Colombo: Marga Institute, 2001.

Nissan, Elizabeth and R.L Stirrat. "The Generation of Communal Identities." In

Sri 19-24.

Lanka: History and the Roots of Conflict, edited by Jonathon Spencer,

London: Routledge, 1990.

Pfaffenberger, Bryan. "The Cultural Dimension of Tamil Separatism in Sri Lanka."Asian Survey 21:11 (1981): 1145-1157.

Pfaffenberger, Bryan. Caste in Tamil Culture: The Religious Foundations of Sudra

Domination in Tamil Sri Lanka. Syracuse: Syracuse University, 1982.

Pfaffenberger, Bryan. "The Political Construction of Defensive Nationalism: The 1968 Temple Entry Crisis in Sri Lanka." In The Sri Lankan Tamils:

Ethnicity and Identity, edited by Chelvadurai Manogram and Bryan Pfaffenberger, 143-167. Colorado: Westview Press, 1994.

Roberts, Michael. "Filial Devotion in Tamil Culture and the Tiger Cult of

Martyrdom." Contributions to Indian Sociology 30:2 (1996):245-272.

Roberts, Michael. "Tamil Tiger 'Martyrs:' Regenerating Divine Potency?"

Studies in

Conflict and Terrorism 28 (2005): 493-514.

Roberts, Michael. "Saivite Symbols, Sacrifice, and Tamil Tiger Rites.” Social 
Analysis 49:1 (2005): 67-93.

Roberts, Michael. "Pragmatic Action and Enchanted Worlds: A Black Tiger Rite of

Commemoration." Social Analysis 50:1 (2006): 73-102.

Sabaratnam, Lakshmanan. Ethnic Attachments in Sri Lanka: Social Change and Cultural Continuity. New York: Palgrave, 2001.

Sastri, K.A. Nilakanta. A History of South India: From Prehistoric Times to the Fall

of Vijayanagar. Delhi: Oxford University Press, 1975.

Schalk, Peter. "Women Fighters of the Liberation Tigers in Tamil Ilam. The Martial

Feminism of Atel Palacinkam." South Asia 14:2 (1994): 163-183.

Schalk, Peter. "Historisation of the Martial Ideology of the Liberation Tigers of Tamil

Ealam (LTTE).” South Asia 20:2 (1997): 35-72.

Schalk, Peter. "The Revival Of Martyr Cults Among Ilavar." Temenos 33 (1997): 151-90.

Schalk, Peter. "Present Concepts of Secularism Among Ilavar and Lankans." Asian

Ethnicity 3: 1 (2002): 37-71.

Schalk, Peter. "Beyond Hindu Festivals: The Celebration of Great Heroes' Day by the

Liberation Tigers of Tamil Ealam (LTTE) in Europe." In Tempel und

Tamilien in Zweiter Heimat, edited by Martin Baumann, 391-411.

Wuerzburg: Ergon Verlag, 2003.

Scott, David. "The Trouble With Thinking: an Interview with Talal Asad." In Powers

of the secular modern: Talal Asad and his interlocutors, edited by David Scott and Charles Hirschkind, 243-303. California: Standford University Press, 2006.

Spencer, Jonathon. "Introduction: the Power of the Past." In Sri Lanka: History and

the Roots of Conflict, edited by Jonathon Spencer, 1-16. London:

Routledge, 1990.

Stokke, Kristian and Anne Kirsti Ryntveit. "The Struggle For Tamil Eelam in Sri Lanka." Growth and Change 31 (2000): 285-304.

Sumathy, Sivamohan. "The Rise of Militant Tamil Nationalism, Its Assumptions and

the Cultural Production of Tamil Women." In Sri Lankan Society In An

Era of Globalization: Struggling To Create a New Order, edited by S.H.

Hasbullah and Barrie M. Morrison, 126-149. New Delhi: Sage

Publications, 2004.

Tambiah, Stanley Jeyaraja. Buddhism Betrayed?: Religion, Politics and Violence in

Sri Lanka. Chicago: Chicago Universtiy Press, 1992.

Tennekoon, Serena. "Newspaper Nationalism: Sinhala identity as historical Jonathon

discourse." In Sri Lanka: History and the Roots of Conflict, edited by

Spencer, 205-226. London: Routledge, 1990. 
Trawick, Margaret. "Reasons for Violence: A Preliminary Ethnographic Account of

the LTTE." In Conflict And Community in Contemporary Sri Lanka:

'Pearl of the East' or the 'Island of Tears'?, edited by Siri Gamage and I.B Watson, 139-163. New Delhi: Sage Publications, 1999.

Whitaker, Mark P. "Learning Politics From Taraki: A Biographical Fragment." In Sri

Lanka: Collective Identities Revisited Volume II, edited by Michael Roberts, 247-270. Colombo: Marga Institute, 1997.

Wickremeratne, L.A. Religion, Nationalism, and Social Change in Ceylon, 18651885. Comparative Studies in Society and History. Colombo: Studies in Society and Culture, 1993.

\section{Electronic Resources:}

Eelam Web. "Tamil Eelam History.” http://www.eelamweb.com/history/te/\#2 (accessed May 16, 2008).

Eelam Web. "A Short History of the Tamil Eelam Liberation Struggle." http://www.eelamweb.com/history/short/ (accessed May 16, 2008).

International Federation of Tamils. "Tamil Eelam - A Reversion to Sovereignty." 2008) http://www.eelam.com/introduction/reversion.html (accessed May 16,

International Federation of Tamils. "Tamil Eelam Demand in International Law." http://eelam.com/introduction/eelam demand.html\#RTFToC2 (accessed May 16, 2008).

International Federation of Tamils. "The Legitimacy of the Armed Struggle of the May

Tamil People.” http://eelam.com/introduction/legitimacy.html (accessed $16,2008)$.

LTTE. "A Struggle For Justice." http://eelam.com/freedom_struggle/ltte_publ/strug_for_just/armed.html (accessed May 16, 2008)

LTTE. Reflections of the Leader. Translated by Peter Schalk and Alvappillai Veluppillai. n.p: LTTE, 2007.

http://publications.uu.se/abstract.xsql?dbid=8404 (accessed May 12, 2008)

LTTE, "The Proposal by the Liberation Tigers of Tamil Eelam on Behalf of the Tamil

People for an Agreement to Establish An Interim Self Governing Authority For the Northeast of the Island of Sri Lanka."

http://www.eelam.com/isga/proposal.pdf (accessed April 30, 2008).

LTTE Peace Secretariat. "Historical Background."

http://www.ltteps.org/list.ltte?folder=11 (accessed May 16, 2008).

Mahadeva, Professor Kopan. "Martyr Thileepan." 2008).

http://www.sangam.org/ANALYSIS/Thileepan_5_12_03.htm (May 16,

Natali, Cristiana. "Building Cemetries, Constructing Identities. Funerary

Practices and 
Nationalist Discourse among the Tamil Tigers of Sri Lanka." http://www.basas.ac.uk/conference05/natali,\%20cristiana.pdf (accessed April 26, 2008)

Prabhakaran, Velupillai. "Tamil National Leader Hon. V. Prabhakaran's Interview." http://www.eelamweb.com/leader/interview/in_199404/(accessed May $16,2008)$.

Prabhakaran, Velupillai. "English translation of Martyrs' Day Speech 1992." http://www.ltteps.org/?view=422\&folder=9 (accessed, May 12, 2008).

Prabhakaran, Velupillai. “English translation of Martyrs' Day Speech 1995.” http://www.ltteps.org/?view=419\&folder=9 (accessed May 16, 2008).

Prabhakaran, Velupillai. "English Translation of Martyrs Day Speech 1996." http://www.ltteps.org/?view=418\&folder=9 (accessed May 16, 2008).

Prabhakaran, Velupillai. "English Translation of Martyrs' Day Speech 1998." http://www.ltteps.org/?view=416\&folder=9 (accessed May 16, 2008).

Prabhakaran, Velupillai. "English Translation of Martyrs' Day Speech 1999." http://www.ltteps.org/?view=415\&folder=9 (accessed May 16, 2008).

Prabhakaran, Velupillai. "English Translation of Martyrs' Day Speech 2000." http://www.ltteps.org/?view=413\&folder=9 (accessed May 16, 2008).

Prabhakaran, Velupillai. "English Translation of Martyrs' Day Speech 2001." http://www.ltteps.org/?view=414\&folder=9 (accessed May 16, 2008).

Prabhakaran, Velupillai. "English Translation of Martyrs' Day Speech 2005." http://www.ltteps.org/?view=996\&folder=9 (accessed May 16, 2008).

Prabhakaran, Velupillai. "English Translation of Martyrs' Day Speech 2006." http://www.ltteps.org/?view=1776\&folder=9 (accessed May 16, 2008).

Schalk, Peter. "Resistance and Martyrdom in the Process of State Formation of Tamil

Eelam.” http://www.tamilnation.org/ideology/schalkthiyagam.htm (accessed May 13, 2008).

TamilNet. "Rules guide on use of Tamileelam National flag published." http://www.tamilnet.com/art.html?catid=13\&artid=16423 (accessed May $16,2008)$. 